\title{
Periodontal complications of hyperglycemia/diabetes mellitus: Epidemiologic complexity and clinical challenge
}

\author{
Thomas Kocher $^{1}$ | Jörgen König ${ }^{1}$ | Wenche Sylling Borgnakke ${ }^{2}$ | Christiane Pink ${ }^{1}$ | \\ Peter Meisel ${ }^{1}$ \\ ${ }^{1}$ Department of Restorative Dentistry, Periodontology, Endodontology, and Preventive and Pediatric Dentistry, University Medicine Greifswald, Greifswald, \\ Germany \\ ${ }^{2}$ Department of Periodontics and Oral Medicine, University of Michigan School of Dentistry, Ann Arbor, Michigan \\ Correspondence \\ Thomas Kocher \\ Email: kocher@uni-greifswald.de
}

\section{1 | INTRODUCTION}

Diabetes is one of the major risk factors for periodontitis. ${ }^{1}$ Individuals with diabetes are more likely to have periodontitis of increased severity when their diabetes is uncontrolled or poorly controlled. In this sense, periodontitis is nowadays considered as a complication of diabetes. ${ }^{2}$ If prediabetes and early diabetes were treated effectively, then the progression of hyperglycemia could be prevented or delayed, which may eventually lead to reduced progression of periodontitis. ${ }^{3}$ Aging is associated both with a progressive decline in glucose tolerance and coincidentally with increasing prevalence of periodontitis. Increasing life expectancy predicts an increasing burden of periodontal diseases worldwide, with considerable variations between different populations. In 2010, severe periodontitis was the world's 6th most prevalent health condition, affecting approximately 10.8\% (743 million) of people worldwide. Between 1990 and 2010, the global age-standardized prevalence of severe periodontitis was estimated to be $11.2 \% .{ }^{4}$ The current pattern of periodontitis reflects distinct risk profiles related to living conditions, environmental and behavioral factors, and oral health-care systems, including the implementation of preventive oral health schemes. ${ }^{5}$

The World Health Organization estimates that, in 2014, 422 million adults in the world ( $8.5 \%$ of the population) had diabetes. Since 1980 , this number has quadrupled and the percentage nearly doubled. Diabetes is described as a "serious, chronic disease that occurs either when the pancreas does not produce enough insulin, or when the body cannot effectively use the insulin it produces". 6 The vast majority (90\%-95\%) of these metabolic hyperglycemic diseases are type 2 diabetes mellitus. ${ }^{7}$ According to the International Diabetes Federation ${ }^{8}$ :

- North America and the Caribbean have the highest prevalence of diabetes (10.8\%-14.5\%), encompassing 44.3 million people. In the USA alone, the estimated prevalence of diabetes has increased from about 26 million people in 2010 to 29.3 million in 2015 (30.3 million as estimated by the Centers for Disease Control and Prevention ${ }^{9}$ ).

- Globally, almost half (46.5\%) of all people with diabetes (192.8 million) are unaware of their disease; more than twothirds are in Africa, despite the relatively low prevalence there of this condition.

- $75 \%$ of people with diabetes live in low- and middle-income countries.

This review, which is generally restricted to type 2 diabetes, provides an overview for a prediabetes-diabetes-periodontitis nexus, particularly involving uncontrolled diabetes. Specifically, the relationships between glycemic state or control and severity of periodontitis, as well as prospects of treatment success in periodontally compromised patients, are considered.

\section{2 | DIABETES THRESHOLDS}

The generally accepted definitions of categories of glycemic states originate from the American Diabetes Association ${ }^{10}$ and the World Health Organization in collaboration with the International Diabetes Federation, ${ }^{6}$ and are based on measures of fasting plasma glucose, oral glucose tolerance tests, or glycated hemoglobin. For glycated hemoglobin, the thresholds for increased risk of diabetes, also known as prediabetes, are set at $5.7 \%$ and $6.4 \%$, with diabetes defined to be present at a level of $\geq 6.5 \%(47.5 \mathrm{mmol} / \mathrm{mol}) .{ }^{10}$ The glycated hemoglobin level of $\geq 6.5 \%$ is especially useful for identifying individuals at risk for developing late complications of diabetes, such as retinopathy. ${ }^{11}$ Unknown diabetes may be present in individuals if there is neither a diagnosis nor a relevant medication and the level of glycated hemoglobin is $\geq 6.5 \%$ or fasting plasma glucose is 
$\geq 7 \mathrm{mmol} / \mathrm{L}$ (126 mg/dL). Nonetheless, diagnosis of prediabetes on the basis of fasting plasma glucose and oral glucose tolerance test data has shown poor correlation with glycated hemoglobin. ${ }^{12}$ The diabetes risk increases continuously with glycemic measures, such as glycated hemoglobin, and becomes disproportionately greater at the higher end of the range.

A large prospective study found that a $5.7 \%$ cut-off point has sensitivity of $66 \%$ and specificity of $88 \%$ for the identification of subsequent 6 -year diabetes incidence. ${ }^{13}$ The prevalence of prediabetes is increasing worldwide with concomitant risks of developing type 2 diabetes and subsequently all the potentially fatal, long-term complications attributed to diabetes, especially when poorly controlled. ${ }^{14,15}$ Individuals identified as having prediabetes are more likely to develop kidney disease or cardiovascular disease and are at higher risk for all-cause mortality compared with those with a normal level of glycated hemoglobin. ${ }^{16}$

\section{3 | NATURAL COURSE OF PREDIABETES AND DIABETES}

Impaired fasting glucose and impaired glucose tolerance represent intermediate stages between normal glucose homeostasis and diabetes mellitus and are predictors for future development of diabetes mellitus and its complications, such as cardiovascular diseases. Although scarcely studied, periodontitis also seems to follow such a course because insulin resistance was observed to predict the incidence of periodontitis. ${ }^{17}$ Thus, special attention should be paid to individuals at increased risk of developing diabetes. ${ }^{18}$ During the natural course of developing hyperglycemia, interfering measures during the period of normoglycemia with concomitant insulin resistance are optimal to prevent further progression (Figure 1).

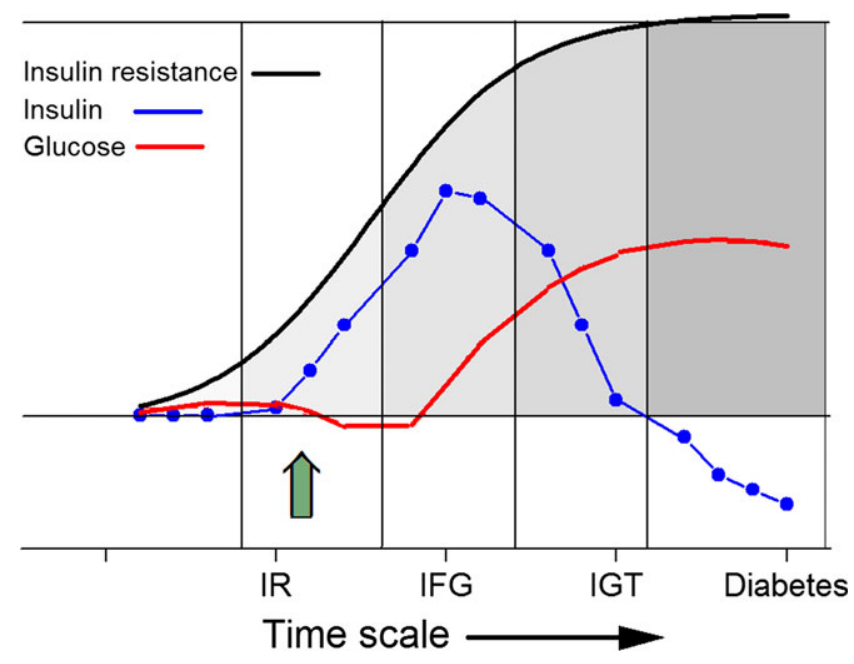

FIGURE 1 Natural history of diabetes, schematic outline. The vertical arrow indicates the condition of normoglycemia with insulin resistance (IR), during which period measures to prevent development of diabetes and periodontitis may be optimal and particularly promising. IFG, impaired fasting glucose; IGT, impaired glucose tolerance

\section{PERIODONTITIS AND DIABETES}

There is strong evidence that periodontitis is associated with diabetes. Not only is glycemic control related to periodontitis in a dose-response manner, microvascular diabetes complications also show associations with severe periodontitis. ${ }^{19}$ Thus, because there is a gradated risk between glycated hemoglobin level and other diabetes complications, such a relationship may also exist between glycated hemoglobin and periodontitis and consequently prediabetes may also represent an elevated risk for developing periodontitis.

If we accept periodontitis as the "sixth complication of diabetes", as it was officially suggested more than 2 decades ago, ${ }^{2}$ then the thresholds used for identification and prevention of late diabetic sequelae should apply also for periodontitis. However, as noted by the American Association of Diabetes ${ }^{10}$ as well as by an international expert committee, ${ }^{11}$ the relationship between chronic glycemic levels and the long-term complications of diabetes may be better expressed as a continuum, rather than as a strictly dichotomous relationship with fixed cut-offs.

Notwithstanding this, if we accept an increased risk of periodontitis by diabetes as an established fact, the considerations with respect to probable risk thresholds of glycated hemoglobin should also be practicable for the diabetes-associated risk for periodontitis. Most studies exploring the association between diabetes and periodontitis have unequivocally shown that periodontal measures or periodontitis risk rises disproportionally with increasing levels of glycated hemoglobin. The level of hyperglycemia, rather than the diagnosis and etiology of diabetes, is associated with periodontitis ${ }^{1,20-22}$ and the probability of later tooth loss. ${ }^{22}$ For this reason, it is justified to search for risk groups especially prone to develop severe periodontitis as a consequence of high blood glucose levels or "uncontrolled diabetes." Especially in some subgroups, such as male or elderly patients, the association between uncontrolled diabetes and periodontitis is striking. ${ }^{23,24}$ The subgroup with "uncontrolled diabetes" comprises subjects with undiagnosed diabetes as well as people with diabetes with poor glycemic control. The underlying reasons are different and may include poor compliance with prescription medications or lifestyle recommendations, lack of efficacy of the medication actually taken, insufficient glucose monitoring, or even medically accepted (but limited) metabolic control in the elderly. ${ }^{25}$

\section{5 | MECHANISMS EXPLAINING THE DIABETES-PERIODONTITIS INTERACTION}

Both periodontitis and diabetes are chronic, inflammation-driven diseases that often occur in the same individuals and also mutually and adversely affect each other. Risk factors for both diseases include higher age, male sex, minority race or ethnicity, low socioeconomic status, genetic predisposition (mostly for impaired immune/inflammatory responses), smoking, obesity, low physical activity level, and unhealthy diet. ${ }^{1,21,24,26,27}$ In especially susceptible individuals, bacterial challenge, particularly from the subgingival plaque, induces 
breakdown of the periodontal soft and hard tissues, ${ }^{28}$ and these subgingival plaque bacteria are also associated with inflammation and insulin resistance. ${ }^{20,29}$ Conversely, hyperglycemia may influence the subgingival microbiome with subsequent impact on the severity of periodontitis. $^{30}$

Both diabetes and periodontitis are associated with enhanced inflammation and impaired immunological responses. ${ }^{31,32}$ Elevated levels of systemic inflammatory cytokines, such as interleukin-1beta and interleukin-6, and the acute-phase inflammatory marker, C-reactive protein, are consistently observed in type diabetes 2 as well as in periodontitis. ${ }^{33,34}$ In each case, a systemic inflammatory susceptibility is observed, eventually with an augmented, even though potentially subclinical, responsiveness to inflammatory stimuli. The increase in systemic markers of inflammation in subjects with uncontrolled diabetes is accompanied by a local proinflammatory environment in the gingiva. ${ }^{35}$ Uncontrolled diabetes influences the expression of tissue-degrading enzymes in the inflamed gingiva, leading to up-regulation of the ratio between metalloproteinase and their inhibitors. $^{36,37}$

A two-way association or interaction between diabetes and periodontitis has been postulated, assuming that either condition interferes with the other. A somewhat different view may postulate the interaction as a type of vicious circle, as exemplified in Figure 2. ${ }^{38,39}$ Chronicity of inflammation presents the strongest plausibility for detrimental effects of deteriorating inflammatory events that could also link periodontal disease to diabetes. In mechanisms underlying the relationship between chronic inflammation in diabetes and the link to chronic periodontitis, the cells and mediators of the immune system play a central role. ${ }^{40,41}$

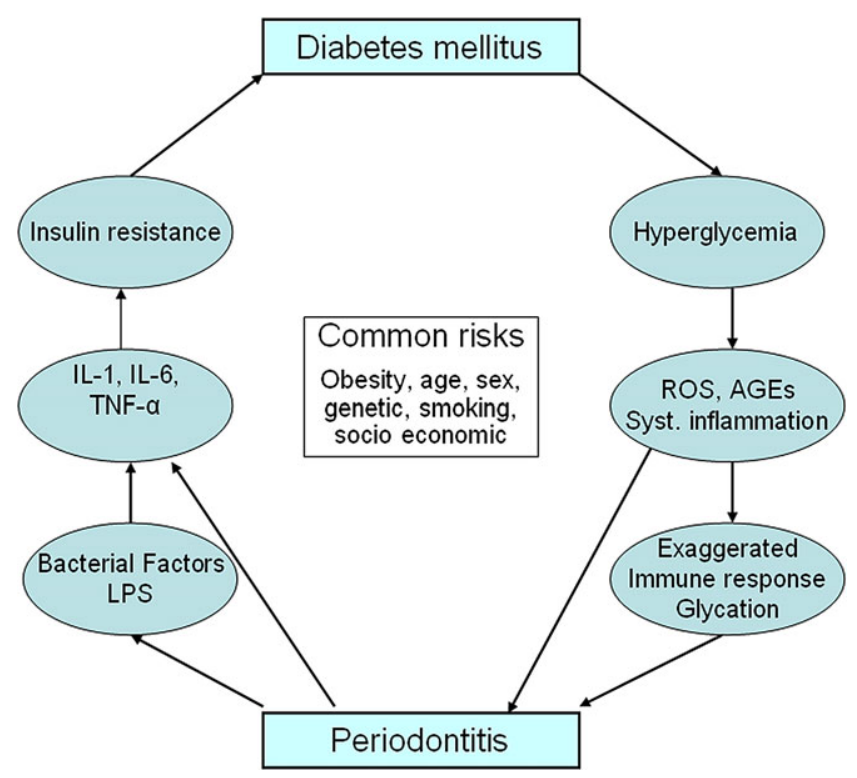

FIGURE 2 Conceptual model connecting diabetes with periodontitis, and showing possible pathogenic factors and risk factors. AGEs, advanced glycation end-products; IL, interleukin; LPS, lipopolysaccharides; ROS, reactive oxygen species; TNF- $\alpha$, tumor necrosis factor-alpha
Advanced glycation end-products are synthesized via nonenzymatic glycation and oxidation of proteins, lipids, and nucleic acids. ${ }^{42}$ Nonenzymatic glycation is also the mechanism by which the protein, hemoglobin, is glycated and forms glycated hemoglobin. ${ }^{43}$ The production of advanced glycation end-products is particularly enhanced in chronic hyperglycemia, as in diabetes mellitus. Interactions of advanced glycation end-products with their receptors and oxidative stress-mediated pathways provide additional links from diabetes to periodontitis. ${ }^{44,45}$ Thus, the chronic complications of diabetes are mainly a consequence of chronically elevated glucose levels.

The effect of periodontitis on diabetes may be related to the penetration of the host tissues by bacteria or their degradation products, such as lipopolysaccharides from the outer membranes (also called endotoxins or lipoglycans), into the systemic circulation. ${ }^{46,47}$ Activation of an exaggerated systemic inflammatory response to subgingival bacteria leads to an acute phase protein burst and systemically elevated levels of proinflammatory mediators, such as interleukins, tumor necrosis factor alpha, and others which facilitate insulin resistance. ${ }^{48,49}$ Experimentally, it has been shown that infusion of tumor necrosis factor alpha in volunteers produces a state of systemic inflammation with increased insulin resistance. ${ }^{50}$ Risk factors contribute to these pathways; in particular, visceral fat contributes to systemic inflammation. ${ }^{51-53}$ If this hypothesized vicious circle reflects the pathogenic relationships in some way, then both conditions - diabetes and periodontitis - would reinforce each other. Insulin resistance and markers of systemic inflammation increase gradually in prediabetes ranges of glucose concentrations. ${ }^{54}$

The most common type of insulin resistance is associated with the metabolic syndrome, which is also closely related to periodontitis. ${ }^{55}$ Obesity is a major source of inflammation and is a confounder of the relationship between diabetes and periodontitis. Analyses of National Health and Nutrition Examination Survey data show that biological variation in glycated hemoglobin is positively associated with inflammation, and that this association is independent of blood glucose concentration and obesity in participants without diabetes. ${ }^{43}$

Associations between chronic activation of the innate immune system and the main risk factors of diabetes and periodontitis support the idea of a nexus between both conditions. Age, obesity, sex and gender, smoking, genetic factors, and socioeconomic status all may contribute to subclinical inflammation. ${ }^{21,23,56}$ However, the existence of an association provides no evidence for causation. There could be an association superimposed by overlapping risk factors for diabetes and periodontitis, including smoking, obesity, socioeconomic status, and life-course-related adverse fate. ${ }^{21,23}$ Periodontitis progression is associated with increased glycated hemoglobin concentration, which is similar to that observed for increases in either waistto-hip ratio or age. ${ }^{57}$

Admittedly, this may also be interpreted in such a way that both diabetes and periodontitis develop in parallel because of susceptibility to low-grade inflammation. Age-related diseases share a proinflammatory status, which may be important in the development of chronic diseases such as diabetes and periodontitis. ${ }^{58}$ Adult height is an indicator of such inflammatory susceptibility developed during 
the life course. Indeed, both diabetes and periodontitis are associated with body height. ${ }^{59,60}$

\section{6 | PREDIABETES}

Prediabetes is the precursor stage for diabetes mellitus. Before the development of type 2 diabetes, glucose levels increase but they are still below the common threshold for diabetes mellitus. According to the American Diabetes Association, people with prediabetes have fasting plasma glucose levels of $100-125 \mathrm{mg} / \mathrm{dL}$ (5.6-6.9 mmol/L) and/or impaired glucose tolerance with 2-hour values of the oral glucose tolerance test of 140-199 mg/dL (7.8-11.1 mmol/L), and/or glycated hemoglobin of $5.7 \%-6.4 \% .{ }^{10}$ Glycated hemoglobin is the test of choice for diagnosis and management of diabetes. ${ }^{61}$ However, glycated hemoglobin is not a sufficiently sensitive or reliable tool for diagnosis of early diabetes/prediabetes, ${ }^{62}$ as the prevalence of being at high risk for diabetes/prediabetes detected by glycated hemoglobin is only about one-tenth of that identified by impaired fasting glucose or impaired glucose tolerance tests. ${ }^{63}$ Impaired fasting glucose predominantly reflects hepatic insulin sensitivity, while impaired glucose tolerance primarily reflects pancreatic beta-cell function. ${ }^{64}$ Homeostatic model assessment is one way to quantify (score) insulin resistance (Homeostatic Model Assessment-Insulin Resistance) and beta-cell function (Homeostatic Model Assessment-Beta). ${ }^{65}$

In 2017, the Centers for Disease Control and Prevention ${ }^{9}$ estimated, based on data from 2015, that one-third (33.9\%) of US adults aged 18 years or older - and almost half (48.3\%) of those aged 65 years or older - had prediabetes, representing 84 million US adults. Almost 9 (88.4\%) in 10 were unaware of their hyperglycemia and hence could not take any precautions. The probability that prediabetes progresses to diabetes is high. Without intervention (oral antidiabetic medication or lifestyle modification), $11 \%$ of persons with prediabetes and a body mass index of $\geq 24 \mathrm{~kg} / \mathrm{m}^{2}\left(\geq 22 \mathrm{~kg} / \mathrm{m}^{2}\right.$ in Asian people) progressed to type 2 diabetes each year during an average of 3 years of follow-up. ${ }^{66}$ A systematic review based on 16 studies including 44,203 participants described the risk of developing diabetes, with 5 -year incidences, to range from $9 \%$ to $25 \%$ for persons with glycated hemoglobin values between $5.5 \%$ and $6.0 \%$ and from $25 \%$ to $50 \%$ for persons with glycated hemoglobin values of $\geq 6.0 \%{ }^{67}$ Moreover, Nathan et al ${ }^{68}$ estimated that up to $70 \%$ of individuals with prediabetes will develop diabetes in the future.

Although diabetes has a gradual onset with blood glucose levels slowly rising over time, the cut-off values used for diagnosis of diabetes - and accordingly the threshold value for prediabetes - are based on the risk of developing a diabetes-related complication. At a glycated hemoglobin cut-off value of $6.5 \%$, the risk for development of diabetic retinopathy increases steeply, independently of macrovascular complications. Diabetic neuropathy has been reported with even lower levels of glycaemia. ${ }^{69}$ A systematic review that explored lower threshold levels of glycated hemoglobin calculated a substantially increased (5-fold) relative diabetes incidence risk at glycated hemoglobin ranges from $5.5 \%$ to $6.0 \%$ compared with a glycated hemoglobin level of $<5 \%$, suggesting the use of a glycated hemoglobin threshold of $5.5 \%$ to ensure that persons at risk are identified in time to benefit from preventive interventions. ${ }^{67}$

Earlier reviews of hyperglycemia and periodontitis have focused mostly on manifest diabetes mellitus without considering prediabetes. In the following, studies are presented to illuminate this precursor stage of diabetes mellitus as associated with periodontal disease.

\section{7 | PREDIABETES AND PERIODONTAL COMPLICATIONS}

The level of hyperglycemia, rather than the diagnosis and etiology of diabetes, is associated with periodontitis ${ }^{1,20-22}$ and the probability of later tooth loss. ${ }^{22}$ Based on existing evidence, we attempted to answer the first question: Does prediabetes impact periodontal health status?

A final PubMed/MEDLINE search was conducted on September 27, 2017, using the following search strategy: (insulin resistance OR glucose intolerance OR impaired glycaemia OR hyperglycemia OR prediabetes OR early diabetes) AND (periodontal disease OR periodontitis OR periodontal OR tooth loss). The search was limited to 'Humans', 'Adult: 19+ years', 'English' languages, and 'published from January 1980' and resulted in 231 potentially relevant publications that were supplemented by 5 additional reports identified by hand searching. Eligibility included original studies with clinical or radiographic periodontal assessment and hyperglycemia assessed by stated criteria. Only studies that took into account the effects of potential confounders were included, and we only report results of the fully adjusted - and weighted, if applicable - models. Table 1 presents characteristics and findings from the 15 reports, of which $2^{17,70}$ were longitudinal and $13^{27,30,71-81}$ were of cross-sectional design.

\section{1 | Longitudinal studies}

In a prospective cohort study, Chiu et $\mathrm{al}^{70}$ analyzed data from a public screening program of 4,387 initially periodontitis-free Taiwanese subjects aged $35-44$ years, for up to 5 years. Originally periodontitis free, 96 (32.3\%) of 297 subjects with prediabetes (fasting plasma glucose: 100-125 mg/dL) versus 1129 (28.0\%) of 4033 subjects with normal fasting plasma glucose $(<100 \mathrm{mg} / \mathrm{dL})$ developed periodontitis (Community Periodontal Index $\geq 3$ ). After adjustment for potential confounders, those with baseline prediabetes had a $25 \%$ higher risk of incident periodontitis (hazard ratio $=1.25$; $95 \%$ confidence interval: 1.00-1.57) compared with those with normal fasting plasma glucose. Also included in the study were 57 individuals with overt diabetes (fasting plasma glucose $\geq 126 \mathrm{mg} / \mathrm{dL}$ ) of whom 22 (38.6\%) developed periodontitis and were almost twice as likely to develop periodontitis (hazard ratio $=1.95 ; 95 \%$ confidence interval: 1.22 3.13) than the normoglycemic subjects. Hence, a dose-response 
TABLE 1 Effect of prediabetes on periodontitis: studies reporting multivariate findings adjusted for potential confounders as of September 27, 2017

\begin{tabular}{|c|c|c|c|c|c|}
\hline $\begin{array}{l}\text { Author(s), yearref. } \\
\text { Country } \\
\text { Duration } \\
\text { Name of study }\end{array}$ & $\begin{array}{l}\text { A) Total no. of subjects } \\
\text { (\%M): } \\
\text { a. Pre-DM } \\
\text { b. Normoglycemic } \\
\text { B) Age range }\end{array}$ & $\begin{array}{l}\text { Exposure } \\
\text { measure: } \\
\text { prediabetes }\end{array}$ & $\begin{array}{l}\text { Outcome measure: } \\
\text { periodontitis }\end{array}$ & $\begin{array}{l}\text { Risk for periodontitis } \\
\text { HR/IRR/OR/RR } \\
\text { (95\% CI) }\end{array}$ & $\begin{array}{l}\text { No. of confounders } \\
\text { controlled }\end{array}$ \\
\hline $\begin{array}{l}\text { Longitudinal studies } \\
\text { Chiu et al }(2015)^{70} \\
\text { Taiwan } \\
5 \text { years } \\
\text { KCIS 2003-2008 }\end{array}$ & $\begin{array}{l}\text { A) } N=4387(\approx 32 \% \mathrm{M}) \\
\text { no PerioDz } \\
\text { a. } \mathrm{n}=297 \\
\text { b. } \mathrm{n}=4033 \\
\text { B) } 35-44 \text { years }\end{array}$ & FPG & $\begin{array}{l}\text { Incident PerioDz: } \\
\mathrm{CPI} \geq 3\end{array}$ & $\begin{array}{l}\mathrm{HR}=1.25 \\
(95 \% \mathrm{Cl}: 1.00-1.57)\end{array}$ & $\begin{array}{l}\text { 12: Ag, Al, Be, Ch, } \\
\text { E, Fi, H, Ph, Se, } \\
\text { Sm, Tr, W }\end{array}$ \\
\hline $\begin{array}{l}\text { Timonen et al } \\
(2013)^{17} \\
\text { Finland } \\
4 \text { years } \\
\text { Health } 2000 \\
\text { Survey: Follow-up } \\
\text { Study on Finnish } \\
\text { Adults' Oral Health } \\
\text { 2004-2005 }\end{array}$ & 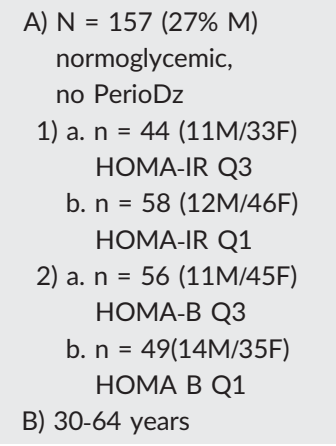 & $\begin{array}{l}\text { 1) HOMA-IR } \\
\text { 2) HOMA-B }\end{array}$ & $\begin{array}{l}\text { Incident PerioDz: } \\
\text { PPD } \geq 4 \mathrm{~mm}\end{array}$ & $\begin{array}{l}\text { 1) IRR = } 1.7 \\
(95 \% \mathrm{Cl}: 1.1-2.7) \\
\text { 2) IRR }=1.6 \\
(95 \% \mathrm{Cl}: 1.0-2.6)\end{array}$ & $\begin{array}{l}\text { 7: Ag, B, De, E, PI, } \\
\text { Se, To }\end{array}$ \\
\hline $\begin{array}{l}\text { Cross-sectional } \\
\text { studies } \\
\text { Benguigui et al } \\
(2010)^{71} \\
\text { France } \\
\text { MONA LISA } \\
\text { 2006-2007 }\end{array}$ & $\begin{array}{l}\text { A) } N=255(55 \% \mathrm{M}) \text {; } \\
n=238 \text { no DM } \\
\text { a. HOMA-IR Q4 } \\
\text { b. HOMA-IR Q1 } \\
\text { B) } 35-74 \text { years }\end{array}$ & HOMA-IR & $\begin{array}{l}\text { 1) } P P D \geq 4 \mathrm{~mm} \\
\text { 2) } C A L \geq 4 \mathrm{~mm}\end{array}$ & $\begin{array}{l}\text { 1) } \mathrm{RR}=1.61 \\
(95 \% \mathrm{Cl}: 1.00-2.61) \\
\text { 2) } \mathrm{RR}=1.52 \\
\text { (95\% Cl: } 1.02-2.27)\end{array}$ & $\begin{array}{l}\text { 7: Ag, Al, C, CR, E, } \\
\text { PI, Se, Sm }\end{array}$ \\
\hline $\begin{array}{l}\text { Emrich et al } \\
(1991)^{72} \\
\text { USA } \\
\text { Pima \& Papago } \\
\text { Indians } 1983\end{array}$ & $\begin{array}{l}\text { A) } N=1342(43 \% M) \\
\text { a. } n=158(46 \mathrm{M} / 112 \mathrm{~F}) \\
\text { b. } n=930(432 \mathrm{M} / 498 \mathrm{~F}) \\
\text { B) } \geq 15 \text { years }\end{array}$ & IGT & $\begin{array}{l}\text { 1) } C A L \geq 5 \mathrm{~mm} \\
\text { 2) } A B L \geq 25 \%\end{array}$ & $\begin{array}{l}\text { 1) OR: ns } \\
\text { 2) OR: ns }\end{array}$ & $\begin{array}{l}\text { 7: Ag, BOP, D, Fl, } \\
\text { PI, Se, T }\end{array}$ \\
\hline $\begin{array}{l}\text { Hong et al }(2016)^{73} \\
\text { South Korea } \\
\text { KNHANES } \\
2012-2013\end{array}$ & $\begin{array}{l}\text { A) } N=9977 \text { no DM }(51 \% \\
\text { M) } \\
\text { a1. IFG1: } n=1551 \\
\text { a2. IFG2: } n=575 \\
\text { b1. NFG1 }(<90 \mathrm{mg} / \mathrm{dL}) \text { : } \\
\mathrm{n}=3107 \\
\text { b2. NFG2 } \\
\text { (90-99 mg/dL): } n=3701 \\
\text { B) } \geq 19 \text { years }\end{array}$ & $\begin{array}{l}\text { 1) IFG1: } 100- \\
110 \mathrm{mg} / \mathrm{dL} \\
\text { 2) IFG2: } 111- \\
125 \mathrm{mg} / \mathrm{dL}\end{array}$ & $\begin{array}{l}\text { PerioDz: } C P I \geq 3 \\
\text { Severe PerioDz: } \\
C P I=4\end{array}$ & $\begin{array}{l}\text { Compared with NFG1: } \\
\text { PerioDz } \\
\text { 1) IFG1: OR = ns } \\
\text { 2) IFG2: } \\
\text { OR = 1.33 } \\
\text { (95\% Cl: } 1.01-1.75) \\
\text { Severe PerioDz: } \\
\text { 1) IFG1: OR = ns } \\
\text { 2) IFG2: OR = ns }\end{array}$ & $\begin{array}{c}\text { 10: Ag, Al, CH, E, H, } \\
\text { I, Se, Sm, Tr, W }\end{array}$ \\
\hline $\begin{array}{l}\text { Kowall et al } \\
(2015)^{74} \\
\text { Germany } \\
\text { SHIP-Trend } \\
\text { 2008-2012 }\end{array}$ & $\begin{aligned} & \text { A) } N=3086(49 \% \mathrm{M}) \\
& \text { a. } n=576 \\
& \text { b. } n=2154 \\
& \text { B) } 20-82 \text { years }\end{aligned}$ & $\begin{array}{l}\text { 1) IGT } \\
\text { 2) FPG } \\
\text { 3) } \mathrm{HbA1c}\end{array}$ & $\begin{array}{l}\text { I) PerioDz: } \\
\text { i) EWP } \\
\text { ii) PPD } \\
\text { iii) CAL } \\
\text { II) no. of teeth }\end{array}$ & $\begin{array}{l}\text { PerioDz; no. of teeth: } \\
\text { I) [1), 2), or 3)] by } \\
\text { [i), ii), or iii)]: OR = ns } \\
\text { II): OR = ns }\end{array}$ & $\begin{array}{l}\text { 9: } \mathrm{Ag}, \mathrm{Al}, \mathrm{B}, \mathrm{CH}, \mathrm{CT} \text {, } \\
\text { E, Se, Sm, Tr }\end{array}$ \\
\hline
\end{tabular}


TABLE 1 (Continued)

\begin{tabular}{|c|c|c|c|c|c|}
\hline $\begin{array}{l}\text { Author(s), year }{ }^{\text {ref. }} \\
\text { Country } \\
\text { Duration } \\
\text { Name of study }\end{array}$ & $\begin{array}{l}\text { A) Total no. of subjects } \\
\text { (\%M): } \\
\text { a. Pre-DM } \\
\text { b. Normoglycemic } \\
\text { B) Age range }\end{array}$ & $\begin{array}{l}\text { Exposure } \\
\text { measure: } \\
\text { prediabetes }\end{array}$ & $\begin{array}{l}\text { Outcome measure: } \\
\text { periodontitis }\end{array}$ & $\begin{array}{l}\text { Risk for periodontitis } \\
\text { HR/IRR/OR/RR } \\
(95 \% \mathrm{Cl})\end{array}$ & $\begin{array}{l}\text { No. of confounders } \\
\text { controlled }\end{array}$ \\
\hline $\begin{array}{l}\text { Lamster et al } \\
(2014)^{75} \\
\text { USA } \\
2009-2010\end{array}$ & $\begin{array}{l}\text { A) } N=1097(36 \% \mathrm{M}) \\
\text { unknown } \mathrm{DM} \\
\text { a. } n=409(130 \mathrm{M} / 279 \mathrm{~F}) \\
\text { b. } n=603(229 \mathrm{M} / 374 \mathrm{~F}) \\
\text { B) } \geq 40 \text { y white, non- } \\
\text { Hispanic; } \\
\geq 30 \text { y non-white/Hispanic }\end{array}$ & $\begin{array}{l}\text { FPG } \\
\text { HbA1c }\end{array}$ & $\begin{array}{l}\text { 1) } \% \text { teeth } \mathrm{w} / \\
\mathrm{PPD} \geq 5 \mathrm{~mm} \\
\text { 2) missing teeth }\end{array}$ & $\begin{array}{l}\text { 1) } \mathrm{OR}=1.26(95 \% \mathrm{Cl} \\
\mathrm{n} / \mathrm{a} ; P=.002) \\
\text { 2) } \mathrm{RR}=1.06(95 \% \mathrm{Cl}: \\
\mathrm{n} / \mathrm{a} ; P=.034)\end{array}$ & $\begin{array}{l}\text { 7: Ag, B, CT, N, R, } \\
\text { Se, Sm }\end{array}$ \\
\hline 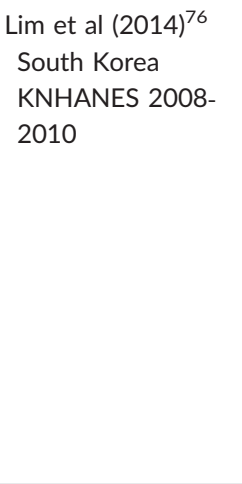 & $\begin{array}{l}\text { A) } 14725(48 \% \text { M) no DM } \\
\text { a. HOMA-IR Q4 } \\
\text { b. HOMA-IR Q1 } \\
\text { B) } \geq 19 \text { years }\end{array}$ & HOMA-IR & PerioDz: $\mathrm{CPI} \geq 3$ & $\begin{array}{l}\text { Q4 versus Q1: } \\
\text { i) Postmenopausal F: } \\
\text { i.1) all ( } \mathrm{n}=3223) \text { : } \\
\text { OR = } 1.47 \\
(95 \% \mathrm{Cl}: 1.07-2.01) \\
\text { i.2) } \mathrm{BMI} \geq 25 \\
(\mathrm{n}=1084): \\
\text { OR }=1.92 \\
\text { (95\% Cl: } 1.29-2.87) \\
\text { ii) Premenopausal F } \\
\text { ( } \mathrm{n}=4442): \text { OR }=\mathrm{ns} \\
\text { iii) } \mathrm{M}(\mathrm{n}=7060): \\
\mathrm{OR}=\mathrm{ns}\end{array}$ & $\begin{array}{l}\text { 10: Ag, Al, E, F, I, } \\
\text { Ph, Sm, TI, To, Y }\end{array}$ \\
\hline $\begin{array}{l}\text { Marugame et al } \\
(2003)^{77} \\
\text { Japan } \\
1997-2000\end{array}$ & $\begin{array}{l}\text { A) } N=664(100 \% M) \text { no } \\
\text { DM } \\
\text { a. IGT: } n=123 \mathrm{M} \\
\text { b. } N G T+I F G: n=495 \\
\text { ( } 495 \mathrm{M} / 0 \mathrm{~F}) \\
\text { B) } 46-57 \text { years }\end{array}$ & FPG & $\begin{array}{l}\text { ABL (Pano): } \\
\text { 1) Mean \% } \\
\text { (pre)molars only } \\
\text { 2) No. of sites }\end{array}$ & $\begin{array}{l}\text { 1) } O R=n s \\
\text { 2) } O R=n s\end{array}$ & $\begin{array}{l}\text { 10: Al, B, CH, CT, } \\
\text { O, PT, So, Sm, To, } \\
\text { Tr }\end{array}$ \\
\hline $\begin{array}{l}\text { Saito et al }(2005)^{79} \\
\text { Japan } \\
\text { Hisayama Study } \\
1988\end{array}$ & $\begin{array}{l}\text { A) } N=583(0 \% \mathrm{M}) \\
\text { a. } n=108 \mathrm{~F} \\
\text { b. } n=435 \mathrm{~F} \\
\text { B) } 40-79 \text { years }\end{array}$ & IGT & $\begin{array}{l}\text { 1) Mean PPD } \\
\text { 2) Mean } C A L\end{array}$ & $\begin{array}{l}\text { Q5 versus Q1-4: } \\
\text { 1) } O R=n s \\
\text { 2) } O R=n s\end{array}$ & 5: Ag, B, PI, Sm, So \\
\hline $\begin{array}{l}\text { Song et al }(2016)^{80} \\
\text { South Korea } \\
\text { KNHANES 2008- } \\
2010\end{array}$ & $\begin{array}{l}\text { A) } N=5690(59 \% \mathrm{M}) \\
\text { w/PerioDz } \\
\mathrm{CPI}=3: \mathrm{n}=4488 \\
\mathrm{CPI}=4: \mathrm{n}=1.202 \\
\text { a. HOMA-IR Q4 } \\
\text { b. HOMA-IR Q1 } \\
\text { B) } \geq 30 \text { years }\end{array}$ & HOMA-IR & $\begin{array}{l}\text { PerioDz: } \\
\mathrm{CPI}=4\end{array}$ & $\begin{array}{l}\text { Q4 versus Q1: } \\
\text { 1) all: } \\
\text { OR = } 1.31 \text { (95\% Cl: } \\
\text { 1.05-1.63) } \\
\text { 2) nonabdominally } \\
\text { obese: } \\
\text { OR = } 1.47 \\
(95 \% \mathrm{Cl}: 1.16-1.87)\end{array}$ & $\begin{array}{l}\text { 13: Ag, Al, B, De, } \\
\text { M, O, Ph, PS, Se, } \\
\text { Sm, So, TI, To }\end{array}$ \\
\hline $\begin{array}{l}\text { Timonen et al } \\
(2011)^{30} \\
\text { Finland } \\
\text { Health } 2000 \\
\text { Survey } \\
2000-2001\end{array}$ & $\begin{array}{l}\text { A) } N=2050(37 \% \text { M) no } \\
\text { DM } \\
\text { a1. HOMA-IR Q5a } \\
\text { a2. HOMA-IR Q5b } \\
\text { b. HOMA-IR Q1 } \\
\text { B) } 30-64 \text { years }\end{array}$ & HOMA-IR & $\begin{array}{l}\text { PerioDz: } \\
\text { no. of teeth with } \\
\text { i) PPD } \geq 4 \mathrm{~mm} \\
\text { ii) PPD } \geq 6 \mathrm{~mm}\end{array}$ & 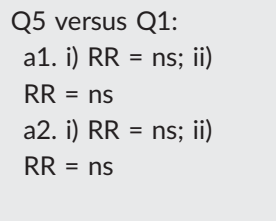 & $\begin{array}{l}\text { 7: Ag, Al, De, E, PI, } \\
\text { Se, To }\end{array}$ \\
\hline
\end{tabular}


TABLE 1 (Continued)

\begin{tabular}{|c|c|c|c|c|c|}
\hline $\begin{array}{l}\text { Author(s), year }{ }^{\text {ref. }} \\
\text { Country } \\
\text { Duration } \\
\text { Name of study }\end{array}$ & $\begin{array}{l}\text { A) Total no. of subjects } \\
\text { (\%M): } \\
\text { a. Pre-DM } \\
\text { b. Normoglycemic } \\
\text { B) Age range }\end{array}$ & $\begin{array}{l}\text { Exposure } \\
\text { measure: } \\
\text { prediabetes }\end{array}$ & $\begin{array}{l}\text { Outcome measure: } \\
\text { periodontitis }\end{array}$ & $\begin{array}{l}\text { Risk for periodontitis }{ }^{a} \\
\text { HR/IRR/OR/RR } \\
(95 \% \mathrm{CI})\end{array}$ & $\begin{array}{l}\text { No. of confounders } \\
\text { controlled }\end{array}$ \\
\hline $\begin{array}{l}\text { Zuk et al }(2017)^{81} \\
\text { Canada } \\
\text { Canadian Health } \\
\text { Measures Survey } \\
2007-2009\end{array}$ & $\begin{array}{l}\text { A) } N=1383(\approx 50 \% \mathrm{M}) \\
\text { no } \mathrm{DM} \\
\text { a. } \mathrm{n} / \mathrm{a} \\
\text { b. } \mathrm{n} / \mathrm{a} \\
\text { B) } 19-79 \text { years }\end{array}$ & $\begin{array}{l}\text { 1) } \mathrm{FPG} 6.1 \\
<7.0 \mathrm{mmol} / \mathrm{L} \\
\text { 2) } 6.0 \% \leq \mathrm{HbA} 1 \mathrm{c} \\
\leq 6.4 \% \\
\text { 3) } \mathrm{FPG} \\
\geq 5.6 \mathrm{mmol} / \mathrm{L} \text { or } \\
\mathrm{HbA} 1 \mathrm{c} \geq 6.0 \% \\
\text { 4) } \mathrm{FPG} \\
\geq 5.6 \mathrm{mmol} / \mathrm{L} \text { or } \\
\mathrm{HbA} 1 \mathrm{c} \geq 5.7 \%\end{array}$ & $\begin{array}{l}\text { PerioDz: } \\
\text { i) no/mild: CAL } \\
\leq 3 \mathrm{~mm} \\
\text { ii) moderate/ severe: } \\
\text { CAL } \geq 4\end{array}$ & $\begin{array}{l}\text { 1) \& 2) \& 3) \& 4): } \\
\text { OR = ns for i) \& ii) }\end{array}$ & $\begin{array}{l}\text { 8: Ag, B, E, I, In, R, } \\
\text { Se, Sm }\end{array}$ \\
\hline
\end{tabular}

Bold font indicates statistical significance at $P<.05$. When the lower $95 \% \mathrm{Cl}$ limit includes values shown as 1.0 or 1.00 (due to rounding), the significance is given in bold if stated by the authors in the original reports, assuming the value is close to 1 , but not quite equal to 1 .

95\% Cl, 95\% confidence interval; $\mathrm{ABL}$, alveolar bone loss; Ag, age; Al, alcohol consumption; $\mathrm{B}$, body mass index/obesity (BMI); Be, betel quid chewing; BOP, bleeding on probing; C, cholesterol; Ca, caries; CAL, clinical attachment loss; CDC/AAP, Centers for Disease Control \& Prevention/American Academy of Periodontology periodontitis case definitions ${ }^{66}$ or $^{150} ; \mathrm{CH}$, cholesterol, high-density lipoprotein (HDL); $\mathrm{CL}$, cholesterol, low-density lipoprotein (LDL); Co, country of origin; CPI, community periodontal index; CR, C-reactive protein (CRP); CT, cholesterol, total; D, decayed, missing, or filled teeth (DMFT); De, dental visits; Di, diet, healthy eating index; DM, diabetes mellitus; E, education; EWP, European Workshop in Periodontology (EWP) periodontitis case definitions ${ }^{105}$; F, flossing; Fi, fruit intake; FPG, fasting plasma glucose; Fl, fluorosis; H, hypertension; HbA1c, glycated hemoglobin; HOMA, homeostatic model assessment to quantify insulin resistance (IR) and $\beta$-cell function (B), HOMA-IR = fasting insulin $\mathrm{x}$ fasting glucose [mmol/L]/ 22.5, HOMA-B = $20 \times$ fasting insulin/ (fasting glucose [mmol/L] - 3.5); HR, hazard ratio; I, income, household; IFG, impaired fasting glucose; IGT, impaired glucose tolerance; In, insurance, health; IR, insulin resistance (= fasting insulin $\times$ fasting glucose); IRR, incidence rate ratio; KCIS, Keelung Community-based Integrated Screening; KNHANES, Korea National Health and Nutrition Examination Survey; M, metabolic syndrome; M/F, male/female; MONA LISA, MOnitoring NAtionaL du rISque Artériel; $N$ (confounder), number of teeth; $N$, number of participants in entire study; $n$, number of participants in subgroup; n/a, not available; NFG, normal fasting glucose; NGT, normal glucose tolerance; NHANES, National Health and Nutrition Examination Survey (USA); NIDDK, National Institute of Diabetes, Digestive and Kidney Diseases, Phoenix, Arizona; ns, not statistically significant; O, oral hygiene; OR, odds ratio; $\mathrm{P}$ (confounder), periodontitis, chronic ${ }^{150}$; Pano, panoramic radiograph; PPD, periodontal probing depth; PerioDz, periodontitis; Ph, physical activity; PI, plaque (index); Pre-DM, prediabetes; PS, prosthetic status; PT, periodontal treatment, history; Q, quantile; R, race/ethnicity; RR, risk ratio; Se, sex/gender; Sm, smoking; So, socio-economic status; SOALS, San Juan Overweight Adults Longitudinal Study; St, study site; To, toothbrushing; T, tartar, calculus; TI, toothbrush, interproximal/other; Tr, triglyceridemia, high triglyceride levels; W, waist circumference; $Y$ (confounder), year surveyed.

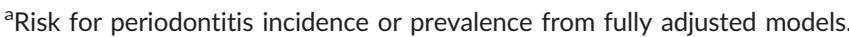

effect was discerned in this study with a gradation in incident periodontitis from no diabetes (28.0\%), through prediabetes (32.3\%), to manifest diabetes (38.6\%).

In a Finnish prospective cohort study among 157 never-smoking adults, 30-64 years of age, with no periodontal probing depth of $\geq 4 \mathrm{~mm}$ (periodontal pocket), and no diabetes at baseline, 108 (68.8\%) had developed periodontal pockets about 4 years later. ${ }^{17}$ When comparing the highest tertile of the Homeostatic Model Assessment index with the lowest tertile, the incidence rate ratio of new periodontal pocket formation was higher among subjects with insulin resistance (Homeostatic Model Assessment-Insulin Resistance, incidence rate ratio $=1.7 ; 95 \%$ confidence interval: $1.1-2.7$ ) as well as in individuals with impaired beta-cell function (Homeostatic Model Assessment-Beta, incidence rate ratio $=1.6 ; 95 \%$ confidence interval: $1.0-2.6){ }^{17}$

\section{2 | Cross-sectional studies}

Within a cardiovascular risk study, Benguigui et $\mathrm{al}^{71}$ investigated the association between metabolic syndrome, its various components, and gingivitis/periodontitis (gingival index, periodontal probing depth, and clinical attachment level) in a 35- to 74-year-old population in southwestern France. Participants without diabetes $(n=238)$ in the highest quartile of the Homeostatic Model Assessment-Insulin Resistance index had a significantly increased risk of having a higher prevalence of sites with clinical attachment level of $\geq 4 \mathrm{~mm}$, clinical attachment level of $\geq 5 \mathrm{~mm}$, and periodontal probing depth of $\geq 4 \mathrm{~mm}$ compared with those without diabetes, in the lowest quartile versus the highest quartile in adjusted analyses (risk ratio $=1.52$ [95\% confidence interval: $1.02-2.27]$; risk ratio $=1.61[95 \%$ confidence interval: $1.00-2.61]$, and risk ratio $=1.82[95 \%$ confidence interval: 1.08-3.07], respectively).

Emrich et $\mathrm{al}^{72}$ investigated whether diabetes was associated with periodontal destruction according to clinical attachment levels of $\geq 5 \mathrm{~mm}$ and alveolar bone loss in Pima \& Papago Indians aged $\geq 15$ years with diabetes ( $n=254$ ), a group with prediabetes (impaired glucose tolerance) ( $n=158$ ), and a group with normal glucose tolerance $(n=930)$. Diabetes and age were significantly correlated to breakdown of periodontal tissues. Subjects with type 2 diabetes had an increased risk of destructive periodontitis, with an adjusted odds ratio of 2.81 (95\% confidence interval: 1.91-4.13) for clinical attachment level and odds ratio of 3.43 (95\% confidence interval: 2.28-5.16) for severe radiographic bone loss; however, no differences were found between subjects with impaired glucose tolerance 
and those with normal glucose tolerance regarding clinical attachment levels and alveolar bone levels.

Genco et $\mathrm{al}^{27}$ explored the relationship between obesity and periodontal disease in 12367 diabetes-free US adults aged 20-90 years who participated in the National Health and Nutrition Examination Survey III. Participants were stratified, according to body mass index, into overweight (defined as body mass index $\left.\geq 27 \mathrm{~kg} / \mathrm{m}^{2}\right)(\mathrm{n}=5326)$ and not overweight ( $n=7041$ ), and these groups were further stratified into quartiles of insulin resistance (expressed as Homeostatic Model Assessment-Insulin Resistance), based on the product of fasting insulin and fasting glucose. Among the overweight US adults, those placed in the highest $\left(4^{\text {th }}\right)$ Homeostatic Model Assessment-Insulin Resistance quartile had a significantly increased risk for having severe periodontitis, with an adjusted odds ratio of 1.48 (95\% confidence interval: 1.13-1.93) compared with the overweight participants in the lowest (1st) Homeostatic Model Assessment-Insulin Resistance quartile. By contrast, the 1 st and the 4th quartiles did not differ statistically in nonoverweight participants. ${ }^{27}$

Hong et $\mathrm{al}^{73}$ found an age- and dose-dependent relationship between the presence of diabetes or prediabetes and periodontitis, defined as Community Periodontal Index $\geq 3$, in a South Korean study comprising 9977 adults. Participants with prediabetes (fasting plasma glucose: $111-125 \mathrm{mg} / \mathrm{dL}$ ) had a $33 \%$ increased risk of periodontitis in subjects aged 19-39 years and 40-64 years, but not in adults 65 years of age and older. The adjusted weighted prevalence of periodontitis was significantly greater in the groups with prediabetes and diabetes compared with the nondiabetes group, and this occurred in a dose-response manner, with prevalence of periodontitis being $23.2 \pm 1.4 \%$ in impaired fasting glucose $100-110 \mathrm{mg} / \mathrm{dL}$, increasing to $29.7 \pm 2.7 \%$ in impaired fasting glucose $111-125 \mathrm{mg} /$ $\mathrm{dL}$, and to $32.5 \pm 2.0 \%$ in manifest diabetes. ${ }^{73}$

In a German survey including 3086 participants, Kowall et al $^{74}$ described a significant relationship between prediabetes and periodontitis (defined as presence of clinical attachment level $\geq 3 \mathrm{~mm}$ at $\geq 2$ nonadjacent teeth or measured via means of clinical attachment level and periodontal probing depth), and edentulism which, however, disappeared after adjusting for potential confounders.

A total of 1097 adult dental patients in Manhattan, New York (aged 40 years or older if non-Hispanic white and $\geq 30$ years if nonwhite or Hispanic), who reported to not have diabetes, had chairside measures made of their glycated hemoglobin values. ${ }^{75}$ More than one-third (37.3\%) were found to have glycated hemoglobin readings in the prediabetes range (5.7\%-6.4\%), and they had $26 \%$ higher risk for having more teeth with periodontal probing depth of $\geq 5 \mathrm{~mm}$ and $6 \%$ higher risk for missing teeth than the normoglycemic subjects after adjusting for potential confounders.

In another South Korean survey, Lim et $\mathrm{al}^{76}$ investigated the association between insulin resistance (scored by Homeostatic Model Assessment-Insulin Resistance) and periodontitis (defined as Community Periodontal Index $\geq 3$ ) in 14725 adults $>18$ years of age. Comparison of the insulin-resistant with insulin-sensitive subjects revealed that only postmenopausal women were more likely to have periodontitis (odds ratio $=1.47 ; 95 \%$ confidence interval: 1.07 -
2.01), not men or premenopausal women. The association was potentiated in overweight postmenopausal women.

In a Japanese case-control study, Marugame et al ${ }^{77}$ examined 664 male military personnel aged $46-57$ years and classified them, according to their glycemic status, into 3 groups: normal glucose tolerance (fasting plasma glucose $<126 \mathrm{mg} / \mathrm{dL}$ and 2 hour impaired glucose tolerance $<140 \mathrm{mg} / \mathrm{dL}$ ); impaired glucose tolerance (fasting plasma glucose $<126 \mathrm{mg} / \mathrm{dL}$ and 2 hour impaired glucose tolerance $140-199 \mathrm{mg} / \mathrm{dL}$ ); and newly diagnosed diabetes (fasting plasma glucose $\geq 126 \mathrm{mg} / \mathrm{dL}$ and/or 2 hour impaired glucose tolerance $\geq 200 \mathrm{mg} / \mathrm{dL}$ ). Neither crude nor adjusted logistic regression models revealed any significant association between impaired glucose tolerance and alveolar bone support or number of sites with bone loss compared with normoglycemia. The study concluded that there is a positive association between type 2 diabetes and alveolar bone loss, but not between impaired glucose tolerance and alveolar bone loss.

Pérez et $\mathrm{al}^{78}$ assessed the association between prediabetes and insulin resistance with bleeding on probing and periodontitis according to case definitions developed by the Centers for Disease Control and Prevention and the American Academy of Periodontology for surveillance of periodontitis in a Puerto Rican study including 1191 overweight or obese 40- to 65-year-old adults without diabetes. Adjusted logistic regression revealed a significant relationship between prediabetes and bleeding on probing and severe periodontitis. Insulin resistance was associated with bleeding on probing of $>30 \%$ but not with any level of periodontitis. Impaired fasting glucose was significantly associated with both high levels of bleeding on probing and moderate or severe periodontitis. By contrast, glycated hemoglobin failed to show any significant relationship with high bleeding on probing or periodontitis.

Among Japanese women aged $40-79$ years, Saito et al ${ }^{79}$ compared the 108 with prediabetes with the 435 without hyperglycemia, but found no significant association between impaired glucose status and periodontal probing depth or clinical attachment level, respectively, after adjustment.

The 3rd Korean study was based on the same epidemiologic data as the study of Lim et $\mathrm{al}^{76}$.

Song et $\mathrm{al}^{80}$ investigated the association between diabetes, prediabetes, and periodontitis (Community Periodontal Index $\geq 3$ ) in 5690 mostly obese adults, aged $\geq 30$ years. After adjustment for 13 confounders, the odds ratios for prevalence of severe periodontitis (Community Periodontal Index $=4$ ) were significantly increased for the diabetes and prediabetes groups compared with healthy subjects. Data comparing the highest quartile of Homeostatic Model Assessment-Insulin Resistance (insulin resistant) with the lowest three quartiles showed that 826 of 1460 subjects in the highest quartile had manifest diabetes, thus preventing the use of Homeostatic Model Assessment-Insulin Resistance for assessment of prediabetes. Furthermore, only nonobese, insulin-resistant subjects had an increased risk for severe periodontitis compared with nonobese, insulin-sensitive subjects (odds ratio $=1.47 ; 95 \%$ confidence interval 1.16-1.87), whereas obese, insulin-resistant subjects did not have an elevated risk for severe periodontitis. 
The baseline status on which the described longitudinal Finnish study $^{17}$ is based was reported as a cross-sectional study ${ }^{30}$ that includes 2050 never-smokers between the ages of 30 and 64 years. Regardless of whether periodontitis was defined according to periodontal probing depth $>4 \mathrm{~mm}$ or periodontal probing depth $>6 \mathrm{~mm}$, and after comparing the highest Homeostatic Model Assessment-Insulin Resistance quintile with the lowest quintile or dichotomizing the Homeostatic Model Assessment-Insulin Resistance values for comparison, no significant associations were identified between prediabetes and periodontitis after adjustment for 7 potential confounders. ${ }^{30}$

Zuk et $\mathrm{al}^{81}$ analyzed the relationship between diabetes, prediabetes, and moderate-to-severe periodontitis with clinical attachment level $\geq 4 \mathrm{~mm}$ in adults aged 19-79 years using data from the Canadian Health Measure Survey. Only subjects with fasting plasma glucose $\geq 110 \mathrm{mg}$ (prediabetes and diabetes) showed significant association with periodontitis after adjustment for the confounders age, sex, ethnicity, body mass index, smoking, and dental insurance. However, after additional adjustment for income and education, the association with an elevated risk was abolished.

In summary, only 2 prospective cohort studies that explored the effect of prediabetes on incident periodontitis are available. ${ }^{17,70}$ Because such studies can yield information on the temporality, namely whether prediabetes or periodontitis existed first, they can providence some evidence regarding which factor (that which existed first) may affect the other, which the cross-sectional studies cannot. The 2 longitudinal studies were conducted in Taiwan ${ }^{70}$ and Finland, ${ }^{17}$ and whereas the former controlled statistically for smoking, the latter excluded smokers. The Taiwanese study analyzed data from a public program screening for 5 chronic diseases and used the Community Periodontal Index, which does not allow estimates of the extent of periodontitis, but only records the most severe periodontal status for an individual. People with any pockets of $\geq 4 \mathrm{~mm}$ (Community Periodontal Index scores 3 or 4) at baseline were excluded, so the new periodontitis cases are those who develop at least 1 pocket of $\geq 4 \mathrm{~mm}$ over 5 years. Moreover, the Community Periodontal Index does not include assessment of clinical attachment level. Hence, the results must be interpreted with caution. The Finnish study reported a statistically significant $70 \%$ higher risk for incident periodontitis (defined as development of new periodontal probing depth of $\geq 4 \mathrm{~mm}$, an inferior measure of periodontitis) in people with insulin resistance (Homeostatic Model Assessment-Insulin Resistance), as well as a $60 \%$ higher risk for incident periodontitis in people with impaired beta-cell function (Homeostatic Model Assessment-Beta).

Thirteen cross-sectional studies ${ }^{27,30,71-81}$ met the inclusion criteria, 12 of them defined periodontitis using a variety of clinical measures, whereas one used panoramic radiographs to score premolars and molars. ${ }^{77}$ Seven ${ }^{27,71,73,75,76,78,80}$ of the 13 cross-sectional studies reported significant associations between prediabetes (designated as the exposure) and periodontitis (designated as the outcome). These significant associations were strongest in the bivariate analyses but were attenuated in multivariate models after adjustment for potential confounders, importantly, age, smoking, and overweight/obesity. Furthermore, when significant associations were reported, the lower boundaries of the $95 \%$ confidence intervals invariably were close to 1 , the point at which there is no statistically significant difference between the groups being compared. Moreover, most of these significant associations were not identified in the entire study population, only in specific subgroups, namely: those who were overweight $^{27}$ or nonabdominally obese ${ }^{80}$; those who were postmenopausal $^{76}$ or postmenopausal and overweight ${ }^{76}$; only the most severe half of those with impaired fasting glucose (111-125 mg/ $\mathrm{dL})^{73}$; and only severe periodontitis. ${ }^{71}$ Three of the seven studies reporting significant associations were analyses of Korean National Health and Nutrition Examination Survey data from either 2008$2010^{76,80}$ or $2012-2013,{ }^{73}$ the rest were conducted in France, ${ }^{71}$ Puerto Rico, ${ }^{78}$ and the USA 27,75 . Of course, a cross-sectional study design is not able to yield information regarding causality.

In conclusion, the 2 longitudinal and the mostly cross-sectional studies may suggest a tendency for prediabetes to be associated with greater incidence, respective prevalence, or severity of periodontitis, irrespective of the glycemic and periodontitis case definitions applied and their corresponding thresholds. A trend for prediabetes to contribute to complications for periodontal health may exist in certain subpopulations, but longitudinal studies that apply the same periodontitis and prediabetes case definitions are needed to provide evidence to support such a relationship.

\section{I UNCONTROLLED DIABETES AND PERIODONTAL COMPLICATIONS}

We then attempted to answer the second question, "Does poorer glycemic control in type 2 diabetes lead to more severe periodontal complications than better control?" or, more broadly, "Is there a doseresponse relationship between level of glycemic control in type 2 diabetes and its periodontal complications (incidence or progression of periodontitis, tooth loss)?" based on existing evidence.

In order to ensure the ability to determine temporality, only longitudinal, descriptive, epidemiologic studies were eligible for inclusion. Furthermore, only studies that report adjusting for potential confounders were included in order to exclude spurious bivariate descriptive results. Hence, cross-sectional studies, case reports, mechanistic and interventional studies, as well as longitudinal studies that did not adjust their results, were excluded. Studies reporting on type 1 diabetes, a mix of types 1 and 2 diabetes, gestational diabetes, or diabetes of unknown types were also ineligible. The limit of publication year since 1980 was selected because only more recent (computer-based) analyses are able to control for several factors at the same time. Because these inclusion criteria were relatively strict and it was not always possible to deduce eligibility from the titles and abstracts from searching bibliographic databases, the majority of the literature searches consisted of manually harvesting references from bibliographies from eligible studies, supplemented with searching electronic databases that provided information about later reports that cited them.

Table 2 summarizes the only 4 studies that met the inclusion criteria. They were published between 1998 and 2012 and were 
TABLE 2 Effect of type 2 diabetes with poor glycemic control on incidence or progression of periodontitis and incident tooth loss: longitudinal studies reporting findings adjusted for potential confounders as of September 27, 2017

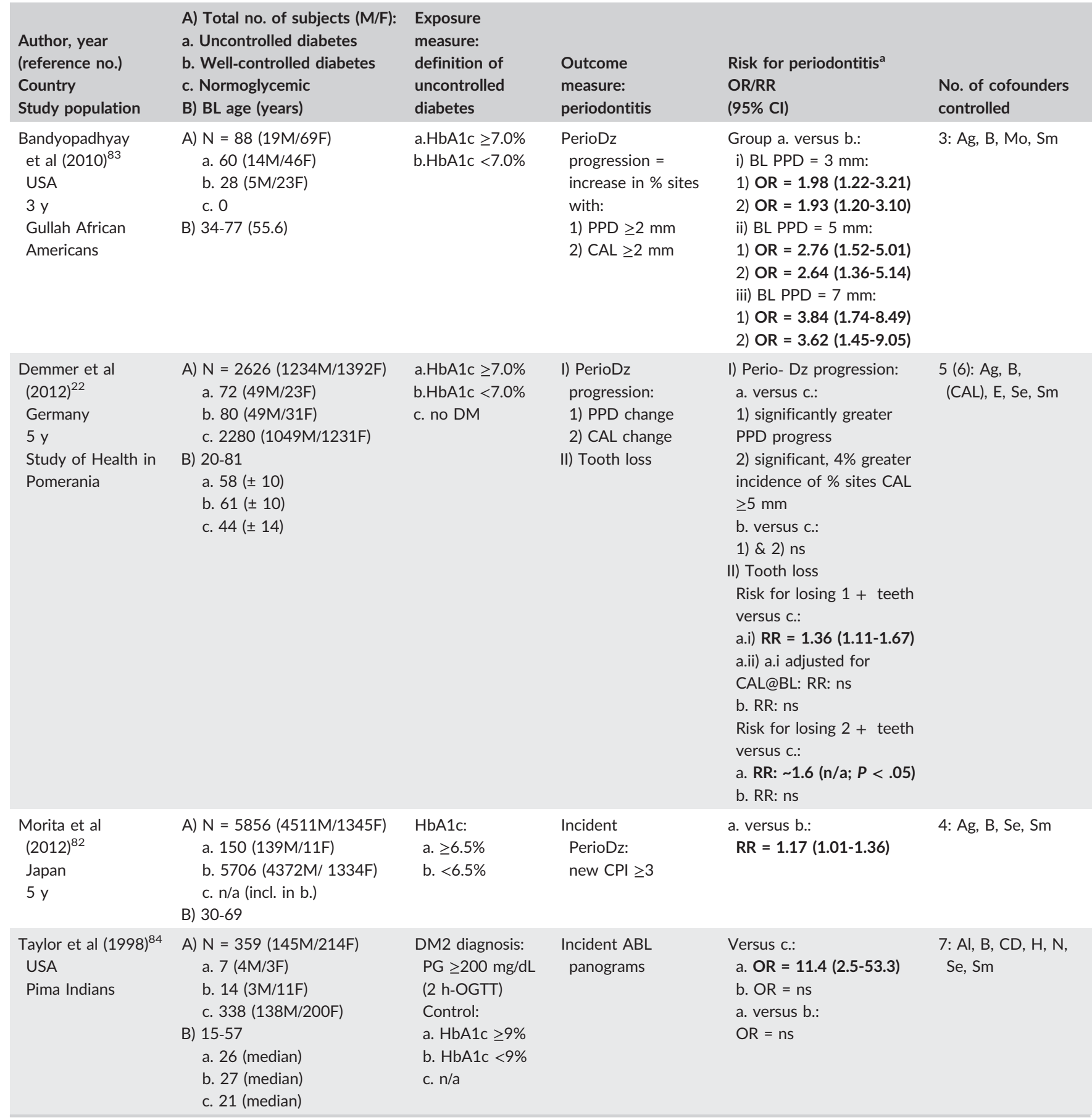

Bold font indicates statistical significance at $P<.05$.

95\% Cl, 95\% confidence interval; $\mathrm{ABL}$, alveolar bone loss; $\mathrm{Ag}$, age; $\mathrm{Al}$, alcohol consumption; $\mathrm{B}$, body mass index/obesity (BMI); $\mathrm{BL}$, baseline; $\mathrm{CD}$, coronary artery disease; CAL, clinical attachment loss; CPI, community periodontal index; DM2, type2 diabetes mellitus; E, education; h, hours; $\mathrm{H}$, hypertension; HbA1c, glycated hemoglobin; IR, insulin resistance; M/F, male/female; Mo, molar; N (confounder), number of teeth; N, number of participants in entire study; n, number of participants in subgroup; n/a, not available; ns, not statistically significant; OGTT, oral glucose tolerance test; OR, odds ratio; panograms, panoramic radiographs; PPD, periodontal probing depth; PerioDz, periodontitis; PG, plasma glucose; RR, risk ratio; Se, sex/gender; Sm, smoking.

${ }^{\text {a}}$ Results: risk for periodontitis incidence or progression from fully adjusted models. 
conducted in Germany, ${ }^{22}$ Japan, ${ }^{82}$ and the USA. ${ }^{83,84}$ However, the populations studied cannot be regarded as representative for their 3 continents. For example, the 2 US studies were conducted among the special groups Pima Indians and Gullah African Americans. Three studies assessed clinical ${ }^{22,82,83}$ and 1 assessed radiographic ${ }^{84}$ measures of incidence or progression of periodontitis, and 1 study additionally reported tooth loss. ${ }^{22}$ The 4 studies encompassed a total of 8735 participants, of whom 2618 had no diabetes and another 5828 had well-controlled type 2 diabetes, leaving only 289 participants with poorly controlled type 2 diabetes. The studies are highly heterogenic. For instance, the selected glycated hemoglobin threshold values for defining poor glycemic control are $6.5 \%,{ }^{82} 7.0 \%,{ }^{22,83}$ and $9.0 \%,{ }^{84}$ respectively. The youngest age of the participants ranges from 15 to 34 years, whereas the oldest ranges from 57 to 81 years; and smokers are included in all 4 studies. Even though final models in 3 of the 4 studies adjust for age, and all final models are adjusted for smoking, such differences may still pose difficulties in comparing the studies. Moreover, the studies were conducted among different race/ethnicities, namely African Americans, American Indians, Asians, and Caucasians.

A total of 88 , mostly very heavy, Gullah African Americans (78\% female; $7 \%$ smokers; $5 \%$ normal weight $/ 23 \%$ overweight $/ 72 \%$ obese), initially aged 34-77 years, in South Carolina were followed for between 1.9 and 4.1 (mean $=3$ ) years. ${ }^{83}$ All non-third molars were probed at 6 sites, thus yielding 9648 sites for which periodontal probing depth/clinical attachment level were available. Participants with baseline glycated hemoglobin $\geq 7.0 \%$ showed significantly more progression of periodontitis at site-level (defined as an increase of periodontal probing depth $\geq 2 \mathrm{~mm}$ or clinical attachment level $\geq 2 \mathrm{~mm}$ ) than those with baseline glycated hemoglobin $<7.0 \%$. The observed association was stronger for sites having deeper pockets at baseline with odds ratios of about 2.0 for sites with baseline periodontal probing depth of $3 \mathrm{~mm}, 2.7$ for sites with $5 \mathrm{~mm}$ and 3.7 for sites with $7 \mathrm{~mm}$.

The 5-year Study of Health in Pomerania is by far the largest and most comprehensively designed population study to illustrate the influence of hyperglycemia on periodontitis progression and tooth loss. ${ }^{22}$ Defining poor control as glycated hemoglobin $\geq 7.0 \%$ and good control as glycated hemoglobin $<7.0 \%$, those with poor control have greater risk for progression of periodontitis and for losing teeth compared with normoglycemic subjects, whereas those with well-controlled type 2 diabetes are not at higher risk than those without diabetes. Risks in the poorly controlled group are $4 \%$ higher for developing new clinical attachment level of $\geq 5 \mathrm{~mm}, 36 \%$ greater for losing any teeth, and about $60 \%$ greater for losing 2 or more teeth. An increase of glycated hemoglobin by 1 percentage point is associated with a mean increase in periodontal probing depth of $0.04 \mathrm{~mm}$ and with a mean increase in clinical attachment level of $0.07 \mathrm{~mm}$. Importantly, this study demonstrates that it is the hyperglycemia that determines the adverse effects on the periodontium, not the reason for the hyperglycemia or the mere diagnosis of diabetes mellitus.

In a large Japanese population study, Morita and colleagues used the Community Periodontal Index to assess periodontitis, which they defined as scores of 3 or $4 .{ }^{82}$ Only 150 subjects among these 30 - to 69-year-old study participants were categorized as having poor glycemic control, defined as glycated hemoglobin $\geq 6.5 \%$, compared with 5706 participants with glycated hemoglobin $<6.5 \%$. Those with poor glycemic control had $17 \%$ higher risk for developing new periodontitis (Community Periodontal Index $\geq 3$ ) over 5 years, which occurred in 2068 (35\%) of that group.

Finally, panoramic radiographs from 359 Pima Indians aged 1557 years were scored for new alveolar bone loss occurring over the 2-year study period (range: 1.2-6.9 years). ${ }^{84}$ Only 7 (4 men, 3 women) participants had poor glycemic control, defined as glycated hemoglobin $>9 \%$, but they had a risk of more than 11 times greater for developing new alveolar bone loss than the 338 participants with normal blood glucose. On the contrary, the 14 participants with well-controlled type 2 diabetes were not at higher risk for alveolar bone loss than those without diabetes, even when using the high threshold of $9 \%$ glycated hemoglobin.

\section{9 | A REAL-LIFE SCENARIO: EXAMPLES FROM THE STUDIES OF HEALTH IN POMERANIA}

In order to illustrate the situation more closely, results from two cross-sectional studies from a general Caucasian population are provided as an example. The Study of Health in Pomerania is a population-based prospective cohort study conducted in the northeast region of Germany. Details regarding study design, recruitment, and examination protocols are published elsewhere. ${ }^{85,86}$ In the first study, called Study of Health in Pomerania-0, a total of 4308 of 6265 eligible subjects participated in baseline examinations between 1997 and $2001 .^{86}$ Another stratified random sample of 8826 adults (aged 20-79 years) was drawn for the next study, called Study of Health in Pomerania-Trend, in which 4420 participated between 2008 and 2012. ${ }^{87}$ Data from these participants were collected independently of Study of Health in Pomerania-0, but in the same geographic area.

For each of 12, 5-year age strata in Study of Health in Pomerania-Trend, the prevalence of moderate/severe periodontitis was calculated by applying the Centers for Disease Control and Prevention and the American Academy of Periodontology case definitions for surveillance of periodontitis ${ }^{88,89}$ and the results are depicted in Figure 3 together with the respective prevalence of prediabetes (glycated hemoglobin: 5.7\%-6.4\%) and manifest diabetes (glycated hemoglobin $\geq 6.5 \%$ ). Visual comparison of the graphs shows that the prevalence of moderate/severe periodontitis and the prevalence of prediabetes according to age group largely coincide by age 40 , after which the prevalence of moderate/severe periodontitis is considerably greater than that of overt diabetes in all age groups.

Table 3 displays diabetes- and obesity-related measures and their combinations among all study participants and among edentulous subjects only in the 2 population studies conducted 10 years apart in the same area in Germany. ${ }^{86,87}$ 


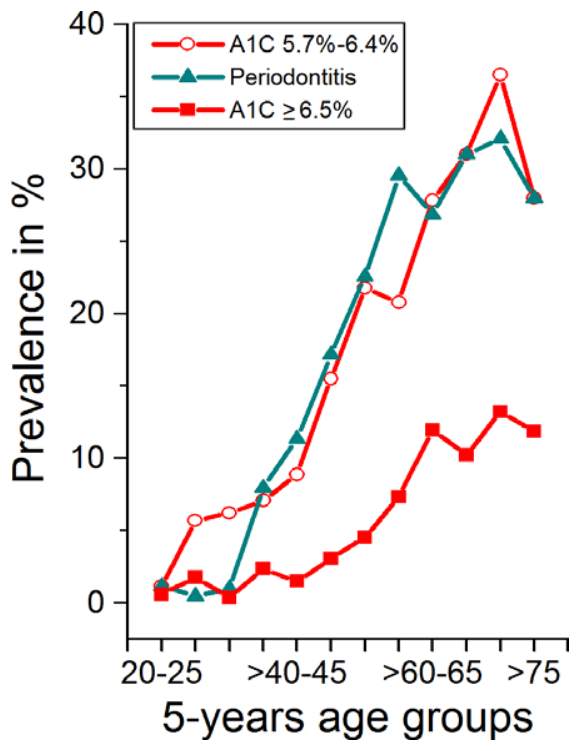

FIGURE 3 Prevalence of prediabetes (HbA1c: 5.7\%-6.4\%), moderate/severe periodontitis, ${ }^{88,89}$ and diabetes ( $\mathrm{HbA} 1 \mathrm{c} \geq 6.5 \%$ ) according to 5-y age groups. Study of Health in Pomerania-Trend, $n=3343 . \mathrm{HbA1}$, glycated hemoglobin
Overall, the mean glycated hemoglobin level of $5.4 \%$ was significantly lower in 2008-2012 than it was 10 years earlier (5.5\%). Nonetheless, the prevalence of objectively measured diabetes (glycated hemoglobin $\geq 6.5 \%$ ) was $10.9 \%$ in the Study of Health in Pomerania- 0 but $12.4 \%, 10$ years later, a relative increase of $13.8 \%$, with exactly the same relative increase in the self-reported prevalence that increased from $8.1 \%$ to $10.5 \%$. Importantly, despite the same increase in objectively and self-assessed diabetes, the proportion of undiagnosed diabetes fell from one-quarter (25.7\%) in 1997 2001 to only $15.3 \%$, 10 years later. For comparison, about one-third of the US population aged 20 years and older was unaware of their diabetes, as found in the National Health and Nutrition Examination Survey 2011-2014. ${ }^{90}$ Based on the same data, the Centers for Disease Control and Prevention reported in 2017 that about one-quarter $(23.8 \%)$ of adults aged 18 years and older with diabetes are undiagnosed (overall diabetes prevalence: 11.5\%; undiagnosed: 2.7\%). ${ }^{9}$ The only independent risk factor for being unaware among both US men and women was not having received any health care in the last year, which was associated with a 6-fold risk. ${ }^{90}$ Being of Hispanic ethnicity was a significant factor among US women, but not among US men. Owing to differences in the health-care delivery

TABLE 3 Prevalence of various measures of hyperglycemia/diabetes and obesity assessed in two population studies in the same area of Germany conducted 10 y apart: Study of Health in Pomerania-0 1997-2001 ${ }^{85,86}$ and Study of Health in Pomerania-Trend 2008-2012 ${ }^{87}$

\begin{tabular}{|c|c|c|c|}
\hline Measures assessed & $\begin{array}{l}\text { Study of Health in } \\
\text { Pomerania- } 0(n=4241)\end{array}$ & $\begin{array}{l}\text { Study of Health in } \\
\text { Pomerania-Trend }(n=4411)\end{array}$ & $P$-value \\
\hline Glycated hemoglobin (\%) & $5.5( \pm 0.9)$ & $5.4( \pm 0.8)$ & $<.001$ \\
\hline \multicolumn{4}{|l|}{ Glycated hemoglobin } \\
\hline$\geq 6.5 \%$ (objective diagnosis) & $10.9(10.0-11.9)$ & $12.4(11.5-13.4)$ & $<.001$ \\
\hline$\geq 6.5 \%$ (diabetes) & $8.7(7.9-9.6)$ & $7.0(6.2-7.8)$ & .003 \\
\hline Large waist ${ }^{\mathrm{b}}(\%)$ & $30.7(29.3-32.1)$ & $36.1(34.7-37.6)$ & $<.001$ \\
\hline Large waist ${ }^{\mathrm{b}}$ among subjects with glycated hemoglobin $\geq 6.5 \%$ (\%) & $56.6(51.4-61.8)$ & $72.1(66.7-77.0)$ & $<.001$ \\
\hline Body mass index $\geq 30.0$ (obese) (\%) & $25.6(24.3-26.9)$ & $31.7(30.3-33.1)$ & $<.001$ \\
\hline Body mass index $\geq 30.0$ (obese) (\%) & $35.3(31.1-39.6)$ & $50.5(44.5-56.6)$ & $<.001$ \\
\hline \multicolumn{4}{|l|}{ Glycated hemoglobin } \\
\hline $5.7-6.4 \%$ (normoglycemic) & $43.9(39.5-48.4)$ & $49.5(43.4-55.5)$ & .14 \\
\hline $5.7-6.5 \%$ (prediabetes) & $32.7(28.6-37.0)$ & $27.8(22.6-33.6)$ & .17 \\
\hline$\geq 6.5 \%$ (diabetes) & $23.4(19.8-27.4)$ & $22.7(17.9-28.1)$ & .82 \\
\hline Body mass index $\geq 30.0$ among glycated hemoglobin $\geq 6.5 \%$ & $46.2(36.9-55.6)$ & $66.1(53.0-77.7)$ & .011 \\
\hline
\end{tabular}

Values are given as mean \pm standard deviation, mean ( $95 \%$ confidence interval) or $n$.

Bold font indicates statistical significance at $P<.05$.

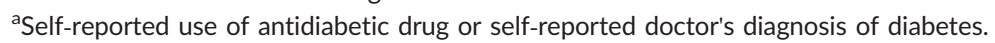

${ }^{b}$ Waist circumference $>102 \mathrm{~cm} / 40$ inches in men or $>88 \mathrm{~cm} / 35$ inches in women). 
TABLE 4 Distribution of characteristics (potential risk factors) stratified according to categories of glycemic control, among dentate participants classified by periodontitis severity levels ${ }^{89}$ in the Study of Health in Pomerania-0 [1997-2001 ${ }^{85,86}$ ] and the Study of Health in Pomerania-Trend [2008-2012 $\left.{ }^{87}\right]$

\begin{tabular}{|c|c|c|c|c|c|c|}
\hline \multirow[b]{2}{*}{ Characteristic $^{a}$} & \multicolumn{3}{|c|}{ Study of Health in Pomerania-0 $(n=3410)$} & \multicolumn{3}{|c|}{$\begin{array}{l}\text { Study of Health in Pomerania-Trend } \\
(n=3343)\end{array}$} \\
\hline & $\begin{array}{l}\text { Glycated } \\
\text { hemoglobin } \\
<5.7 \%\end{array}$ & $\begin{array}{l}\text { Glycated } \\
\text { hemoglobin } \\
5.7-6.4 \%\end{array}$ & $\begin{array}{l}\text { Glycated } \\
\text { hemoglobin } \\
\geq 6.5 \%\end{array}$ & $\begin{array}{l}\text { Glycated } \\
\text { hemoglobin } \\
<5.7 \%\end{array}$ & $\begin{array}{l}\text { Glycated } \\
\text { hemoglobin } \\
5.7-6.4 \%\end{array}$ & $\begin{array}{l}\text { Glycated } \\
\text { hemoglobin } \\
\geq 6.5 \%\end{array}$ \\
\hline$n$ & 2582 & 627 & 201 & 2764 & 412 & 167 \\
\hline Age (years) & $43.5 \pm 14.2$ & $54.2 \pm 13.9$ & $60.3 \pm 11.8$ & $46.3 \pm 14.1$ & $57.5 \pm 12.4$ & $60.8 \pm 11.4$ \\
\hline Education to $<10$ th grade (\%) & 25.5 & 48.6 & 64.9 & 13.6 & 24.7 & 42.0 \\
\hline Body mass index $\geq 30$ (obese) (\%) & 19.8 & 32.9 & 46.5 & 24.2 & 38.2 & 61.1 \\
\hline \multicolumn{7}{|l|}{ Waist circumference } \\
\hline Male (cm) & $93 \pm 11$ & $98 \pm 11$ & $104 \pm 11$ & $94 \pm 12$ & $100 \pm 13$ & $107 \pm 12$ \\
\hline No/mild (\%) & 50.4 & 28.2 & 16.3 & 53.6 & 30.9 & 21.6 \\
\hline Moderate (\%) & 32.8 & 42.4 & 46.8 & 32.1 & 44.0 & 47.9 \\
\hline Severe (\%) & 16.7 & 29.3 & 36.9 & 14.3 & 25.1 & 30.5 \\
\hline Clinical attachment level/loss $\geq 3 \mathrm{~mm}$ (\%) (people) & 27.6 & 49.3 & 68.8 & 24.0 & 45.1 & 54.5 \\
\hline Clinical attachment level/loss (mm) & $2.3 \pm 1.7$ & $3.2 \pm 1.8$ & $4.1 \pm 1.9$ & $2.2 \pm 1.5$ & $3.1 \pm 1.7$ & $3.6 \pm 2.0$ \\
\hline Bleeding on probing (\%) & $29(13-50)$ & $35(17-56)$ & $44(25-70)$ & $17(5-33)$ & $21(10-46)$ & $27(13-50)$ \\
\hline \multicolumn{7}{|l|}{ Diabetes } \\
\hline 1. Self-reported ${ }^{\mathrm{b}}(\%)$ & 1.2 & 5.8 & 63.4 & 2.5 & 14.0 & 66.7 \\
\hline 2. Total $^{\mathrm{C}}(\%)$ & 1.2 & 6.0 & 100 & 2.5 & 14.5 & 100 \\
\hline
\end{tabular}

Values are given as $\mathrm{n}$, mean \pm standard deviation or median (interquartile range).

${ }^{a}$ Some $95 \%$ confidence intervals are omitted for clarity.

${ }^{\mathrm{b}}$ From self-reported antidiabetic drug use and/or self-reported doctor's diagnosis.

${ }^{\mathrm{c}}$ Self-reported + subjects with glycated hemoglobin concentration $\geq 6.5 \%$ or non-fasting glucose level $\geq 11.1 \mathrm{mmol} / \mathrm{L}$.

systems and to the homogenous, Caucasian German population in our study, these factors do not directly apply to our study.

Obesity - especially abdominal obesity (waist circumference) was also substantially more prevalent in the most recent study and was closely linked to age (data not shown) as well as to glycated hemoglobin levels. Almost three-quarters of people with diabetes had a large waist, and more than $60 \%$ of people with diabetes - and $66 \%$ of the edentulous among them - were obese. Total loss of all teeth was significantly associated with glycemia level. Over 10 years, edentulism was reduced by almost half (namely, by $46.2 \%$, from $11.7 \%$ to $6.3 \%$ ), but the relationship with the glycated hemoglobin level remained significant. This finding is in accord with the predicted continued decline of the rate of edentulism in the USA as a result of differences among birth cohorts, resulting in the predicted prevalence of edentulism to be $30 \%$ lower in 2050 than in $2010 .{ }^{91}$ Table 4 presents the distribution of periodontitis, diabetes, and risk factors among the different glycated hemoglobin strata for both population cohorts.

With increased glycemia, the prevalence of moderate or severe periodontitis classified according to the Centers for Disease Control and Prevention and the American Academy of Periodontitis case definitions ${ }^{88,89}$ increased and the number of teeth decreased, both also related to age. An improved state of periodontitis after 10 years is evident in Table 4. While the prevalence of diabetes increased slightly (Table 3 ), the glycemic control among participants with diabetes improved (Table 4). Compared with normoglycemic subjects, and in both time periods, those with diabetes (glycated hemoglobin $\geq 6.5 \%$ ) had a risk almost 3 times higher (2.79) for having severe periodontitis and double the risk for having moderate periodontitis.

The probable cause of these differences in the decade elapsing between the Study of Health in Pomerania- 0 and the Study of Health in Pomerania-Trend emerged when behavioral and socioeconomic factors were included and revealed improvements in educational level, hygiene awareness, self-assessment of oral health, and changing use of antidiabetic medications (data not shown).

For comparison with these Study of Health in Pomerania findings, analyses of National Health and Nutrition Examination Survey data for adults 20 years of age and older revealed a similar increase in the prevalence of prediabetes and unhealthy waist circumferences between 1988/1994 and 2012. ${ }^{92}$ The 2011-2012 National Health 


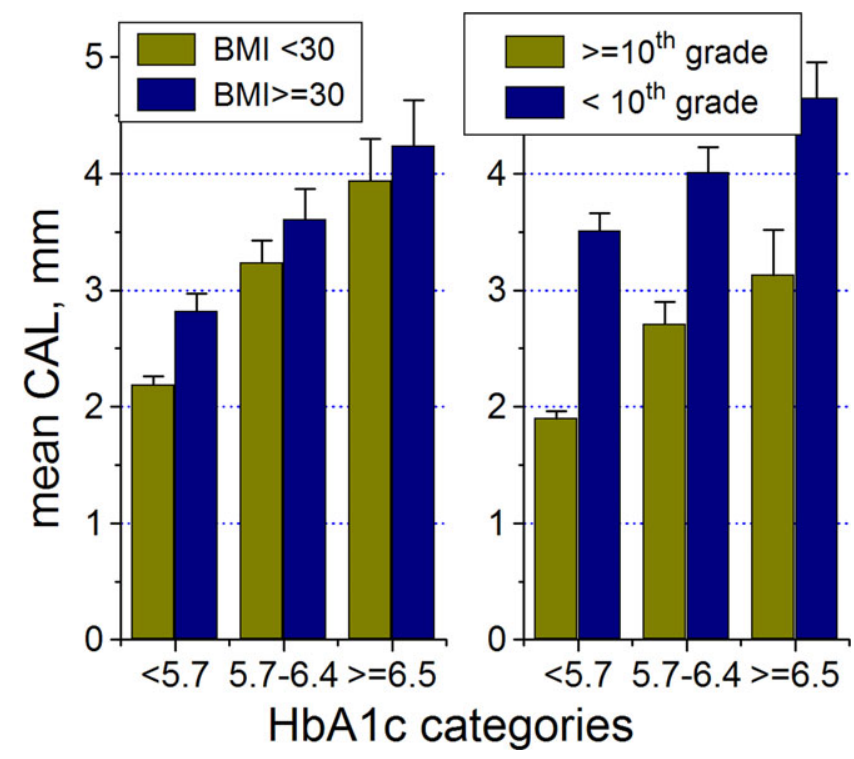

FIGURE 4 Mean clinical attachment loss (CAL), stratified according to obesity and education, in normoglycemia (HbA1c $<5.7 \%$ ), prediabetes (HbA1c 5.7\%-6.4\%), and diabetes ( $\mathrm{HbA1c}$ $\geq 6.5 \%$ ). Study of Health in Pomerania-0, crude data, $n=3410$. 10th grade, 10th grade of school education; BMI, body mass index; $\mathrm{HbA1c}$, glycated hemoglobin

and Nutrition Examination Survey data showed a diabetes prevalence of $12 \%-14 \%$ among US adults, ${ }^{93}$ so the prevalence of diabetes had increased, but the proportion of undiagnosed diabetes decreased. ${ }^{94}$

Furthermore, the observation of increased diabetes prevalence, but improved metabolic control, is in line with the decline in all diabetes-related complications during 2 decades in the USA, such as acute myocardial infarction and hyperglycemic crises. ${ }^{95}$ Thus, it is important, for further research, to be aware that characteristics of cohorts change with time and therefore comparisons with older studies should be made with caution, even if identical catchment areas are considered. Most studies compare groups of poorly and well-controlled diabetes - or groups with hyperglycemia versus healthy (normoglycemic) groups - and typically find increased risk of periodontitis with elevated glycated hemoglobin, regardless of the selected glycated hemoglobin threshold. This holds true also in the presence of additional risk factors, such as obesity and socioeconomic factors.

As an example from the Study of Health in Pomerania-0, the mean clinical attachment level or clinical attachment loss (used as synonyms) is shown across the glycated hemoglobin cut-offs for prediabetes and diabetes in Figure 4. Risk factors such as these shown here, namely obesity and education, probably exacerbate the severity and extent of periodontitis, but the strong, underlying characteristic, namely the fundamental glycated hemoglobin-dependency, is preserved and reflects the relationship as it is true also without these risk factors.

The ultimate objective of all dental-preventive and treatment measures is to preserve the patients' teeth and their oral function to

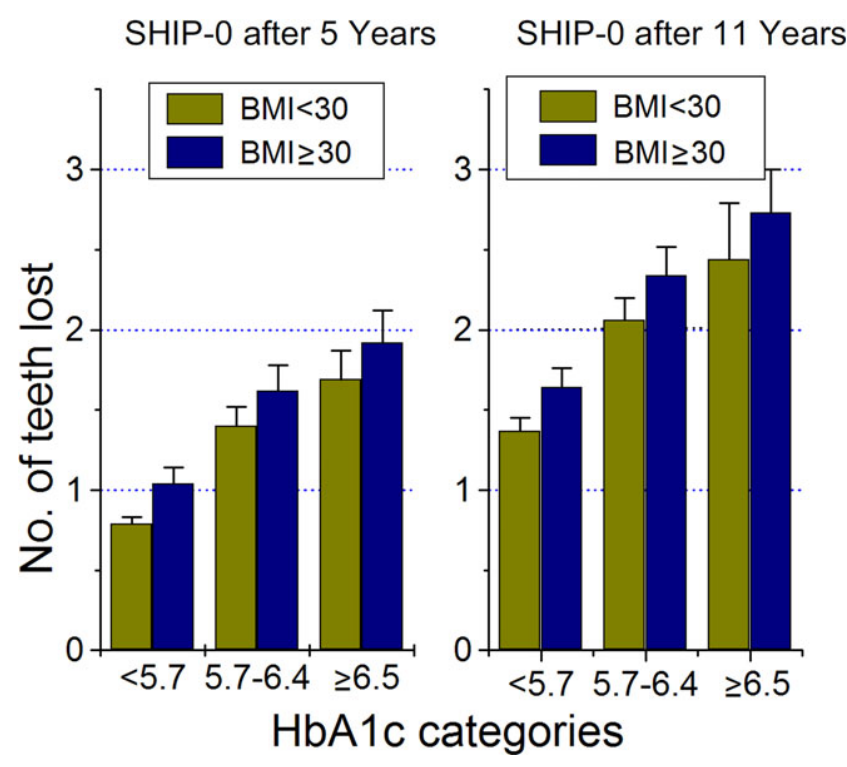

FIGURE 5 Predicted mean number of teeth lost during 5 and 11 y of follow-up, stratified according to obesity (body mass index [BMI]) and glycemic control - normoglycemia (HbA1c <5.7\%), prediabetes (HbA1c: 5.7\%-6.4\%), and diabetes (HbA1c $\geq 6.5 \%$ )upon adjustment for age, sex, education, and obesity. Study of Health in Pomerania-0 (SHIP-0) at 5 y (left panel; $n=3300$ ) and 11 y (right panel; $n=2323$ ). HbA1c, glycated hemoglobin

preserve or improve their quality of life. The number of teeth lost was assessed in the follow-up studies of Study of Health in Pomerania- 0 after 5 and 10 years, respectively. In Figure 5 , the number of teeth lost, after adjustment for major risk factors for both diabetes and periodontitis, is shown. Again, there is a distinct pattern following the glycated hemoglobin categories, even when stratified according to obesity. These tooth-loss data are in agreement with reports from elsewhere, for instance France. ${ }^{96}$ Follow-up tooth loss is subject to the same pattern in relation to glycemia state (Figure 5) as was shown for cross-sectional clinical attachment level in Figure 4. When comparing groups of persons, poorer glycemic status is associated with more severe periodontitis.

\subsection{The individual and the cohort}

Hyperglycemia is one of the most important risk factors of periodontitis, as shown in several studies that agree with astonishing consistency. ${ }^{21}$ But what is the dental care professional to do when a new patient who complains of symptoms potentially consistent with periodontitis enters the dental practice? Most published studies that relate periodontitis to glycemic control are studies among groups in which individual participant characteristics are anonymously embedded. In the dental practice, however, the individual patient comes in and has to be treated, so the dentist will be confronted with the special problems of this particular patient to estimate the risk imposed by glycemic control on periodontal destruction. For illustration, Figure 6 shows the relationship between clinical attachment level and glycated hemoglobin in each individual participating in the 2 independent cross-sectional studies mentioned. 

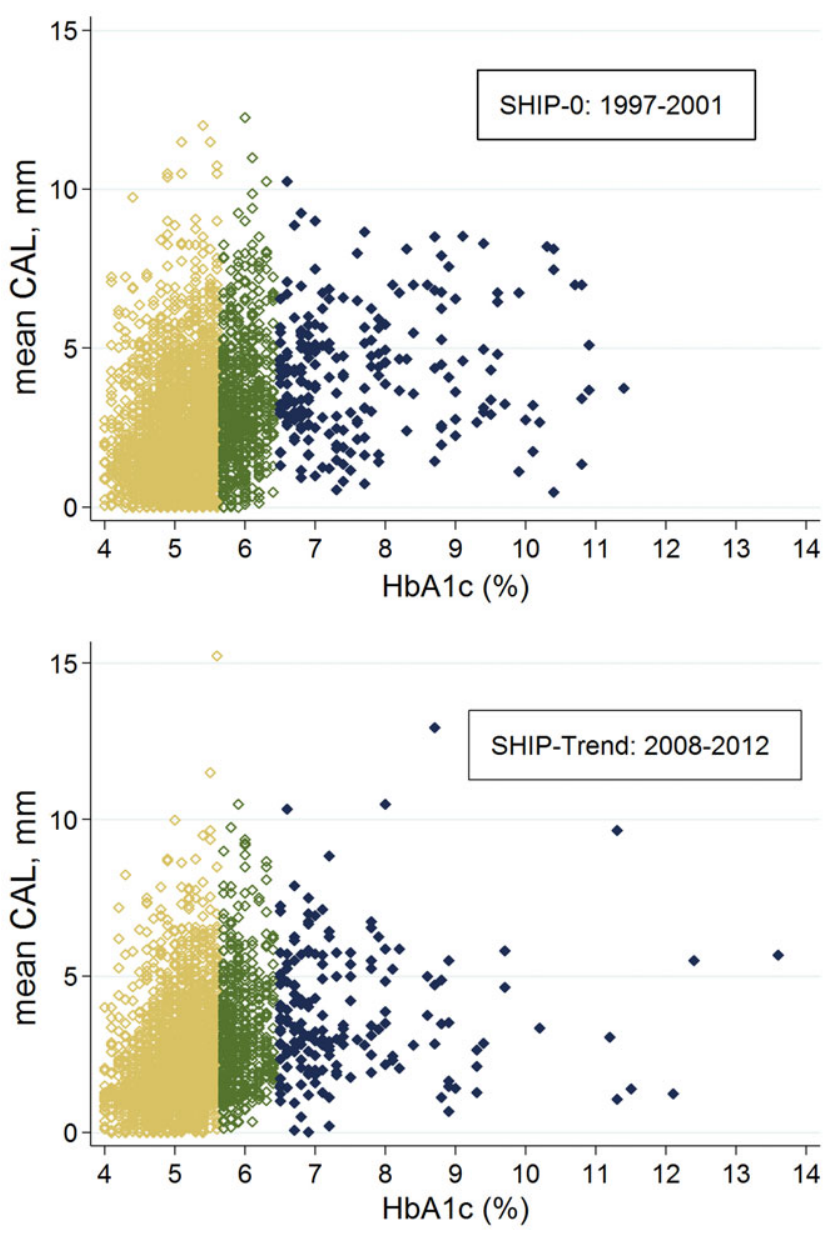

FIGURE 6 Distribution of mean attachment loss according to glycated hemoglobin (HbA1c) percentage in each individual participant in the 2 population studies Study of Health in Pomerania-0 (SHIP-0) (1997-2001) and Study of Health in Pomerania-Trend (SHIP-Trend) (2008-2012). Yellow indicates normoglycemia (HbA1c <5.7\%); green indicates prediabetes (HbA1c: 5.7\%-6.4\%), and dark blue indicates diabetes (HbA1c >6.5\%). SHIP-0, $\mathrm{n}=3410$; SHIP-Trend, $\mathrm{n}=3343$. CAL, clinical attachment loss

Obviously, a risk prediction for a single person regarding the glycemic state and its potential impact on periodontal health seems to be nearly impossible, regardless of what risk ratios or odds ratios could be statistically deduced from population group comparisons. Despite the increasing risk with deteriorating glycemic control, subjects with severe periodontitis are found within all glycated hemoglobin categories. For example, among 40- to 60-year-old participants in the Study of Health in Pomerania-0, 25\%, 31\%, and $36 \%$ were categorized as having severe periodontitis at glycated hemoglobin levels of $<5.7 \%, 5.7-6.4 \%$, and $\geq 6.5 \%$, respectively. The corresponding values 10 years later (in the Study of Health in Pomerania-Trend) were $19 \%, 22 \%$, and $25 \%$, respectively.

Individuals with glycated hemoglobin below $6.5 \%$ comprise all those with healthy blood sugar levels, prediabetes, or well-controlled diabetes, whereas the group with glycated hemoglobin levels of $\geq 6.5 \%$ consists of diabetes patients who are treated but have not attained glycated hemoglobin levels below this threshold, as well as those with undiagnosed diabetes.

Thus, instead of considering group-based statistical risk, the frequency distribution of all study participants across the range of glycemia allows the relationship between hyperglycemia and periodontitis to be appraised. Nevertheless, frequency distributions of the population also reveal that the proportion of more severe periodontitis is associated with increasing levels of glycated hemoglobin. This is shown in Figure 7, in which the individuals are distributed according to glycemic control while being grouped according to the Centers for Disease Control and Prevention and the American Academy of Periodontology periodontitis case definitions. For instance, slightly more than 100 participants had glycated hemoglobin levels of $4.9 \%$ or $5.0 \%$ in the Study of Health in Pomerania-0. The population-derived frequency distribution of periodontitis grades shows widely overlapping curves. The differences between the periodontitis grades are most substantial within the prediabetes glycated hemoglobin range $(5.7 \%-6.4 \%)$ or even below. The distribution pattern of the population of the Study of Health in Pomerania-Trend appears narrower than that of the study 10 years earlier because of a reduced number of participants with high glycated hemoglobin levels (see Table 3).

Transformation of the histograms, shown in Figure 7, into cumulative frequency distributions reveals that $\geq 50 \%$ of subjects have glycated hemoglobin levels well below $5.7 \%$, irrespective of their periodontitis category. ${ }^{88,89}$ The glycated hemoglobin medians in no/ mild, moderate, and severe periodontitis are 5.0\%, 5.2\%, and 5.4\%, respectively, in this population. For comparison, the 2009-2012 National Health and Nutrition Examination Survey data exposed mean glycated hemoglobin levels of $5.6 \%$ and $5.9 \%$, respectively, for individuals without and with some form of periodontitis (mild, moderate, or severe). ${ }^{97}$

Because of the close interdependence between glycemic metabolism, obesity, age, and socioeconomic status, and their effects on periodontitis, the frequency distributions of confounders are also important. Similarly to Figure 7, concerning glycemic control, the frequency distribution of 3 periodontitis severity grades according to body mass index as a measure of overweight and obesity is shown in Figure 8.

Subdividing the glycated hemoglobin frequency distributions (Figure 7) by important risk factors for both diabetes and periodontitis results in a different pattern. Now, the distribution of glycated hemoglobin between participants with no/mild and severe periodontitis is hard to distinguish. The main difference is the relative risk for periodontitis but no longer the dependence on glycemic level. The no/mild and severe periodontitis frequency distributions by glycated hemoglobin are stratified by 20-year age groups (Figure 9) and education level ( $<10$ th grade or $\geq 10$ th grade) (Figure 10$)$. With increasing age, the distribution moves to higher glycated hemoglobin levels but remains nearly identical between participants with and without periodontitis. In multivariate regression analyses, it was frequently observed that the association between diabetes and periodontitis was attenuated when adjusted for age $\mathrm{e}^{74}$ or for body mass index, ${ }^{30}$ 

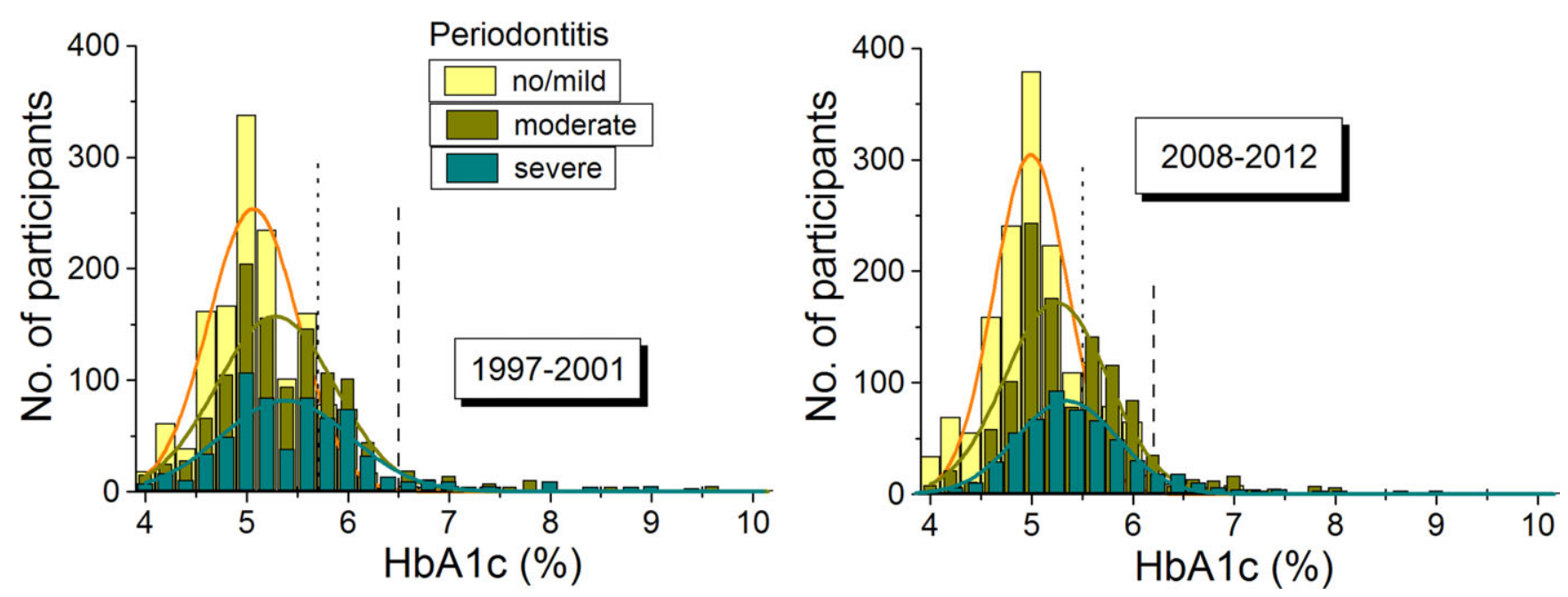

FIGURE 7 Distribution of study participants according to their periodontitis classification as no/mild, moderate, or severe ${ }^{88,89}$ according to glycemic hemoglobin (HbA1c) in Study of Health in Pomerania-O (SHIP-0) (1997-2001) and Study of Health in Pomerania-Trend (SHIP-Trend) (2008-2012). The dotted and dashed lines indicate HbA1c thresholds of 5.7\% and 6.5\%, respectively. SHIP-0, $n=3410 ;$ SHIP-Trend, $n=3343$
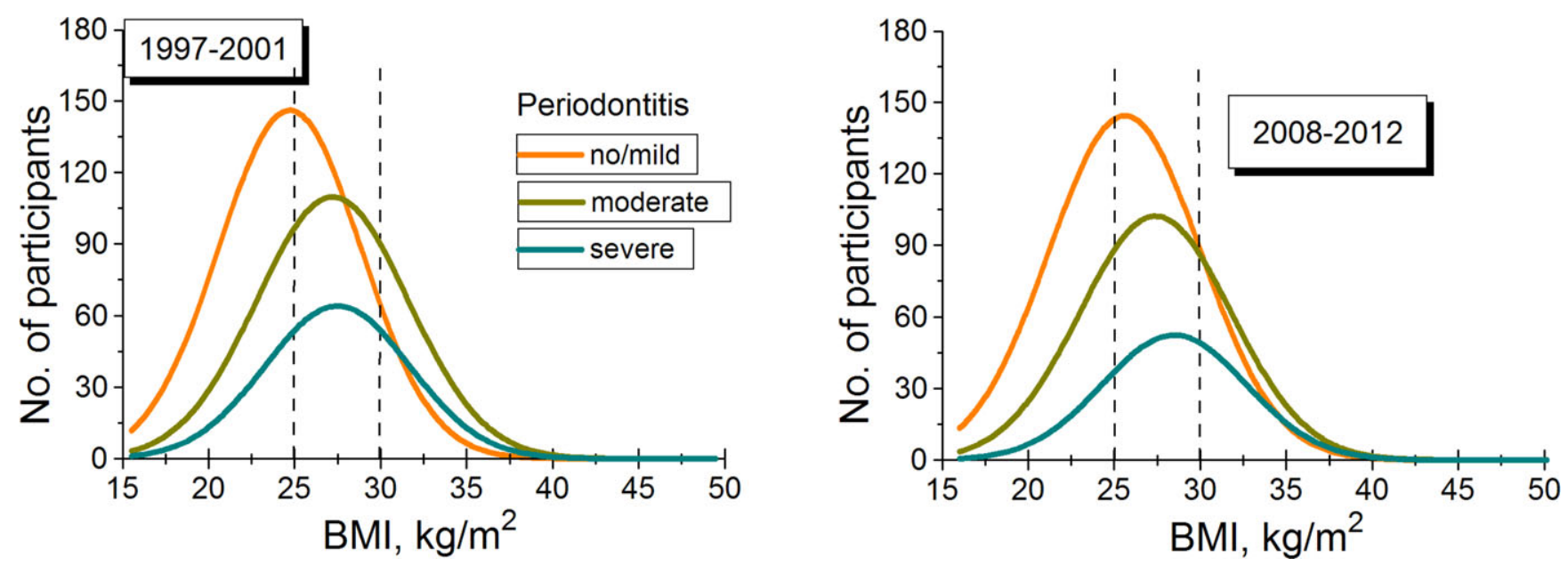

FIGURE 8 Distribution of study participants according to their periodontitis classification ${ }^{88,89}$ as no/mild (orange), moderate (olive green), or severe (dark cyan), according to level of obesity (body mass index [BMI]). The dashed vertical lines indicate the BMI thresholds of $25 \mathrm{~kg} / \mathrm{m}^{2}$ and $30 \mathrm{~kg} / \mathrm{m}^{2}$. Study of Health in Pomerania-O (SHIP-0), $\mathrm{n}=3410$; Study of Health in Pomerania-Trend (SHIP-Trend), $\mathrm{n}=3343$

for example. This may be better understood by viewing the patterns shown in Figure 9. Likewise, there is only a small displacement toward higher glycated hemoglobin by the factor education in the distributions between subjects with and without periodontitis, but noticeably more individuals with low education tend to have high glycated hemoglobin. Here, the marked distinction comes from diverging relative risks $(61.7 \%$ and $19.6 \%$ for low and high education, respectively) (Figure 10).

In summary, the results of studies on the effects of diabetes/hyperglycemia on periodontitis are confused by 2 overlapping effects (ie, the true influence of metabolic disturbance on periodontal inflammation and the differing distributions of subjects with and without periodontitis within a population studied).

When comparing groups of persons, a poorer glycemic state is associated with more severe periodontitis. This conclusion should be supplemented with the constraint that the frequency distributions imposed by additional risk factors within these groups may overwhelm any influence of hyperglycemia.

\subsection{Is there a glycated hemoglobin concentration threshold for periodontitis risk?}

Suggestions to conduct glycated hemoglobin screening in the dental office setting aim at early identification of hitherto unknown diabetes or even prediabetes. The objective should be to select patients at high risk for developing periodontitis and tooth loss or, by chance, to identify underlying causes of the disease. Step-wise, increasing thresholds were tested to identify a reliable cut-off point separating periodontally affected subjects with glycated hemoglobin above any cut-off value from those individuals with glycated hemoglobin below 

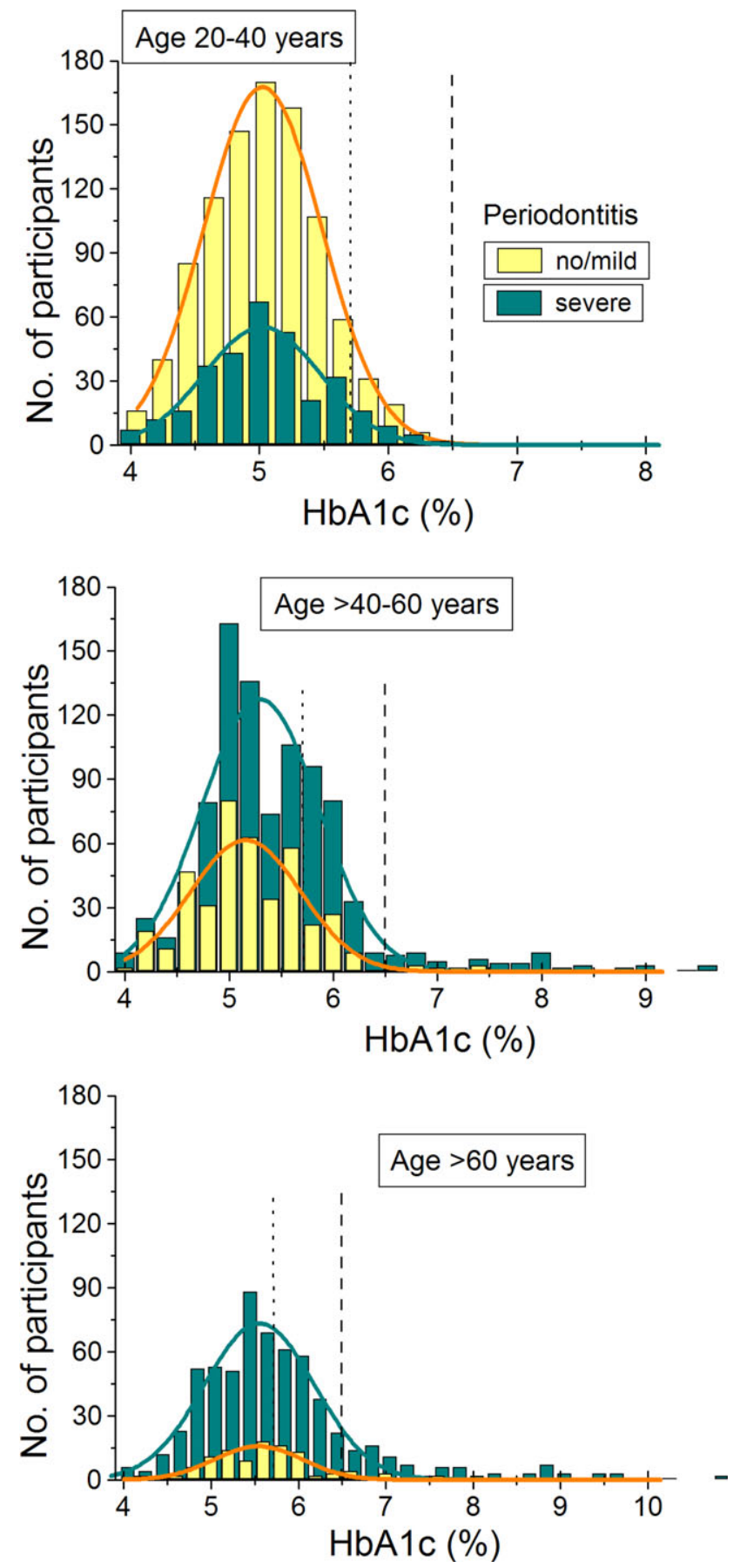

FIGURE 9 Age-stratified distribution of study participants with the periodontitis categories ${ }^{88,89}$ no/mild (orange) or severe (dark cyan), according to level of glycemic control (HbA1c). The dotted and dashed lines indicate $\mathrm{HbA1c}$ thresholds of $5.7 \%$ and $6.5 \%$, respectively. Study of Health in Pomerania-0, $n=3410$. HbA1c, glycated hemoglobin

the cut-off value. The proportion with severe periodontitis increased with increasing glycated hemoglobin cut-off levels from glycated hemoglobin $\geq 5.5 \%$ and reached a nearly constant level at $\geq 6.5 \%$ (Figure 11). Concomitantly, the proportion with no/mild periodontitis decreases. A nearly constant percentage of subjects with moderate periodontitis exists at all thresholds. Differences between the 2
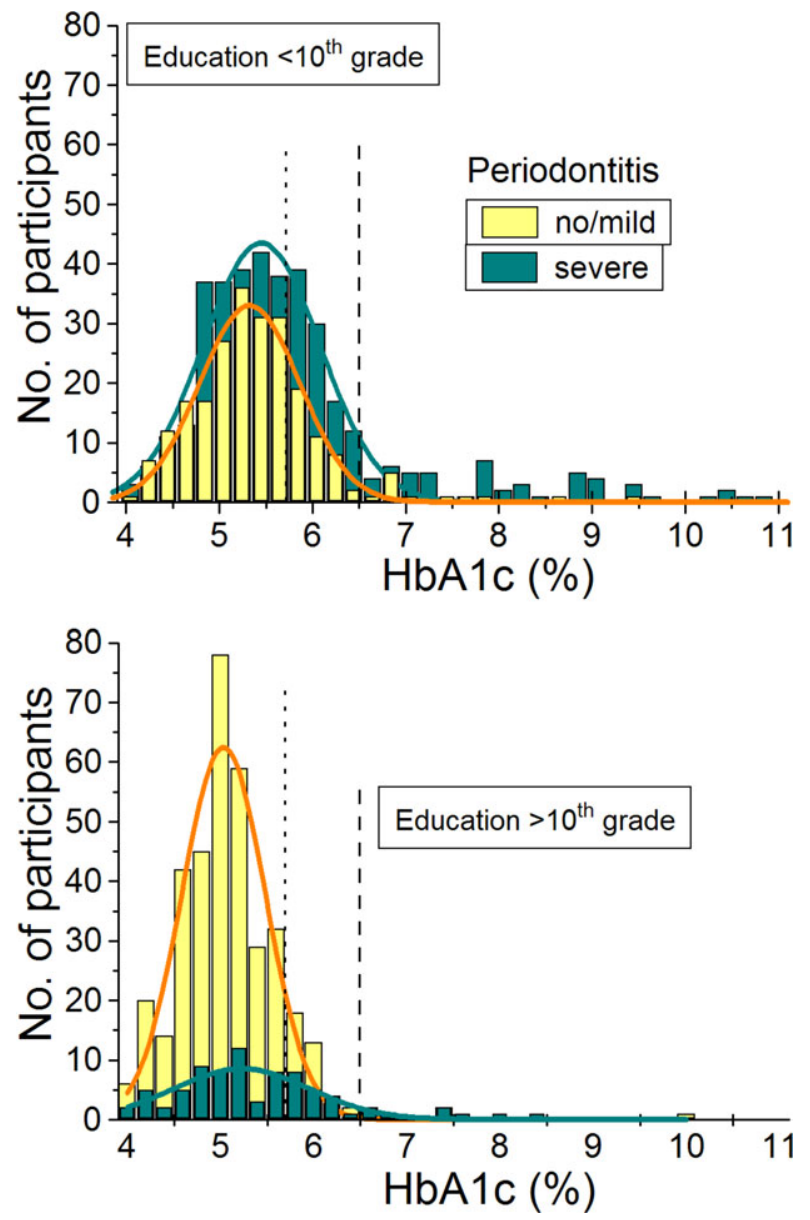

FIGURE 10 Education-stratified distribution of study participants with the periodontitis categories ${ }^{88,89}$ no/mild (orange) or severe (dark cyan), according to level of glycemic control. The dotted and dashed lines indicate glycated hemoglobin thresholds of $5.7 \%$ and $6.5 \%$, respectively. Study of Health in Pomerania-0, $n=3410$. HbA1c, glycated hemoglobin

studies, 10 years apart, are obvious. However, the proportion of participants above the glycated hemoglobin thresholds was similar despite the 10-year difference in populations. As mentioned, there were fewer participants who had glycated hemoglobin levels of $\geq 6.5 \%$, and hence there were smaller numbers of participants with periodontitis. Consequently, the confidence intervals increase, as seen in Figure 11, which ultimately diminishes the statistical power to find a significant difference.

However, such high cut-off levels remain significant even in multivariate analyses including demographic factors, as demonstrated with the 2009-2012 National Health and Nutrition Examination Survey data. ${ }^{97}$

There is a continuously increasing number of periodontitis cases at glycated hemoglobin levels at or above the cut-off, with a marked difference between the studies. However, in both studies there remain cases of severe periodontitis with glycated hemoglobin below any chosen cut-off, which are nearly independent of glycated hemoglobin, at least when this is $>6.5 \%$. 


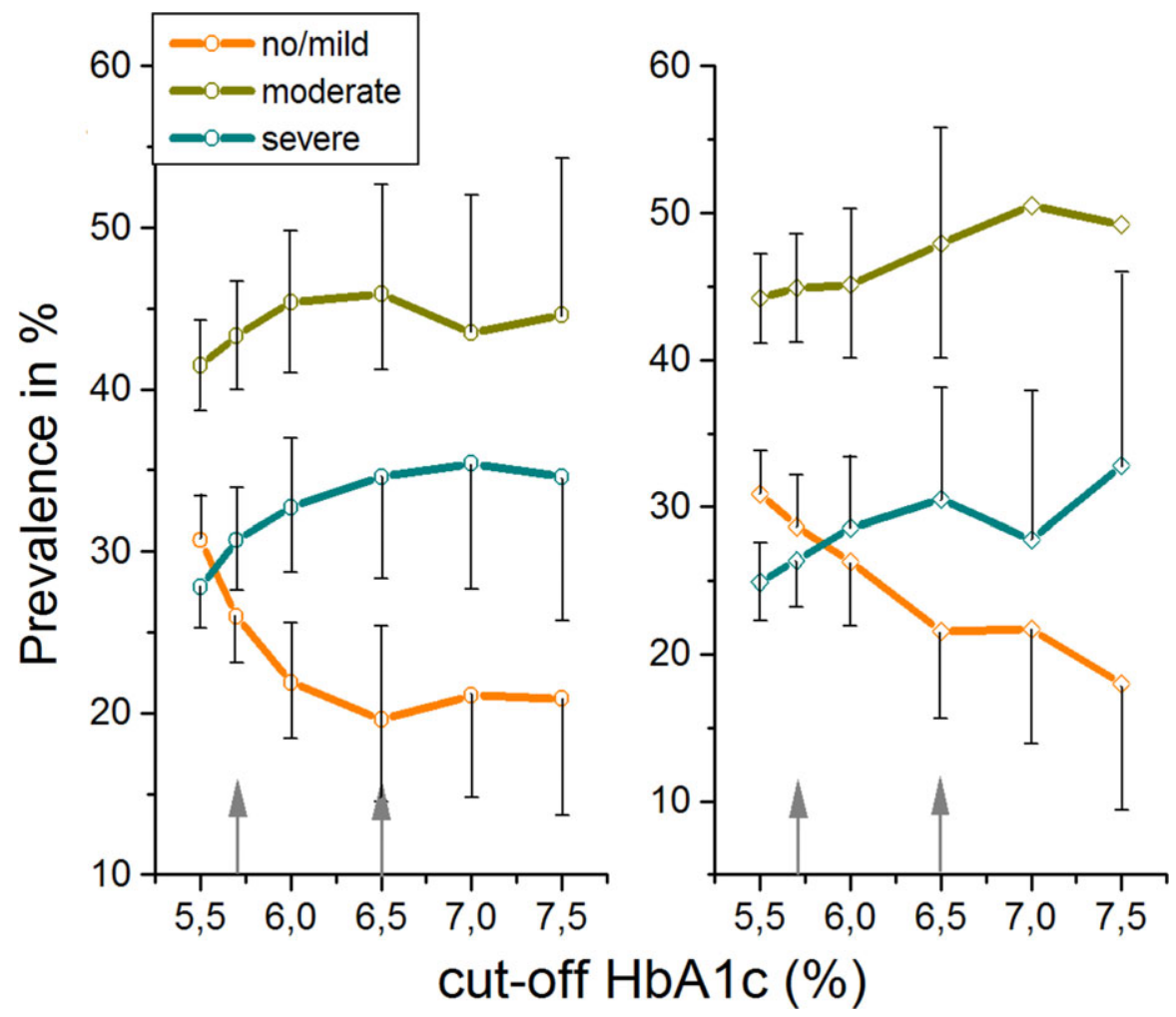

FIGURE 11 Testing consecutive glycated hemoglobin (HbA1c) values as potential cut-off points for the prevalence of no/mild (orange), moderate (olive green), and severe (dark cyan) periodontitis categories. ${ }^{88,89}$ At each $\mathrm{HbA1c}$ level tested, the proportion with the three periodontitis case categories at or greater than that HbA1c level is shown. The arrows mark the $\mathrm{HbA} 1 \mathrm{c}$ thresholds $5.7 \%$ and $6.5 \%$; the vertical bars show the $95 \%$ confidence intervals. Study of Health in Pomerania-0 (SHIP-0), n = 3410; Study of Health in Pomerania-Trend (SHIP-Trend), $\mathrm{n}=3343$
The suggested use of the established glycated hemoglobin thresholds to detect individuals at risk of periodontitis seems plausible, as higher glycated hemoglobin is associated with higher periodontal probing depth or clinical attachment level measures, necessitating further periodontal treatment. However, the continuous risk increase with glycated hemoglobin makes such an objective questionable. The population-derived frequency distribution of periodontitis grades according to the Centers for Disease Control and Prevention and the American Academy of Periodontology criteria shows widely overlapping curves (Figure 7). The differences between the periodontitis grades are most substantial within the glycated hemoglobin range defined as prediabetes (ie, between $5.7 \%$ and $6.4 \%$, or even below). If glycated hemoglobin screening is considered, identification of patients at risk for periodontitis must be expanded to prediabetes states. This would be a matter of prevention, rather than diagnosis, as manifest periodontitis occurs at all possible glycemic states.

\section{0 | TREATMENT OPTIONS BASED ON BIDIRECTIONAL PATHOLOGY}

The mutual relationship between diabetes and periodontitis spurred doctors on both sides of the scenario to seek for improvement of periodontal inflammation by adequate blood sugar control or for reduction of glycated hemoglobin by thorough dental treatment. There is low to moderate quality evidence that nonsurgical treatment of periodontitis does improve glycemic control in people with diabetes, as concluded by at least 15 systematic reviews with meta- analyses of mostly randomized controlled trials, including a 2015 review by the Cochrane Group, ${ }^{98}$ as well as 2 umbrella reviews published in 2016 of these meta-analyses. ${ }^{99,100}$ All these reviews agree that nonsurgical periodontal treatment leads to a decrease in glycated hemoglobin, 3-4 months postintervention, of between 0.24 and 1.21 percentage points (absolute decrease) glycated hemoglobin. The minimum decrease was calculated from 3 mostly randomized controlled trials ${ }^{101}$ and the maximum decrease was calculated from 10 mostly randomized controlled trials. ${ }^{102}$ However, the quality of the included studies is deemed as low or low/moderate.

The largest randomized clinical trial, the Diabetes and Periodontal Therapy Trial, was conducted in the USA, cost 18 million US dollars, and reported no reduced level of glycated hemoglobin. ${ }^{103}$ However, design, recruitment, and outcome were controversial. ${ }^{104-108}$

The potential effect in the opposite direction, namely improvement of periodontal conditions by improved glycemic control, has rarely been studied. Effective metabolic control with glycated hemoglobin decreases is achieved by taking antidiabetic drugs and lifestyle improvement. Each decrement of glycated hemoglobin is associated with a decrease in diabetes complications, including myocardial infarction and death. ${ }^{109}$ Thus, the assumption is that any reduction in glycated hemoglobin should also translate into a reduced risk of diabetes-related periodontitis.

The effect of antidiabetic drugs on periodontal conditions is still unclear. Antiglycemia intervention improved gingivitis, but not periodontitis, as measured by periodontal probing depth or marginal bone loss. ${ }^{110,111}$ It was shown that applying rosiglitazone ameliorates the tissue damage associated with periodontitis only in animal experiments. ${ }^{112,113}$ Newer antidiabetic drugs, such as exenatide and 
sitagliptin, were without effect on alveolar bone loss in periodontally affected rats. ${ }^{114}$ Intensified metabolic treatment with glycated hemoglobin reduction resulted in an improved inflammation state, characterized by decreased levels of C-reactive protein. ${ }^{115}$ Otherwise, lipidlowering agents, such as statins, exert an anti-inflammatory effect and thus may reduce gingivitis and periodontitis symptoms. ${ }^{116,117}$ In summary, all these drug effects rely on their anti-inflammatory potential rather than on reduction of glycated hemoglobin.

Lifestyle interventions, such as diet and physical activity, are beneficial in reducing the risk of progression from prediabetes to type 2 diabetes mellitus. ${ }^{118}$ The Diabetes Prevention Program Research Group has published several studies showing that type 2 diabetes may be preventable by diet and exercise. ${ }^{119,120}$ Future similar studies, following such interventions over time, could elucidate whether, in this way, also the onset or progression of periodontitis could be effectively halted because diabetes and periodontitis share common risk factors and also the measures to prevent them effectively are largely identical. ${ }^{121}$ This would encompass increasing the awareness in individuals at risk and in health professionals as well as intensive behavioral counseling to promote a healthy diet and increased physical activity. Lifestyle changes targeting both diabetes and periodontitis could interfere with the bidirectional or cyclic interdependence of both conditions. ${ }^{122-124}$

It should be kept in mind that the duration of diabetes/hyperglycemia exposure is of major influence, although the timelines of mutual disease lengths of diabetes and periodontitis are scarcely studied. In diabetes, the duration of disease and age of disease onset are important factors in determining the probability of late complications. ${ }^{125}$ Therefore, not unexpectedly, duration of diabetes is also significantly associated with periodontal health in diabetic individuals. ${ }^{126}$ Unless people with prediabetes change their lifestyle, most will develop manifest type 2 diabetes within the next years. Lifestyle interventions, such as diet and physical activity, are beneficial in reducing the risk of progression from prediabetes to type 2 diabetes mellitus. Studies following such interventions over time could also elucidate whether the progression of periodontitis could be effectively halted.

\section{1 | IMPACT OF HYPERGLYCEMIA (GLYCEMIC CONTROL) ON PERIODONTAL TREATMENT OUTCOMES}

\section{1 | Background}

Diabetes mellitus as a systemic factor affects wound healing via complex pathophysiological mechanisms. In hyperglycemic subjects, advanced glycation endproducts impede local wound healing. Moreover, impaired cell migration and cell proliferation, chronic inflammation, defective innate immunity, impaired angiogenesis, increased oxidative stress, and abnormal expression of matrix metalloproteinases also contribute to impaired local wound healing. Diabetic wounds are accompanied by hypoxia because of insufficient perfusion and angiogenesis. ${ }^{127}$ Such impairments probably also concern periodontal wound healing after scaling or flap surgery, as well the long-term stability of periodontal conditions.
As shown in the previous paragraphs of this review, the results of epidemiologic studies consistently show that patients with type 2 diabetes mellitus with uncontrolled diabetes exhibit more severe periodontitis and more tooth loss than subjects with controlled diabetes. Based on these observations, it was anticipated that periodontal wound healing would occur without problems in subjects with good metabolic control but might be impaired in subjects with uncontrolled diabetes. ${ }^{128}$

Citing 2, 20-year-old reports, Lalla \& Papapanou ${ }^{123}$ state: "With respect to non-surgical periodontal therapy, patients with adequately controlled diabetes can respond well and achieve reduced probing depth and attachment gain ${ }^{129} \ldots .$. However, in patients with poor glycemic control, long diabetes duration, and other diabetes complications, response to periodontal therapy appears to be unpredictable as tissue repair and wound healing are compromised. ${ }^{130,}$

Both groups cited considered glycated hemoglobin concentration of $\leq 8.5 \%$ as good glycemic control and glycated hemoglobin of $\geq 10 \%$ as compromised (poor) glycemic control. The notion that diabetes influences the stability of long-term periodontal results is reflected in risk-assessment tools, in which diabetes or systemic diseases are considered as predictors for periodontal progression. ${ }^{131}$ The risk of micro- and macrovascular complications in patients with type 2 diabetes is related to hyperglycemia; and a 1\% absolute increase in glycated hemoglobin was found to be associated with a $21 \%$ increase in clinical diabetes complications. ${ }^{132}$

To prevent such complications, the American Diabetes Association recommends, as a general target, attaining glycated hemoglobin of $<7 \%$. However, achievable metabolic control depends on patient attitude, risk of hypoglycemia, comorbidities, life expectancy, etc. The younger the patient, the closer they should attain the target, but some less stringent glycated hemoglobin goals $(7.5 \%-8.0 \%$ or even slightly higher) are appropriate for older patients with limited life expectancy and comorbidities. ${ }^{133}$

As there seems to be no unanimously accepted threshold regarding what constitutes uncontrolled diabetes, we used glycated hemoglobin as a continuous measure to explore whether a threshold exists beyond which periodontal healing is impaired. The periodontal community has only limited data illuminating to what extent metabolic control impacts periodontal healing.

Thus, our first objective was to perform a literature review to evaluate the effects of metabolic control on the reduction of periodontal probing depth and gain in clinical attachment in people with type 2 diabetes and chronic periodontitis after nonsurgical scaling and root planing.

It is important for the dentist to know whether they need to be more cautious in performing periodontal procedures in patients with poorly controlled diabetes and whether scaling leads to compromised results, with more residual pockets of $\geq 4 \mathrm{~mm}$, which in turn has to be considered as risk in treatment planning and which may impact long-term periodontal stability. This point was spurred by discussion in the Diabetes and Periodontal Therapy Trial, in which, as mentioned earlier, no change was reported in glycated hemoglobin following scaling and root planing. ${ }^{103}$ The critique concerned mainly 
that because the participants at the end of the study, at the 6 months post-intervention visit, had plaque and periodontal pockets sufficient for them to be eligible for inclusion in the trial from the beginning, the researchers should honestly have concluded that because of the continued plaque accumulation and subsequent inflammation, no conclusion could be made regarding whether successful periodontal treatment would have led to an improvement in glycemic control. Hence, commentaries to this trial asserted that the periodontal treatment results reported were inferior to the standard scaling and root planing results, referring to previous treatment results in patients with unknown diabetes status. So, the arguments went back and forth because it is unknown which results should be expected and which results are lower than expected after standard scaling and root planing.

Unfortunately, there are very few comparable studies among subjects with diabetes in which different levels of metabolic control are compared. Thus, we decided to search for studies that reported baseline values of glycated hemoglobin, as well as changes in mean periodontal probing depth and clinical attachment level after nonsurgical periodontal treatment with an observation period of at least 3 months. Our first hypothesis was, in brief: the worse the glycemic control, the less periodontal probing depth reduction or attachment gain that would occur after scaling and root planing in people with type 2 diabetes, possibly even in a dose-response manner.

A second objective was to compare the scaling and root planing results in people with diabetes with those in systemically healthy patients. Our hypothesis was that scaling and root planing leads to less periodontal probing depth reduction and attachment gain in people with diabetes compared with systemically healthy patients. As we could not find a convincing conclusion regarding what may constitute a "good" or "acceptable" result after scaling and root planing, we included studies reporting scaling and root planing results in systemically healthy subjects. Comparison of the studies identified by these 2 search strategies allowed us to evaluate the impact of glycemic control on periodontal healing after scaling and root planing. As full-mouth scaling versus quadrant-wise scaling does not render different clinical results according to a 2015 Cochrane review, we included both treatment modalities. ${ }^{134}$

We considered studies eligible for inclusion if they were conducted among participants $\geq 35$ years of age with chronic periodontitis (as defined by the authors) and with type 2 diabetes (objectives 1 and 2) or without diabetes (objective 2 only), respectively, who received scaling and root planing without use of adjunctive systemic antibiotics or subantimicrobial doxycycline and had no recent history of antibiotic treatment, and that reported periodontal probing depth (and eventually clinical attachment level) as patient means.

\section{2 | Results}

Question 1: Does short-term periodontal probing depth reduction and clinical attachment level gain after scaling and root planing depend on glycemic control in type 2 diabetes?
We included 29 randomized clinical trials with 3 months of follow-up that reported results from 37 test arm groups comprising 1089 subjects with type 2 diabetes and periodontal measurements (Table 6). Several studies reported periodontal findings from 2 or more groups stratified according to their baseline glycated hemoglobin values and therefore the number of study groups is larger than the number of studies included. Nine study groups originated in Latin America, 6 in Turkey/Iran, 6 in China/Taiwan, 4 in India, and the rest in Europe, the USA, Arab countries, and Japan. Overall, $52.8 \%$ of subjects were male and the mean age was 55.0 years. Most cohorts included only nonsmokers. The mean glycated hemoglobin was $7.95 \%$ (range: $6.0 \%-10.7 \%$ ), and around $70 \%$ of the cohorts reported a diabetes duration of mean 9.2 (range: 4.0-17.0) years. The baseline mean periodontal probing depth was $3.2 \mathrm{~mm}$ (Tables 5) and 6 exhibits the values for each of the 37 study groups.

The mean periodontal probing depth reduction after 3 months was 0.58 (95\% confidence interval: $0.56-0.60) \mathrm{mm}$, with range 0 $1.5 \mathrm{~mm}$ (Figure 12). The mean clinical attachment level gain in 33 study groups was 0.55 (95\% confidence interval: 0.52-0.58) mm, with range $-0.08 \mathrm{~mm}$ to $1.4 \mathrm{~mm}$ (Figure 13). Changes in both mean periodontal probing depth and mean clinical attachment level varied widely across the cohorts, as visualized in Figures 12 and 13.

Question 2: Are short-term scaling and root planing outcomes in people with hyperglycemia/diabetes inferior to those in people without diabetes?

For the second question, we included 53 reports including 66 study groups and a total of 1474 healthy (normoglycemic) subjects in which scaling and root planing outcomes were reported (Table 7). The majority of the groups, namely 26, were recruited in Europe, 10 in Latin America, 10 in Turkey/Iran, 7 in India/Pakistan, and 5 in the USA. Overall, $49.1 \%$ of the subjects were male, and the mean age was 46.5 years.

TABLE 5 Characteristics of study groups according to diabetes status and periodontal health measures

\begin{tabular}{|lll|}
\hline Periodontal health measure & $\begin{array}{l}\text { Diabetes } \\
\text { mellitus }\end{array}$ & No diabetes mellitus \\
\hline Groups with periodontal probing & depth measurements \\
\hline Number of study groups & 37 & 66 \\
\hline Number of participants & 1089 & 1474 \\
\hline Males (\%) & 52.8 & 49.1 \\
\hline Mean age (years) & 55.0 & 46.5 \\
\hline Mean periodontal probing & 3.2 & 3.9 \\
\hline depth before therapy (mm) & & \\
\hline Groups with clinical attachment loss measurements \\
\hline Number of study groups & 33 & 54 \\
\hline Number of participants & 1009 & 1220 \\
\hline Males (\%) & 52.6 & 47.5 \\
\hline Mean age (years) & 55.2 & 46.6 \\
\hline $\begin{array}{l}\text { Mean clinical attachment } \\
\text { loss before therapy (mm) }\end{array}$ & 3.2 & 3.8 \\
\hline
\end{tabular}

Values represent weighted means using the sample size of each group. 
TABLE 6 Studies evaluating the effect of scaling and root planing on periodontal probing depth and clinical attachment level/loss in subjects with type 2 diabetes mellitus: pretreatment characteristics

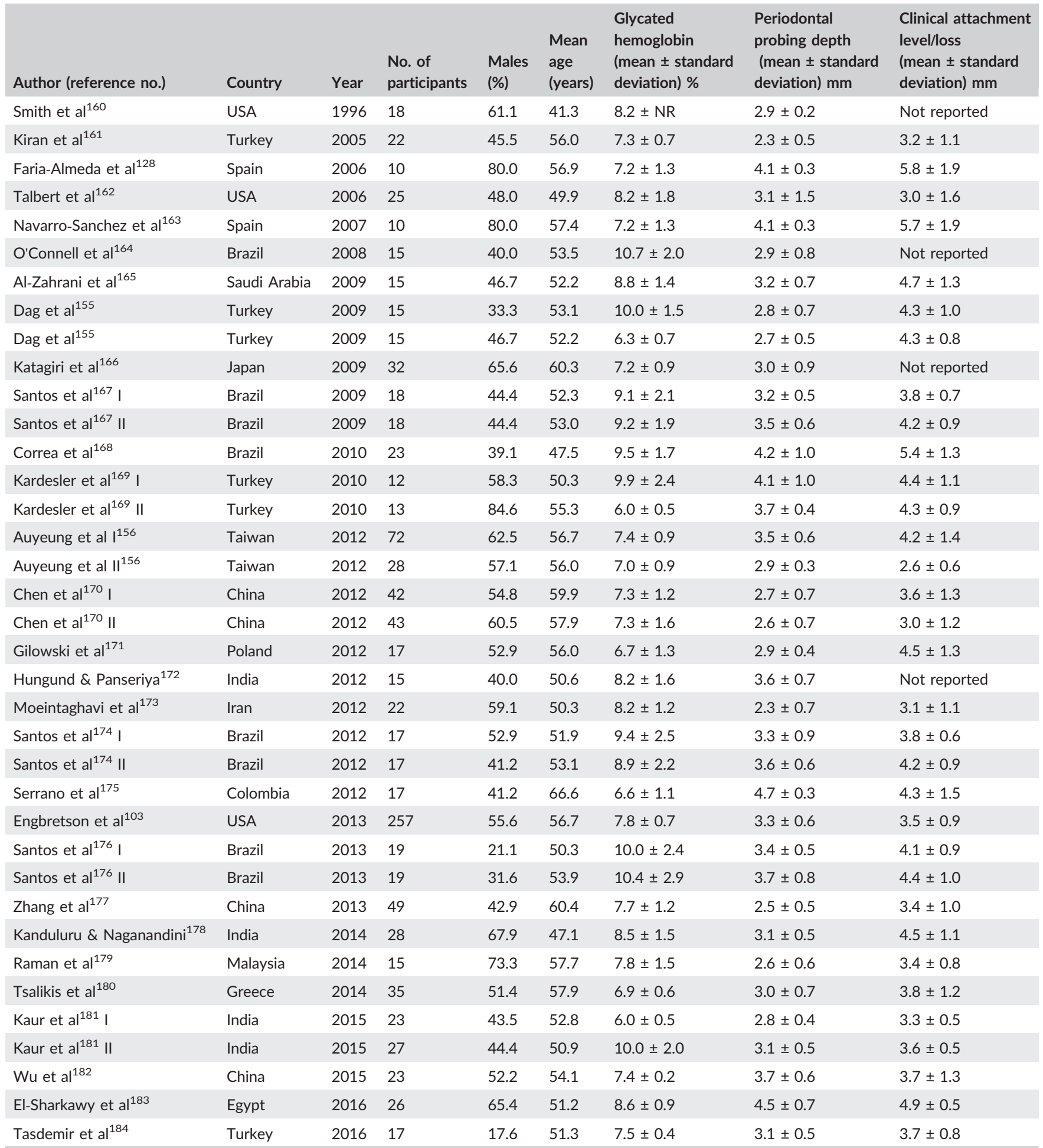

I/II: groups within the same study.

In these study groups without diabetes, the mean baseline periodontal probing depth was $3.9 \mathrm{~mm}$ (Table 5), and the mean periodontal probing depth reduction was 0.78 (95\% confidence interval: 0.76 $0.79) \mathrm{mm}$, with range $0.08-1.98 \mathrm{~mm}$ (Figure 14). The mean clinical attachment level gain was 0.65 (95\% confidence interval: $0.63-0.67)$ $\mathrm{mm}$, with range $-0.04 \mathrm{~mm}$ to $1.86 \mathrm{~mm}$ (Figure 15). The changes in the means of both periodontal probing depth and clinical attachment level varied widely across the cohorts, as seen in Figures 14 and 15.

Although the systemically healthy subjects were, on average, nearly 10 years younger than the participants with diabetes, they 
had more severe periodontitis, as reflected in greater baseline means of periodontal probing depth $(3.9 \mathrm{~mm}$ versus $3.2 \mathrm{~mm}$ ) and clinical attachment level ( $3.8 \mathrm{~mm}$ versus $3.2 \mathrm{~mm}$ ) (Table 5). Before adjustment for covariates, there was a positive association between greater baseline glycated hemoglobin levels and mean periodontal probing depth, both at baseline and after therapy (Figure 16).

Even though the mean reduction in both periodontal probing depth and clinical attachment level gain predicted from adjusted meta-regression analyses seemed more pronounced in subjects without diabetes than in subjects with diabetes, this difference did not reach statistical significance. After adjustment for age and sex, no significant associations between baseline glycated hemoglobin and mean periodontal probing depth or its change persisted (Table 8 , Model 1).

On the contrary, each additional $\mathrm{mm}$ in mean periodontal probing depth at baseline was associated with a reduction of $0.34 \mathrm{~mm}$ in mean periodontal probing depth following scaling and root planing $(P<.001$; Table 8, Model 2). Regarding clinical attachment level, unadjusted meta-regression analyses demonstrated seemingly higher values of mean clinical attachment level at baseline and after therapy in relation to higher glycated hemoglobin levels. But, similarly to the situation with periodontal probing depth, no significant associations between glycated hemoglobin and mean clinical attachment level or its post-treatment change persisted after adjustment for age and sex (Table 9, Model 1), whereas each additional $\mathrm{mm}$ in mean clinical attachment level at baseline was associated with $0.16 \mathrm{~mm}$ gain in clinical attachment level following periodontal therapy $(P=.05$; Table 9, Model 2).

The presented analyses were performed using meta-regression tools. It was not possible to adjust the analyses for covariates such as education, smoking, body mass index, etc., because these variables were not available across the studies included.

Comparison of participants with diabetes with healthy subjects found strong correlation between baseline values of mean periodontal probing depth and clinical attachment level and the corresponding measures 3 months after scaling and root planing, irrespective of whether the participants have diabetes. Concomitantly, higher values of mean periodontal probing depth at baseline were associated with greater reductions in mean periodontal probing depth after 3 months (healthy: $P<.001$, diabetes: $P=.01$ ) (Figure 17). Regarding the shape of the association, no significant differences between systemically healthy and diabetes groups were detected. In similar analyses of mean clinical attachment level, analogous results were obtained (data not shown).

Our first hypothesis, that type 2 diabetes with poor glycemic control affects short-term results after scaling and root planing, is not supported. At first glance, metabolic control in diabetes patients seemed to impact periodontal probing depth reduction and attachment gain, but this spurious association disappeared for both periodontal measures when baseline values of the respective measure (periodontal probing depth/clinical attachment level) were taken into account. This is confirmed by the comparison of periodontal probing depth reduction and attachment gain between subjects with and without diabetes: there was no significant difference between the 2 groups. Hence, our second hypothesis, that periodontal patients with diabetes would attain less periodontal probing depth reduction and less clinical attachment gain, was also not supported by the evidence. On the contrary, the evidence demonstrated that the main predictor for mean periodontal probing depth reduction or attachment gain is the baseline periodontal status, irrespective of glycemic control. This observation is in line with a meta-analysis comparing scaling and root planing with no treatment that did not mention diabetes. $^{135}$ Wennström \& Tomasi ${ }^{136}$ reported a mean reduction of periodontal probing depth of 1-2 $\mathrm{mm}$ and an attachment gain of 0 $1 \mathrm{~mm}$ in sites initially 4-6 mm deep. Similar conclusions were presented by Lindhe et $a^{137} 35$ years ago from a single study. The researchers described the initial periodontal probing depth versus change of attachment with $0.2 \pm 0.04 \mathrm{~mm}$ attachment gain versus $1 \mathrm{~mm}$ increase of initial periodontal probing depth. Their data corroborate quite well with our crude regression slope of $0.16 \mathrm{~mm}$ attachment gain with each additional millimeter of initial periodontal probing depth (shown in Table 9).

Our meta-regression results are in agreement with previous case series reported by Christgau et al $^{129}$ ( $n=3$ with baseline glycated hemoglobin $>8 \%$ ) as well as by Westfelt et $\mathrm{al}^{138}$ who also did not find a correlation between glycated hemoglobin and change of periodontal probing depth during a 5 -year observation period in 20 subjects with type 1 or type 2 diabetes.

As an aside and for the sake of completion, Tervonen \& Karjalainen ${ }^{130}$ observed impaired short-term healing in 8 patients with type 1 diabetes with glycated hemoglobin $\geq 10 \%$ and multiple comorbidities. It is important to assess to what extent basic demographic information, such as medical information about drug intake, comorbidities, or duration of diabetes, may influence periodontal therapy outcomes for the individual patient. Representative for many authors who did not find any impact of scaling and root planing on glycated hemoglobin, Gay et al ${ }^{139}$ wrote "Non-surgical periodontal therapy... should be considered as a component in the routine medical care of individuals with type 2 diabetes mellitus and periodontitis", based on a study with a mean glycated hemoglobin level of $9.0 \%$.

Dentists should not delay nonsurgical periodontal therapy in patients with diabetes until good metabolic control is achieved; this should be performed as indicated in patients without diabetes.

Averaging whole-mouth periodontal probing depth and clinical attachment level underestimates the benefits of scaling and root planing; positive results are more pronounced when analyzing deep pockets. Mean values cannot be translated easily into clinically meaningful data. As most sites in a patient are shallow or moderately deep, nothing can be said about the clinical significance of these results. There is a wide variation in reduction of mean periodontal probing depth or mean clinical attachment level. The severity of baseline periodontitis varied greatly across the included studies (Figures 12-15). The more severe the periodontal destruction, the greater the periodontal probing depth reduction or attachment gain that can be expected. ${ }^{135}$ 


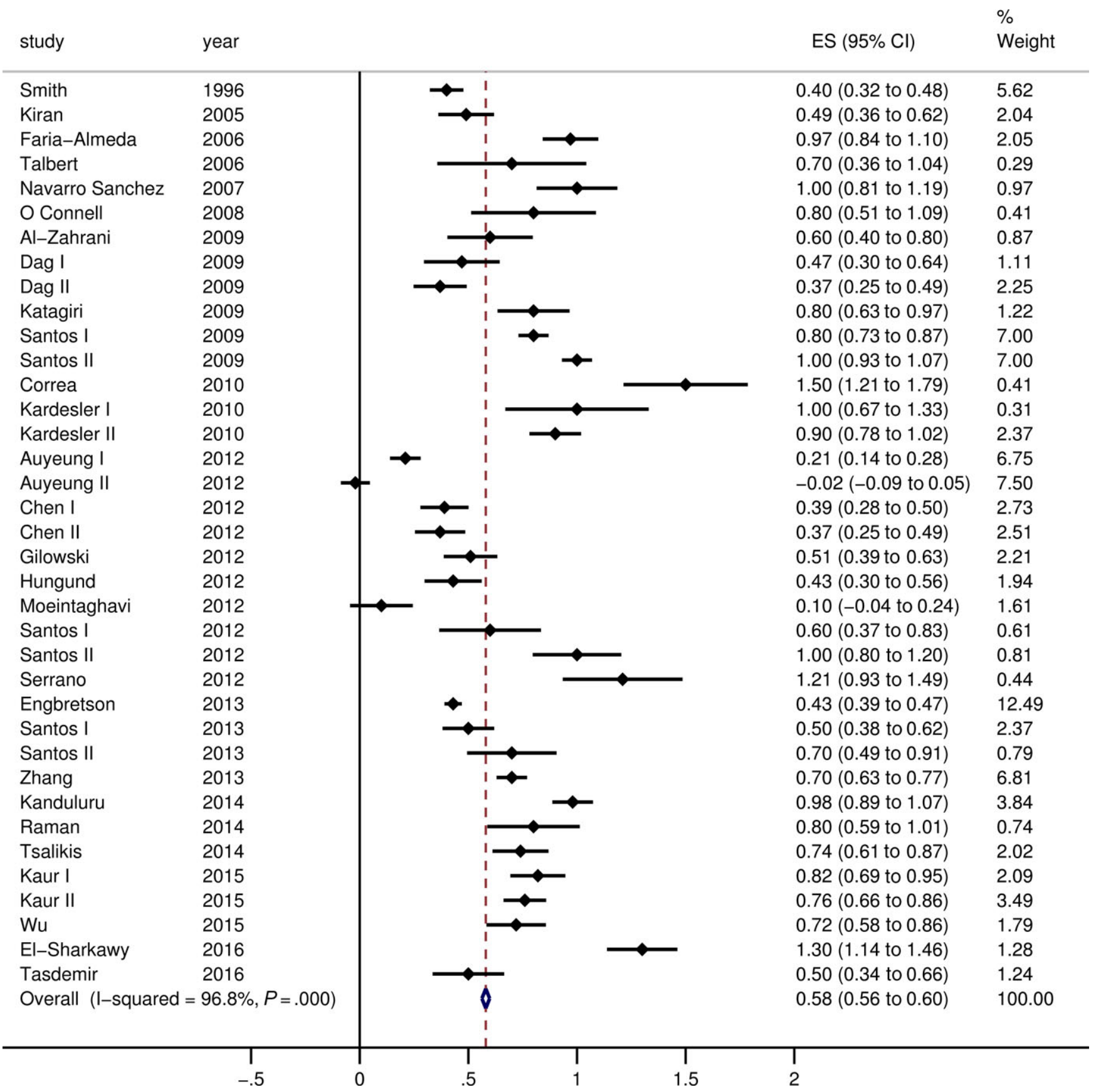

FIGURE 12 Reduction of mean periodontal probing depth at 3 mo after scaling and root planing in patients with diabetes mellitus based on 37 groups comprising a total of 1089 subjects. The study weights are proportional to the precision of each group estimate (calculated as the inverse of its squared within-study standard error). Please see Table 6 for sources. $95 \% \mathrm{Cl}, 95 \%$ confidence interval; ES, estimate in millimeters; year, year of publication

Short-term periodontal wound healing in people with diabetes seems to be comparable with wound healing in systemically healthy subjects. Local mechanical debridement and improved oral hygiene have more impact on periodontal healing compared with blood sugar control in a short-term perspective. Through scaling, the biofilm is removed, an active wound is created, and the local mechanism of staged wound healing follows its normal process of hemostasis, inflammation, proliferation, and remodeling. ${ }^{127}$
Studies reporting mean clinical attachment level gains or periodontal probing depth reduction below the $95 \%$ confidence band as, for example in Figure 17, fail to attain average expected results. This may be a result of patient selection, patient handling, thoroughness of scaling, carefulness of the operator, etc. Coming back to the discussion with respect to the results of the Diabetes and Periodontal Therapy Trial, ${ }^{103}$ it can be concluded that the reported periodontal probing depth reduction is at the lower end of what represents standard care. ${ }^{98}$ 


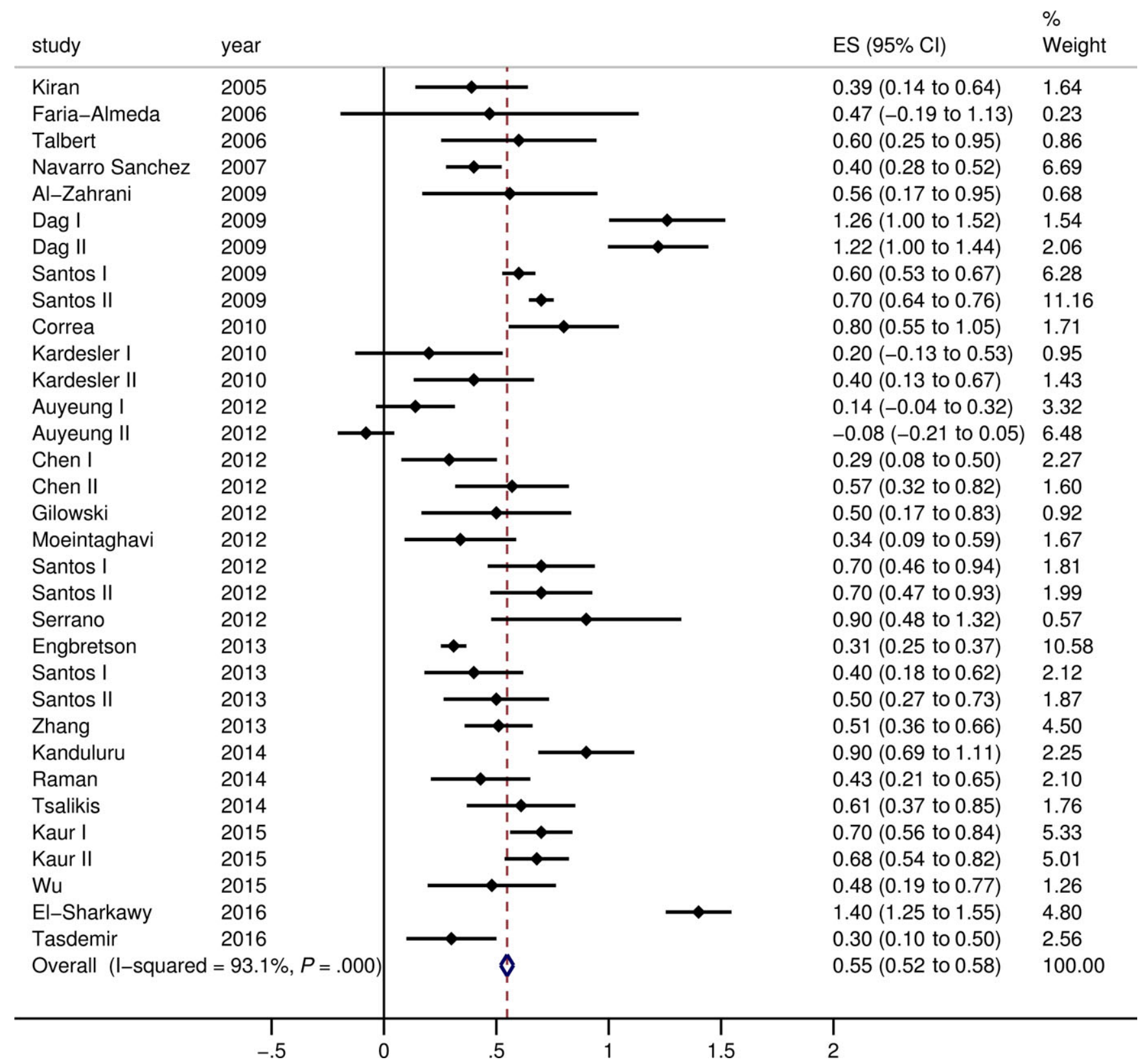

FIGURE 13 Reduction of mean clinical attachment level at 3 mo after scaling and root planing in patients with diabetes mellitus based on 33 groups comprising a total of 1009 subjects. The study weights are proportional to the precision of each group estimate (calculated as the inverse of its squared within-study standard error). Please see Table 6 for sources. $95 \% \mathrm{Cl}, 95 \%$ confidence interval; ES, estimate in millimeters; year, year of publication

\section{PERIODONTAL TREATMENT WITH ADJUNCTIVE SYSTEMIC ANTIBIOTICS OF PEOPLE WITH DIABETES}

Any successful periodontal therapy aims at a gain in clinical attachment level and a reduction in periodontal probing depth. Resolution of periodontal pockets to a state of healthy sulci is regarded as the ultimate goal in periodontal treatment. Especially in patients with diabetes and periodontitis, the oral infection may add to dysregulated glycemic control and residual pockets may increase the risk of further attachment loss and eventually to tooth loss. ${ }^{29,57}$ A 2015 meta-analysis exploring the effect of adjunctive antibiotics in the treatment of chronic periodontitis showed that systemic antibiotic intake combined with scaling offered some additional clinical improvement of periodontal probing depth reduction compared with scaling and root planing alone, but there was no benefit in attachment gain. ${ }^{140}$ Thus the question arose regarding whether a patient with diabetes benefits more from systemic antibiotics than a systemically healthy patient, because scaling alone may be insufficient to achieve a microbial profile compatible with periodontal health in subjects with diabetes. ${ }^{141}$ Recently, 2 meta-analyses addressed this question: one was based on 13 studies $^{142}$ and the other on 5 
TABLE 7 Studies evaluating the effect of scaling and root planing on periodontal probing depth and clinical attachment level/loss in subjects without diabetes: pretreatment characteristics

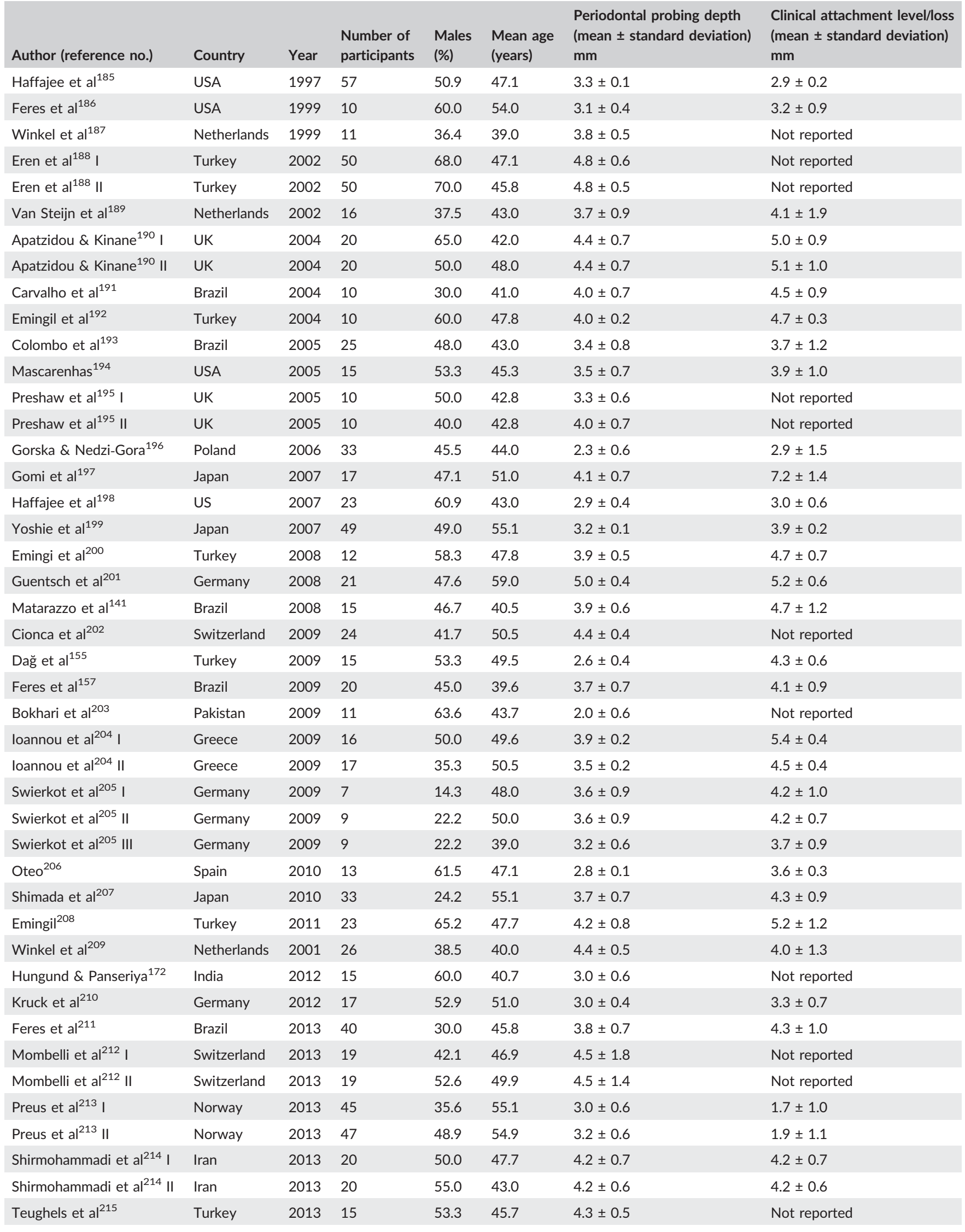


TABLE 7 (Continued)

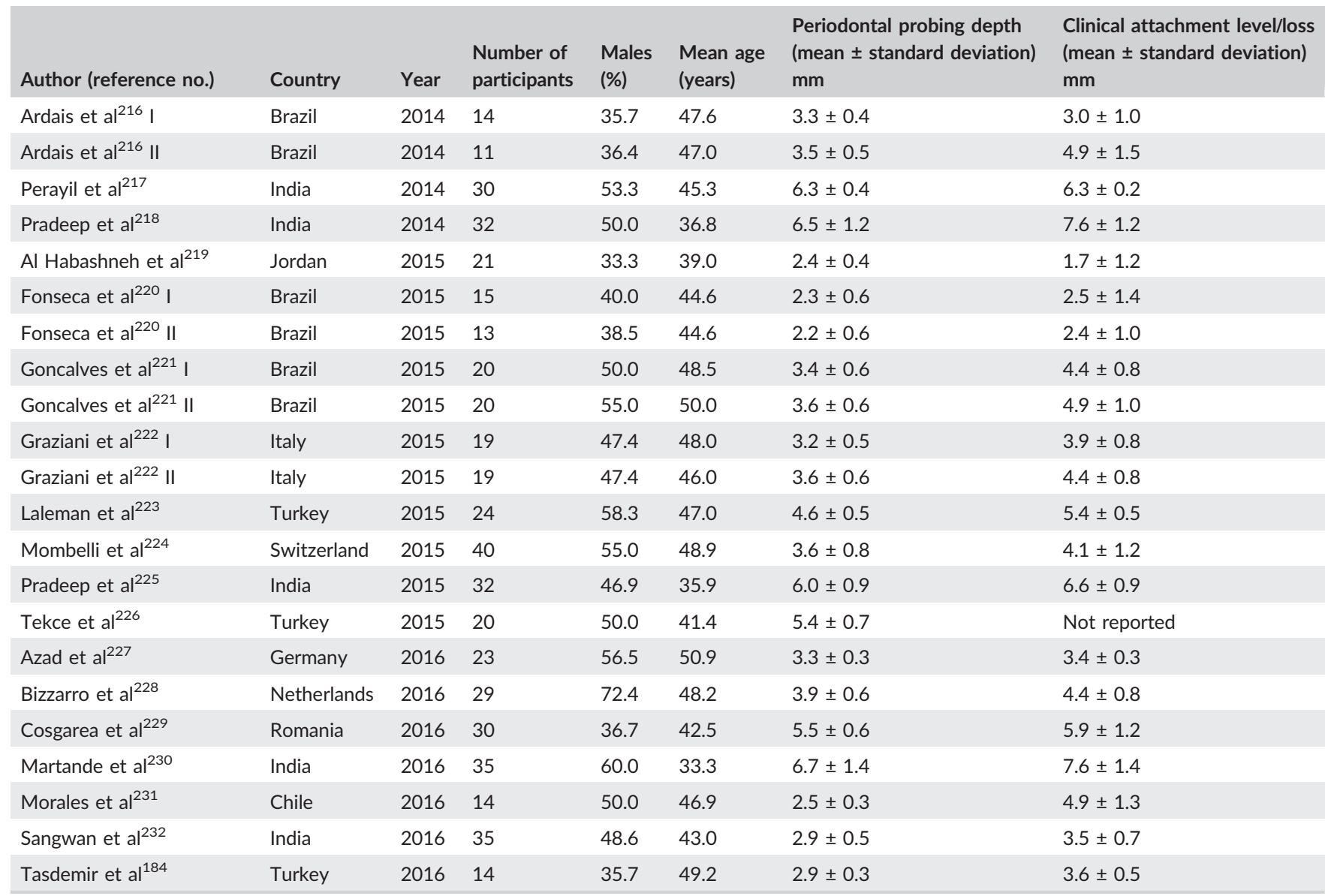

I/II/III: groups within the same study.

studies. ${ }^{143}$ Both meta-analyses reported that scaling and root planing with adjunctive antibiotic therapy attained more periodontal probing depth reduction, but not attachment gain, than scaling and root planing alone. The mean difference in periodontal probing depth reduction between test and control groups was 0.15 (95\% confidence interval: $0.24-0.06) \mathrm{mm}^{142}$ or 0.22 (95\% confidence interval: 0.34 $0.11) \mathrm{mm},{ }^{143}$ respectively. In a subanalysis based on 3 publications specifically reporting results from patients with uncontrolled diabetes (glycated hemoglobin range: $8.3 \%-10.6 \%$ ), the periodontal probing depth reduction was 0.26 (95\% confidence interval: $0.39-0.13) \mathrm{mm}$ greater, and the clinical attachment gain was 0.26 (95\% confidence interval: 0.46-0.05) $\mathrm{mm}$ higher, in those taking systemic antibiotics compared with controls. ${ }^{143}$

A meta-analysis published in 2016 compared the effect of scaling and root planing only with scaling and root planing with local antimicrobial treatment in patients with chronic periodontitis and diabetes. ${ }^{144}$ Only in patients with well-controlled, but not in those with uncontrolled diabetes, greater periodontal probing depth reduction and attachment gain were achieved, especially in deep pockets, in the scaling and root planing group with adjuvant locally delivered antimicrobials as compared to scaling and root planing alone.

The prescription of adjunctive systemic antibiotics must take into consideration whether the clinical benefit of marginally more periodontal probing depth reduction outweighs the potential side effects. The decision should be based on individual periodontal destruction severity and be restricted to the most severe cases. This is in line with current recommendations for treatment of patients with chronic periodontitis. ${ }^{140,145,146}$

\section{3 | LONG-TERM PERIODONTAL MAINTENANCE OF PATIENTS WITH TYPE 2 DIABETES}

As shown in the foregoing, short-term scaling results do not seem to be influenced by the degree of metabolic control. However, these studies only lasted for 3 months. Periodontal long-term results of $\geq 5$ years showed a tendency for the attained periodontal probing depth reduction and attachment gain to relapse with time. ${ }^{147,148}$ Unanimously, cohort studies report male sex, socioeconomic status, smoking, and diabetes mellitus as predictors for periodontitis progression and tooth loss. ${ }^{123}$ Unfortunately, only one long-term study is available that reports the influence of glycemic control on treated periodontal patients. In a prospective clinical cohort periodontal results were assessed during a 5-year follow up of 238 participants. ${ }^{149}$ From this pool, 23 patients with poorly controlled diabetes 


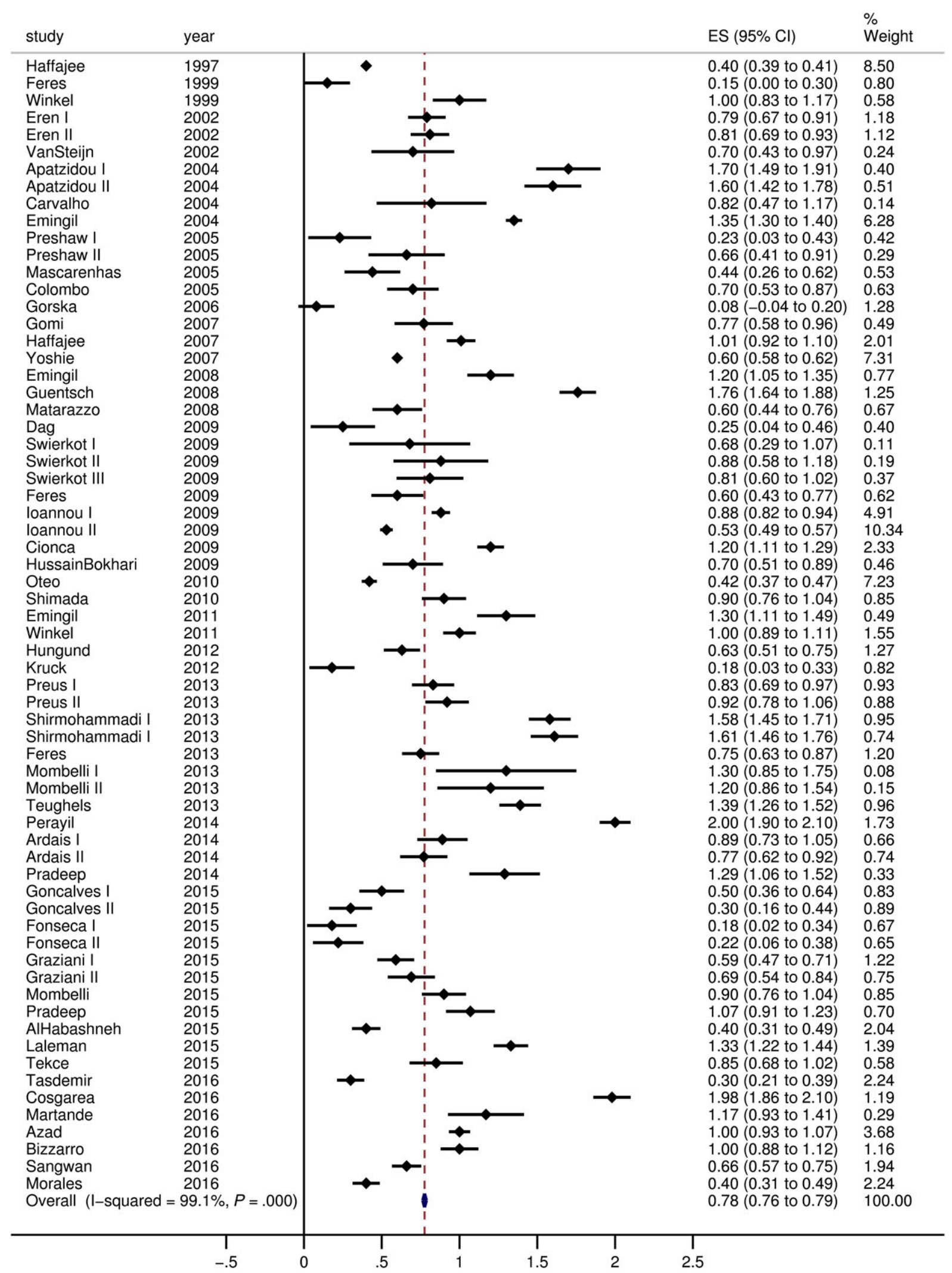

FIGURE 14 Reduction of mean periodontal probing depth at 3 mo after scaling and root planing in systemically healthy patients based on 66 groups comprising a total number of 1474 subjects. The study weights are proportional to the precision of each group estimate (calculated as the inverse of its squared within-study standard error). Please see Table 7 for sources. $95 \% \mathrm{Cl}, 95 \%$ confidence interval; ES, estimate in millimeters; year, year of publication 


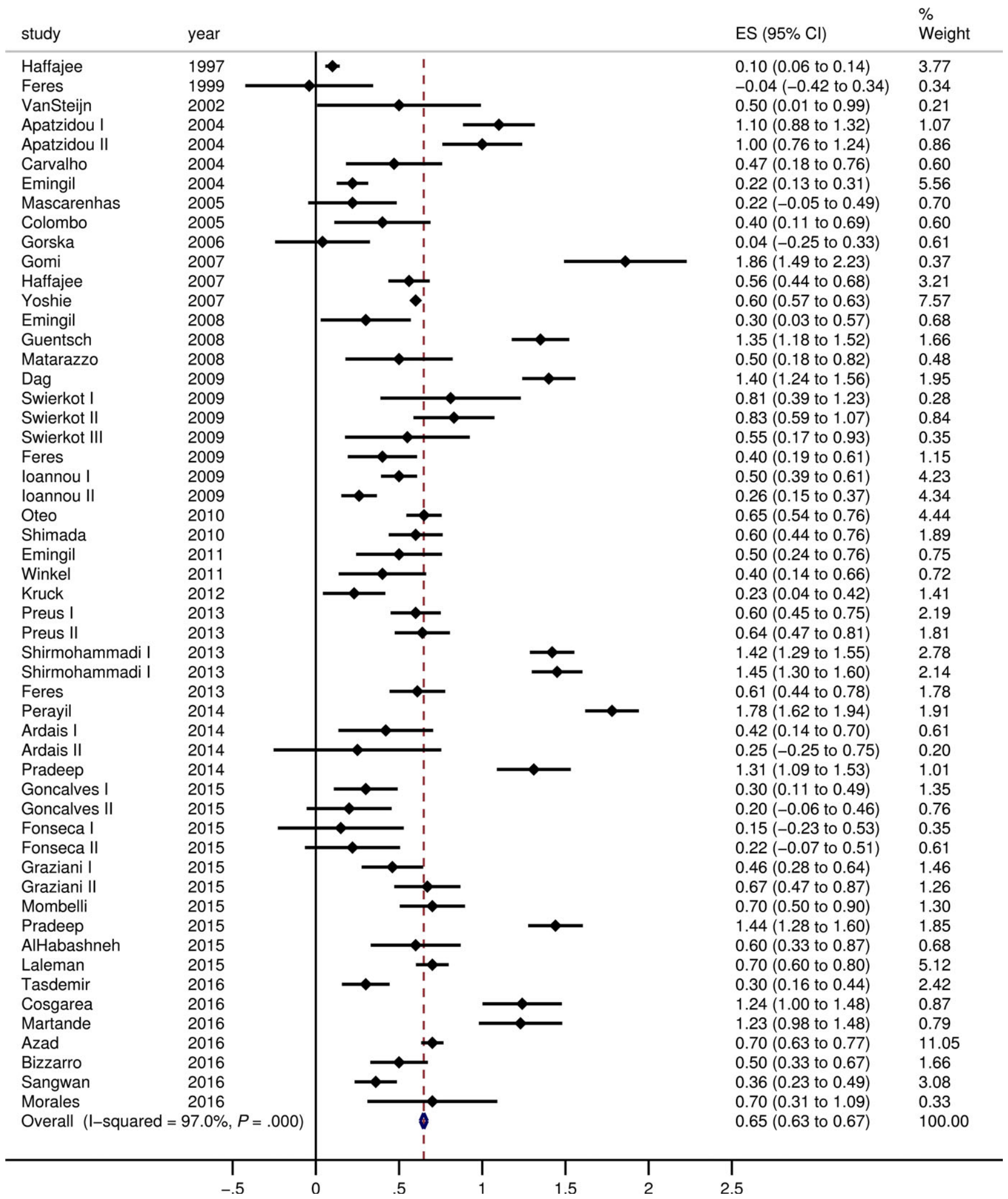

FIGURE 15 Reduction of mean clinical attachment level at 3 mo after scaling and root planing in systemically healthy patients based on 54 groups comprising a total of 1220 subjects. The study weights are proportional to the precision of each group estimate (calculated as the inverse of its squared within-study standard error). Please see Table 7 for sources. $95 \% \mathrm{Cl}$, $95 \%$ confidence interval; ES, estimate in millimeters; year, year of publication 


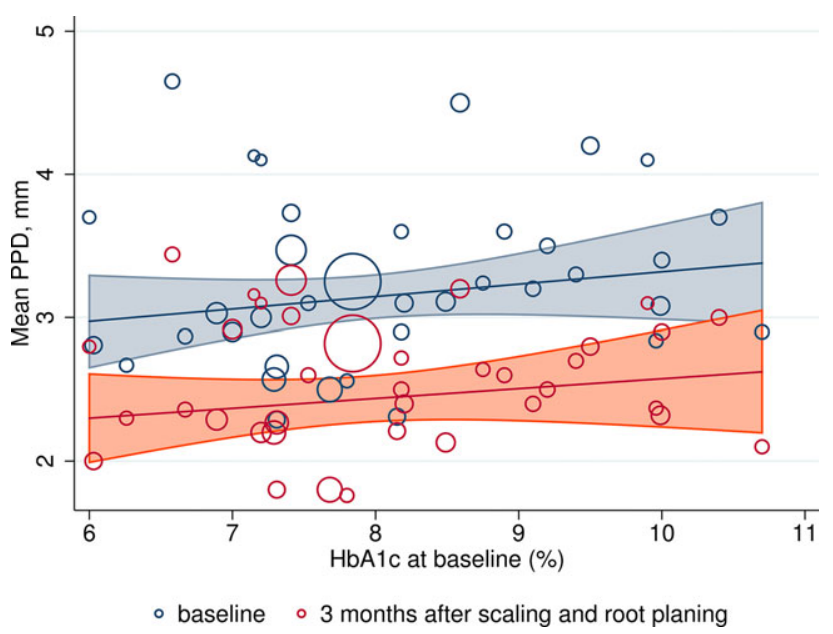

FIGURE 16 Mean periodontal probing depth (PPD), before (blue) and after (red) scaling and root planing, according to baseline glycated hemoglobin ( $\mathrm{HbA1c}$ ) concentration in study groups with diabetes based on 29 reports comprising 37 study groups (as listed in Table 6) involving 1089 subjects. The circle sizes represent the respective study sizes. The study weights for regression are proportional to the precision of each group estimate.

(glycated hemoglobin $=9.1 \pm 1.4 \%$ ), 23 with well-controlled diabetes (glycated hemoglobin $=6.1 \pm 0.4 \%$ ), and 46 without diabetes (fasting plasma glucose $<126 \mathrm{mg} / \mathrm{dL}$, annually) were selected while matching for age and sex. ${ }^{150}$ Educational background, smoking, diabetes duration, supragingival plaque control, and frequency of maintenance visits were comparable among the 3 groups. Patients with poorly controlled diabetes had statistically more pockets of $\geq 5 \mathrm{~mm}$ and clinical attachment loss of $\geq 5 \mathrm{~mm}$ and had also lost more teeth than patients with well-controlled diabetes or metabolically healthy patients (Figure 18).
In analyses adjusted for 10 potential confounders, patients with poorly controlled diabetes were found to have 3-fold higher risk for further periodontal breakdown (odds ratio $=2.9,95 \%$ confidence interval: $1.43-9.81$ ) as well as for losing teeth (odds ratio $=3.1 ; 95 \%$ confidence interval: 1.03-10.89), whereas those with glycated hemoglobin $<6.5 \%$ experienced no higher risk than the normoglycemic.

Primarily based on epidemiologic data, diabetes, especially poorly controlled or uncontrolled diabetes, has been regarded as risk factor for periodontitis and tooth loss for decades by the periodontal community, but there is a dearth of data to illuminate whether this holds true also for intervention studies. A total of 17 retrospective studies published since 1996 have evaluated predictors for tooth loss as an outcome in multivariate analyses in patients during periodontal maintenance (Table 10).

All but one study included information on smoking, whereas 8 of 17 studies did not report diabetes as a predictor. In contrast to smoking, diabetes was a significant predictor for tooth loss in only 2 out of 6 studies conducting multivariate analyses. It seems that in many routinely used medical history recordings on which retrospective studies rely, diabetes was not included, possibly because the dentist omitted to ask or to record this health issue as diabetes did not seem to impose any therapeutic long-term problem. Explanations for this unexpected finding may be that the studies were underpowered to detect small effects of diabetes or that a diagnosis of diabetes did not impose any problem in periodontal maintenance (see paragraph above). Some studies may have included only participants with controlled diabetes because people with uncontrolled diabetes might seek dental care too rarely. ${ }^{151}$ In addition, diabetes mellitus was a rather rare disease until a few decades ago, and still is in some developed countries, such as in Scandinavia. For instance, the prevalence of diabetes in Denmark was only about 3\% in 2000, but increased to $5 \%$ in 2011, mostly because of the influx of

TAB LE 8 Coefficients from meta-regression analyses ${ }^{a}$ of the associations between baseline glycemic control and periodontal probing depth before and 3 mo after scaling and root planing

\begin{tabular}{|c|c|c|c|c|c|c|}
\hline Model & \multicolumn{2}{|c|}{$\begin{array}{l}\text { Mean periodontal probing depth } \\
\text { at baseline }(\mathrm{mm})\end{array}$} & \multicolumn{2}{|c|}{$\begin{array}{l}\text { Mean periodontal probing depth at } \\
3 \text { mo after scaling and root planing } \\
(\mathrm{mm})\end{array}$} & \multicolumn{2}{|c|}{$\begin{array}{l}\text { Reduction of mean periodontal } \\
\text { probing depth } 3 \mathrm{mo} \text { after scaling } \\
\text { and root planing }(\mathrm{mm})\end{array}$} \\
\hline \multicolumn{7}{|c|}{ Model 1: Adjusted for mean age and proportion of male subjects } \\
\hline Baseline glycated hemoglobin (\%) & $0.14(-0.06$ to 0.34$)$ & .16 & $0.06(-0.09$ to 0.21$)$ & .43 & $0.09(-0.02$ to 0.20$)$ & .09 \\
\hline \multicolumn{7}{|c|}{ Model 2: Model 1 with additional adjustment for mean periodontal probing depth at baseline } \\
\hline Baseline glycated hemoglobin (\%) & & & $-0.03(-0.12$ to 0.05$)$ & .45 & $0.04(-0.05$ to 0.13$)$ & .34 \\
\hline $\begin{array}{l}\text { Mean periodontal probing depth } \\
\text { at baseline }(\mathrm{mm})\end{array}$ & & & $0.64(0.49$ to 0.79$)$ & $<.001$ & $0.34(0.19$ to 0.50$)$ & $<.001$ \\
\hline
\end{tabular}

Bold font indicates statistical significance at $P<.05$.

aUsing aggregate-level data based on 37 groups with 1089 subjects. The analytic weight for each group is proportional to the precision of the respective estimate. 
TABLE 9 Coefficients from meta-regression analyses ${ }^{a}$ of the associations between baseline glycemic control and clinical attachment level/ loss before and 3 mo after scaling and root planing

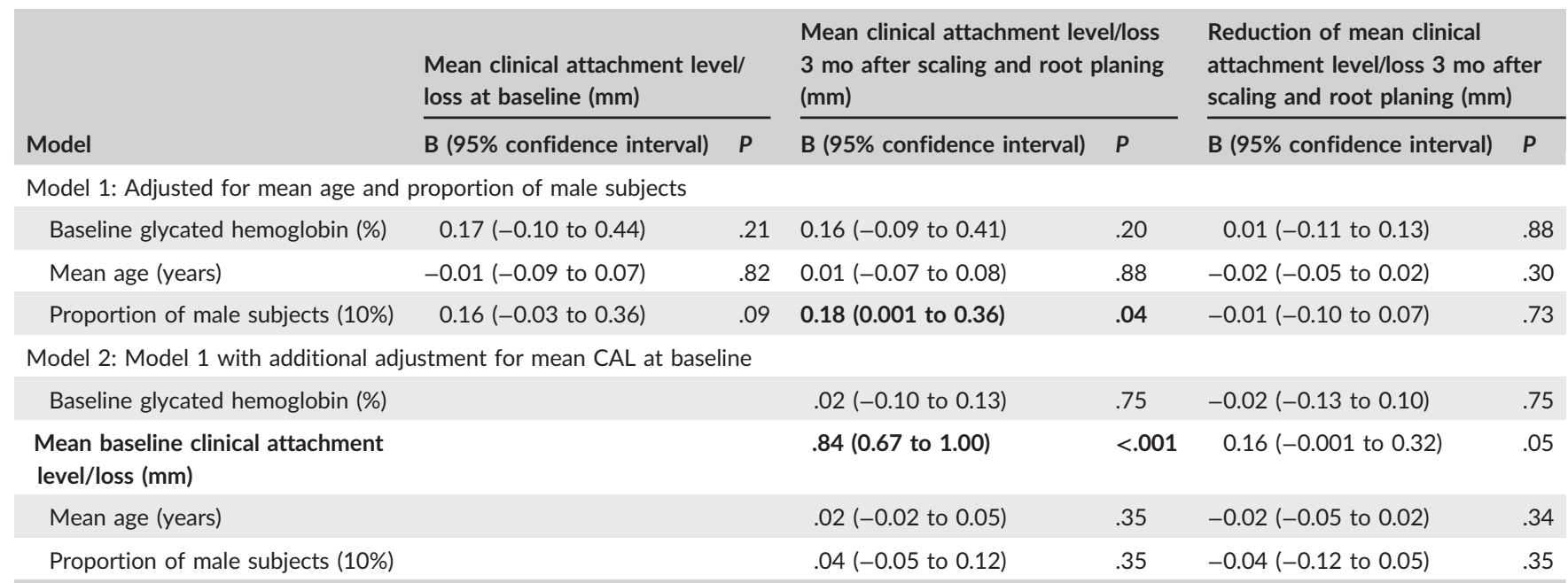

Bold font indicates statistical significance at $P<.05$.

aUsing aggregate-level data based on 33 groups with 1009 subjects. The analytic weight for each group is proportional to the precision of the respective estimate.

immigrants. ${ }^{152,153}$ This illustrates that, just a short time ago, dentists did not need to know about treating patients with diabetes as much as they do now.

In patients with chronic periodontitis and diabetes, scaling and root planing is an effective treatment for reducing periodontal probing depth and improving the clinical attachment level, irrespective of metabolic control during a short duration of follow-up. The question has yet to be answered by the dental profession to understand the impact of diabetes/hyperglycemia on treatment planning and maintenance in a long-term perspective.

\section{ESSENTIAL FINDINGS AND CONCLUSIONS}

The prevalence and incidence of prediabetes and type 2 diabetes is increasing worldwide. ${ }^{14}$ Prediabetes increases the risk of developing diabetes. In industrialized countries, metabolic control seems to improve and most patients are now well controlled. The studies presented provide some evidence that prediabetes is associated with initial periodontal alterations, but not with tooth loss. The 2 longitudinal and 6 of the 12 cross-sectional studies report a statistically significant association between prediabetes and periodontitis incidence or prevalence. Variations in the diagnosis of prediabetes are obvious as a result of different measures of glucose metabolism, such as glycated hemoglobin, fasting plasma glucose, impaired fasting glucose, impaired glucose tolerance, Homeostatic Model Assessment-Insulin Resistance, Homeostatic Model Assessment-Beta, and oral glucose tolerance test.

The true threshold for what constitutes uncontrolled diabetes with respect to periodontitis is not known, but uncontrolled diabetes (as defined by the reported studies) seems to impact periodontal progression and tooth loss.

Resolution of pockets is independent of metabolic control in the short term. Adjuvant systemic administration of antibiotic drugs improves pocket closure, but not attachment gain, in patients with diabetes. Any decision to prescribe antibiotics depends upon the severity of periodontal destruction and the inflammatory status, rather than metabolic control.

The duration of both diabetes and chronic periodontitis is mostly unknown and so is their mutual influence and interaction. Life course may determine later chronic disease risk in both diabetes and periodontitis. To promote healthy ageing, studies on those interactions, as well as their interactions with environmental factors, will be important, with implications for public health.

Increasing life expectancy means that the prevalence of diabetes will probably continue to rise and so will the prevalence of periodontitis as an increasingly larger proportion of the older adults keep their teeth for longer. Secular trends influence, to a large extent, the nexus diabetes-periodontitis. Conclusions based on distinct studies may not be meaningful in other time/geographical circumstances. Older data may reflect a more "natural history" because of less medical intervention, very different risk profiles in potential patients, etc.

Glycemia thresholds for risk prediction of complications are valuable tools in preventing long-term sequelae of diabetes. For the diabetes-periodontitis nexus, the glycemic threshold for assessing the risk imposed by elevated insulin resistance and hyperglycemia for impacting periodontitis is not known.

A great deal of attention should be targeted at risk factors for diabetes and periodontitis, which are largely identical, ${ }^{21,23}$ such as smoking, obesity, sedentary lifestyle, etc. Nowadays, dentists start to discuss the utility of health education with respect to diabetes and 

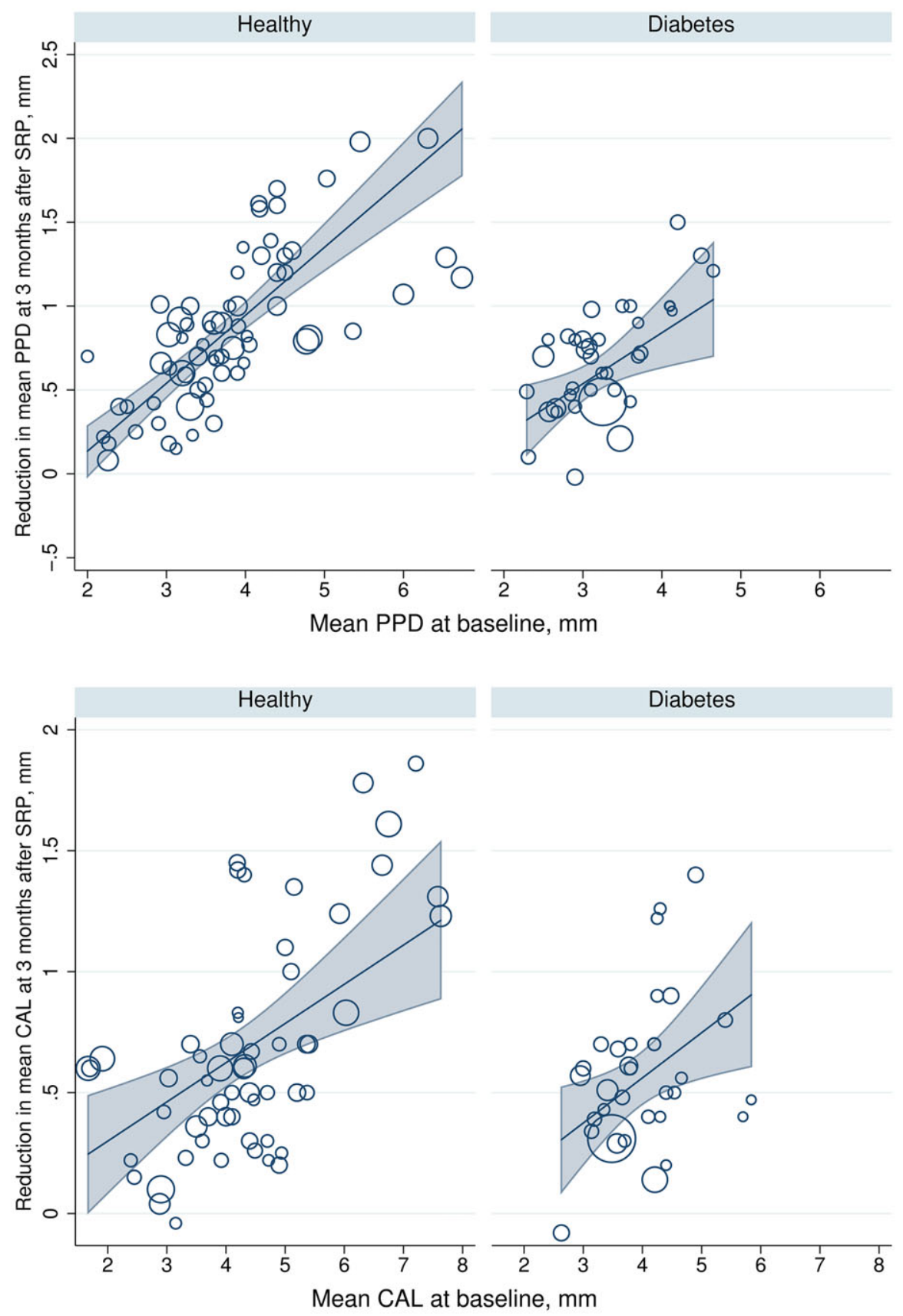

FIGURE 17 Reduction in mean periodontal probing depth (PPD) according to mean baseline PPD (upper panel) and reduction in mean clinical attachment loss (CAL) according to mean baseline CAL (lower panel), 3 mo after scaling and root planing (SRP) in normoglycemia (Healthy) and in hyperglycemia/diabetes (Diabetes). The circles sizes represent the respective study sizes. The study weights for regression are proportional to the precision of each group estimate. Please see Tables 6 and 7 for lists of the included studies and Figures 12-15 for details on the study outcomes

prediabetes to facilitate the prevention of both diabetes and periodontal complications. Programs including counseling on diet, physical activity, socioenvironmental conditions, and self-awareness in health are important issues. In a randomized clinical trial, Lalla and colleagues ${ }^{154}$ were able to show that both basic information and enhanced controlled interventions result in a significant reduction of glycated hemoglobin in predominantly prediabetes patients after only 6 months, suggesting that education by dental professionals may contribute to improve the health of patients with, or at risk for, diabetes. Control of glycemic status may be used as an appropriate tool for monitoring the general metabolic status. There have been claims, for many years, that efforts aimed at educating patients with diabetes to change their attitude and behavior in a desirable direction can work; however, the evidence for any efficacy when provided in periodontists' or general practitioners' office settings is poor. 

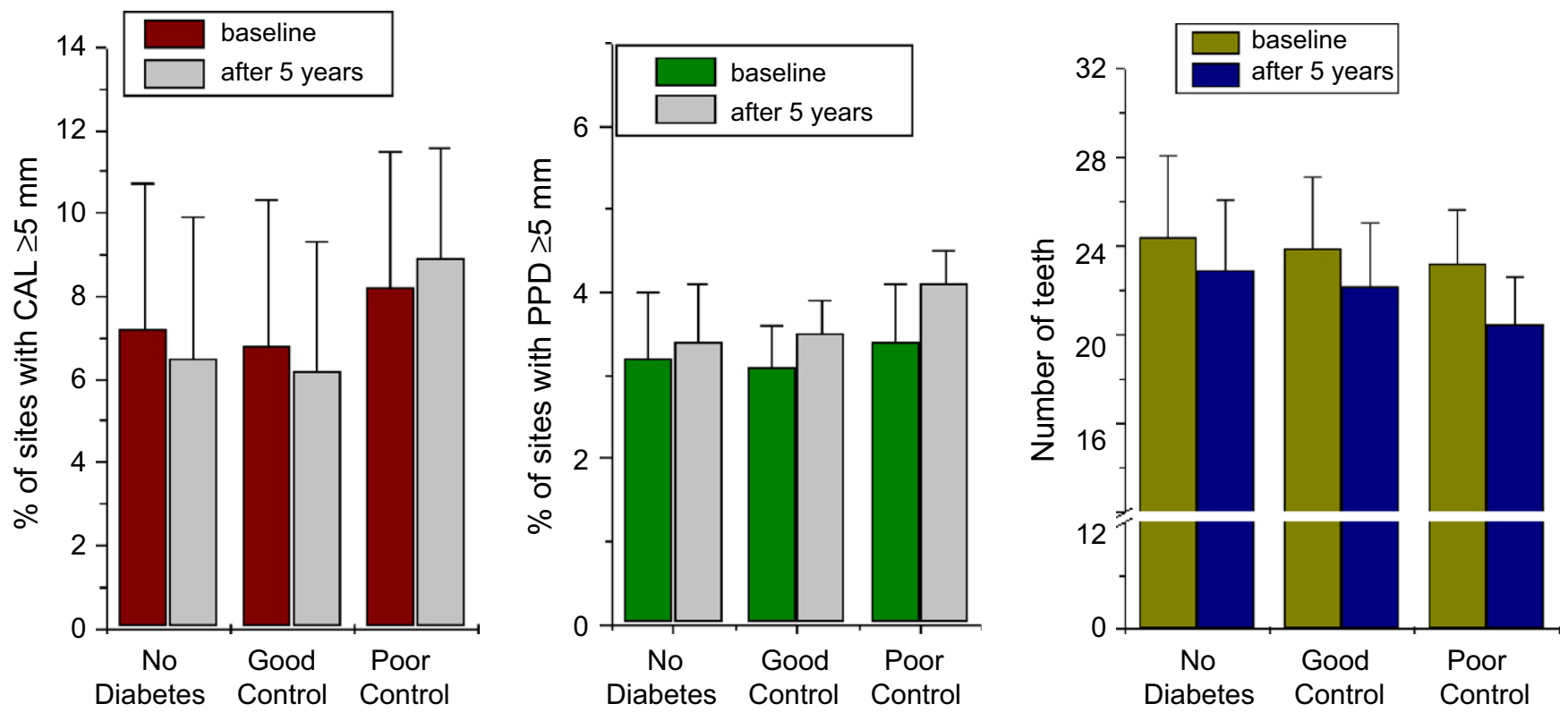

FIGURE 18 Proportion of sites with clinical attachment loss (CAL) of $\geq 5 \mathrm{~mm}$ or periodontal probing depth (PPD) $\geq 5 \mathrm{~mm}$, and number of natural teeth present after 5 y of follow-up maintenance therapy visits every 4-6 mo after initial treatment for moderate/severe periodontitis in sex- and age-matched patients without diabetes (fasting plasma glucose $<126 \mathrm{mg} / \mathrm{dL}, \mathrm{n}=46$ ), and with well-controlled (glycated hemoglobin $<6.5 \%, \mathrm{n}=23$ ) or poorly controlled (glycated hemoglobin $\geq 6.5 \%, \mathrm{n}=23$ ) type 2 diabetes, respectively ${ }^{150}$

While evidence deduced from epidemiological studies can support best clinical practice, this needs to be placed in context of all the conditions of a specific patient. It has to be reflected whether the focus, for the clinical practice, has to change from the statistical risk considerations toward an assessment and judgment of the individual patient's personal situation. In this respect, personalized medicine is imperative and has always been the intent of dentists in treating patients. Thus, the challenge of the dentist or the hygienist with an individual patient is to make a decision. Should this decision be guided by the science of probability (risk of periodontitis caused

TABLE 10 Diabetes as a risk factor for tooth loss during periodontal maintenance in retrospective studies using multivariate analyses published from 1996

\begin{tabular}{|c|c|c|c|c|c|c|}
\hline Author & $\begin{array}{l}\text { Publication } \\
\text { year }\end{array}$ & $\begin{array}{l}\text { Number of } \\
\text { periodontal } \\
\text { patients }\end{array}$ & $\begin{array}{l}\text { Study duration } \\
\text { (years) }\end{array}$ & Diabetes & Diabetes effect & Smoking \\
\hline Carnevale et $\mathrm{al}^{233}$ & 2007 & 300 & 7.8 & Not reported & Not reported & Reported \\
\hline Chambrone \& Chambrone ${ }^{234}$ & 2006 & 120 & 17.4 & Excluded & Not reported & Reported \\
\hline Costa et $a^{155}$ & 2013 & 212 & 5 & Reported & Significant & Reported \\
\hline Eickholz et al ${ }^{235}$ & 2008 & 100 & 10.5 & Reported & Not statistically significant & Reported \\
\hline Fardal et $\mathrm{al}^{237}$ & 2004 & 100 & 9.8 & Not reported & Not reported & Reported \\
\hline Jansson \& Lagervall ${ }^{238}$ & 2008 & 60 & 16.2 & Not reported & Not reported & Reported \\
\hline König et al ${ }^{147}$ & 2002 & 146 & 10.5 & Not reported & Not reported & Reported \\
\hline Martinez-Canut ${ }^{239}$ & 2015 & 500 & 20 & Not reported & Not reported & Reported \\
\hline McLeod et $\mathrm{al}^{242}$ & 1998 & 114 & 12.5 & Not reported & Not reported & Not reported \\
\hline Miyamato et $\mathrm{al}^{243}$ & 2006 & 505 & $\geq 10.0$ & Not reported & Not reported & Reported \\
\hline Muzzi et al ${ }^{159}$ & 2006 & 60 & 10.0 & Excluded & Not reported & Excluded \\
\hline $\mathrm{Ng}$ et $\mathrm{al}^{244}$ & 2011 & 273 & 10.7 & Reported & Not statistically significant & Reported \\
\hline Tsami et $a^{245}$ & 2009 & 280 & 10.8 & Not reported & Not reported & Reported \\
\hline
\end{tabular}


by prediabetes or diabetes), by the art of clinical judgment, or by both?

\section{REFERENCES}

1. Genco RJ, Borgnakke WS. Risk factors for periodontal disease. Periodontol 2000. 2013;62():59-94.

2. Loe H. Periodontal disease; the sixth complication of diabetes mellitus. Diabetes Care. 1993;16(1):329-334.

3. Phillips LS, Ratner RE, Buse JB, Kahn SE. We can change the natural history of type 2 diabetes. Diabetes Care. 2014;37(10):26682676.

4. Kassebaum NJ, Bernabe E, Dahiya M, Bhandari B, Murray CJ, Marcenes W. Global burden of severe periodontitis in 1990-2010: a systematic review and meta-regression. J Dent Res. 2014;93 (11):1045-1053.

5. Petersen PE, Ogawa $\mathrm{H}$. The global burden of periodontal disease: towards integration with chronic disease prevention and control. Periodontol 2000. 2012;60(1):15-39.

6. World Health Organization (WHO). Global Report on Diabetes. Geneva, Switzerland: World Health Organization; 2016. Available: http://apps.who.int/iris/bitstream/10665/204871/1/ 9789241565257_eng.pdf?ua=1\&ua=1. Accessed October 1, 2017.

7. World Health Organization. Definition and Diagnosis of Diabetes Mellitus and Intermediate Hyperglycaemia; Report of a WHO/IDF Consultation. Geneva, Switzerland: World Health Organization, International Diabetes Federation; 2006. Available: http://www. who.int/diabetes/publications/Definition\%20and\%20diagnosis\% 20of\%20diabetes_new.pdf. Accessed October 1, 2017

8. International Diabetes Federation (IDF). IDF Diabetes Atlas, 7th edn. Brussels, Belgium: IDF; 2015.

9. Centers for Disease Control and Prevention (CDC). National diabetes statistics report, 2017; estimates of diabetes and its burden in the United States. 2017. Available at: https://www.Cdc.Gov/di abetes/pdfs/data/statistics/national-diabetes-statistics-report.Pdf

10. American Diabetes Association. 2. Classification and diagnosis of diabetes. Diabetes Care. 2017;40(Suppl 1):S11-S24.

11. International Expert Committee. International Expert Committee report on the role of the A1c assay in the diagnosis of diabetes. Diabetes Care. 2009;32(7):1327-1334.

12. Bansal N. Prediabetes diagnosis and treatment: a review. World J Diabetes. 2015;6(2):296-303.

13. Droumaguet C, Balkau B, Simon D, et al. Use of HbA1c in predicting progression to diabetes in French men and women: data from an epidemiological study on the insulin resistance syndrome (DESIR). Diabetes Care. 2006;29(7):1619-1625.

14. Edwards CM, Cusi K. Prediabetes: a worldwide epidemic. Endocrinol Metab Clin North Am. 2016;45(4):751-764.

15. Heianza $\mathrm{Y}$, Hara S, Arase $\mathrm{Y}$, et al. HbA1c 5.7-6.4\% and impaired fasting plasma glucose for diagnosis of prediabetes and risk of progression to diabetes in Japan (TOPICS 3): a longitudinal cohort study. Lancet. 2011;378(9786):147-155.

16. Warren B, Pankow JS, Matsushita K, et al. Comparative prognostic performance of definitions of prediabetes: a prospective cohort analysis of the atherosclerosis risk in communities (aric) study. Lancet Diabetes Endocrinol. 2017;5(1):34-42.

17. Timonen $P$, Saxlin $T$, Knuuttila M, et al. Role of insulin sensitivity and beta cell function in the development of periodontal disease in adults without diabetes. J Clin Periodontol. 2013;40(12):1079-1086.

18. Colagiuri S. Epidemiology of prediabetes. Med Clin North Am. 2011;95(2):299-307, vii.

19. Nitta $H$, Katagiri $S$, Nagasawa $T$, et al. The number of microvascular complications is associated with an increased risk for severity of periodontitis in type 2 diabetes patients: results of a multicenter hospital-based cross-sectional study. J Diabetes Invest. 2017;8 (5):677-686.

20. Borgnakke WS. Ch. 6. Hyperglycemia/diabetes mellitus and periodontal infection adversely affect each other. In: Genco RJ, Williams RC, eds. Periodontal Disease and Overall Health: A Clinician's Guide, 2nd edn. Yardley, PA: Professional Audience Communications; 2014:99-122. Available at: Http://www.Colgateprofessional. Com/professional/v1/en/us/locale-assets/docs/periodontal-diseaseand-overall-health-a-clinicians-guide-2nd-edition.Pdf

21. Borgnakke WS. Modifiable risk factors for periodontitis and diabetes. Cur Oral Health Rep. 2016;3(3):254-269.

22. Demmer RT, Holtfreter B, Desvarieux $M$, et al. The influence of type 1 and type 2 diabetes on periodontal disease progression: prospective results from the Study of Health in Pomerania (SHIP). Diabetes Care. 2012;35(10):2036-2042.

23. Eke PI, Wei L, Thornton-Evans GO, et al. Risk indicators for periodontitis in US adults: NHANES 2009 to 2012. J Periodontol. 2016;87(10):1174-1185.

24. Eke PI, Wei L, Borgnakke WS, et al. Periodontitis prevalence in adults $>/=65$ years of age, in the USA. Periodontol 2000. 2016;72 (1):76-95

25. Simon D. Therapeutic inertia in type 2 diabetes: insights from the PANORAMA study in France. Diabetes Metab. 2012;38(Suppl 3): S47-S52.

26. Borgnakke WS. "Non-modifiable" risk factors for periodontitis and diabetes. Cur Oral Health Rep. 2016;3(3):270-281.

27. Genco RJ, Grossi SG, Ho A, Nishimura F, Murayama Y. A proposed model linking inflammation to obesity, diabetes, and periodontal infections. J Periodontol. 2005;76(11):2075-2084.

28. Bartold PM, Van Dyke TE. Periodontitis: a host-mediated disruption of microbial homeostasis; unlearning learned concepts. Periodontol 2000. 2013;62(1):203-217.

29. Demmer RT, Breskin A, Rosenbaum M, et al. The subgingival microbiome, systemic inflammation and insulin resistance: the Oral Infections, Glucose Intolerance and Insulin Resistance Study. J Clin Periodontol. 2017;44(3):255-265.

30. Timonen P, Suominen-Taipale L, Jula A, Niskanen M, Knuuttila M, Ylöstalo P. Insulin sensitivity and periodontal infection in a non-diabetic, non-smoking adult population. J Clin Periodontol. 2011;38 (1):17-24

31. Calle MC, Fernandez ML. Inflammation and type 2 diabetes. Diabetes Metab. 2012;38(3):183-191.

32. Knight ET, Liu J, Seymour GJ, Faggion CM Jr, Cullinan MP. Risk factors that may modify the innate and adaptive immune responses in periodontal diseases. Periodontol 2000. 2016;71(1):22-51.

33. Liu C, Feng X, Li Q, Wang Y, Li Q, Hua M. Adiponectin, TNF-alpha and inflammatory cytokines and risk of type 2 diabetes: a systematic review and meta-analysis. Cytokine. 2016;86:100-109.

34. Polepalle T, Moogala S, Boggarapu S, Pesala DS, Palagi FB. Acute phase proteins and their role in periodontitis: a review. J Clin Diagn Res. 2015;9(11):ZE01-ZE05.

35. Duarte PM, Bezerra JP, Miranda TS, Feres M, Chambrone L, Shaddox LM. Local levels of inflammatory mediators in uncontrolled type 2 diabetic subjects with chronic periodontitis. J Clin Periodontol. 2014;41(1):11-18.

36. Bastos MF, Tucci MA, de Siqueira A, et al. Diabetes may affect the expression of matrix metalloproteinases and their inhibitors more than smoking in chronic periodontitis. J Periodontal Res. 2017;52 (2):292-299.

37. Gupta N, Gupta ND, Garg S, et al. The effect of type 2 diabetes mellitus and smoking on periodontal parameters and salivary matrix metalloproteinase-8 levels. J Oral Sci. 2016;58(1):1-6.

38. Albert DA, Ward A, Allweiss $P$, et al. Diabetes and oral disease: implications for health professionals. Ann N Y Acad Sci. 2012;1255 (1):1-15. 
39. Gurav AN. Periodontitis and insulin resistance: casual or causal relationship? Diabetes Metab J. 2012;36(6):404-411.

40. Hasturk H, Kantarci A. Activation and resolution of periodontal inflammation and its systemic impact. Periodontol 2000 2015;69 (1):255-273.

41. Sonnenschein SK, Meyle J. Local inflammatory reactions in patients with diabetes and periodontitis. Periodontol 2000. 2015;69(1):221254.

42. Gurav AN. Advanced glycation end products: a link between periodontitis and diabetes mellitus? Curr Diabetes Rev. 2013;9(5):355361.

43. Liu S, Hempe JM, McCarter RJ, Li S, Fonseca VA. Association between inflammation and biological variation in hemoglobin A1c in U.S. nondiabetic adults. J Clin Endocrinol Metab. 2015;100 (6):2364-2371.

44. Chapple IL. Genco R, working group 2 of the joint EFP/AAP workshop. Diabetes and periodontal diseases: consensus report of the Joint EFP/AAP Workshop on Periodontitis and Systemic Diseases. J Clin Periodontol. 2013;40(Suppl 14):S106-S112.

45. Lalla E, Lamster IB, Stern DM, Schmidt AM. Receptor for advanced glycation end products, inflammation, and accelerated periodontal disease in diabetes: mechanisms and insights into therapeutic modalities. Ann Periodontol. 2001;6(1):113-118.

46. Araya AV, Pavez V, Perez C, et al. Ex vivo lipopolysaccharide (LPS)induced TNF-alpha, IL-1beta, IL-6 and PGE2 secretion in whole blood from type 1 diabetes mellitus patients with or without aggressive periodontitis. Eur Cytokine Netw. 2003;14(3):128-133.

47. Hayashi C, Gudino CV, Gibson FC III, Genco CA. Review: pathogen-induced inflammation at sites distant from oral infection: bacterial persistence and induction of cell-specific innate immune inflammatory pathways. Mol Oral Microbiol. 2010;25(5):305-316.

48. Acharya AB, Thakur S, Muddapur MV, Kulkarni RD. Systemic cytokines in type 2 diabetes mellitus and chronic periodontitis. Curr Diabetes Rev. 2018;14(2):182-188.

49. Mesia R, Gholami F, Huang H, et al. Systemic inflammatory responses in patients with type 2 diabetes with chronic periodontitis. BMJ Open Diabetes Res Care. 2016;4(1):e000260.

50. Nielsen ST, Lehrskov-Schmidt L, Krogh-Madsen R, et al. Tumour necrosis factor-alpha infusion produced insulin resistance but no change in the incretin effect in healthy volunteers. Diabetes Metab Res Rev. 2013;29(8):655-663.

51. Akram Z, Abduljabbar T, Abu Hassan MI, Javed F, Vohra F. Cytokine profile in chronic periodontitis patients with and without obesity: a systematic review and meta-analysis. Dis Markers. 2016;2016:4801418.

52. Levine RS. Obesity, diabetes and periodontitis-a triangular relationship? Br Dent J. 2013;215(1):35-39.

53. Zhu M, Nikolajczyk BS. Immune cells link obesity-associated type 2 diabetes and periodontitis. J Dent Res. 2014;93(4):346-352.

54. Rhee EJ, Kim YC, Lee WY, et al. Comparison of insulin resistance and serum high-sensitivity C-reactive protein levels according to the fasting blood glucose subgroups divided by the newly recommended criteria for fasting hyperglycemia in 10059 healthy Koreans. Metabolism. 2006;55(2):183-187.

55. Nibali L, Tatarakis N, Needleman I, et al. Clinical review: association between metabolic syndrome and periodontitis: a systematic review and meta-analysis. J Clin Endocrinol Metab. 2013;98(3):913-920.

56. Pink C, Kocher T, Meisel P, et al. Longitudinal effects of systemic inflammation markers on periodontitis. J Clin Periodontol. 2015;42 (11):988-997.

57. Demmer RT, Desvarieux M, Holtfreter B, et al. Periodontal status and A1c change: longitudinal results from the Study of Health in Pomerania (SHIP). Diabetes Care. 2010;33(5):1037-1043.

58. Chung HY, Lee EK, Choi YJ, et al. Molecular inflammation as an underlying mechanism of the aging process and age-related diseases. J Dent Res. 2011;90(7):830-840.
59. Meisel P, Kohlmann T, Kocher T. Association of height with inflammation and periodontitis: the Study of Health in Pomerania (SHIP). J Clin Periodontol. 2007;34(5):390-396.

60. Vangipurapu J, Stančáková A, Jauhiainen R, Kuusisto J, Laakso M. Short adult stature predicts impaired beta-cell function, insulin resistance, glycemia and type 2 diabetes in Finnish men. J Clin Endocrinol Metab. 2017;102(2):443-450.

61. Gillett MJ. International Expert Committee report on the role of the A1c assay in the diagnosis of diabetes; Diabetes care 2009; 32: 1327-1334. Clin Biochem Rev. 2009;30(4):197-200.

62. Fajans SS, Herman WH, Oral EA. Insufficient sensitivity of hemoglobin $\mathrm{A}((1) \mathrm{C})$ determination in diagnosis or screening of early diabetic states. Metabolism. 2011;60(1):86-91.

63. Cowie CC, Rust KF, Byrd-Holt DD, et al. Prevalence of diabetes and high risk for diabetes using A1c criteria in the U.S. Population in 1988-2006. Diabetes Care. 2010;33(3):562-568.

64. Faerch K, Borch-Johnsen K, Holst JJ, Vaag A. Pathophysiology and aetiology of impaired fasting glycaemia and impaired glucose tolerance: does it matter for prevention and treatment of type 2 diabetes? Diabetologia. 2009;52(9):1714-1723.

65. Matthews DR, Hosker JP, Rudenski AS, Naylor BA, Treacher DF, Turner RC. Homeostasis model assessment: insulin resistance and beta-cell function from fasting plasma glucose and insulin concentrations in man. Diabetologia. 1985;28(7):412-419.

66. Knowler WC, Barrett-Connor E, Fowler SE, et al. Diabetes Prevention Program Research Group. Reduction in the incidence of type 2 diabetes with lifestyle intervention or metformin. $N$ Engl J Med. 2002;346(6):393-403.

67. Zhang $X$, Gregg EW, Williamson DF, et al. A1c level and future risk of diabetes: a systematic review. Diabetes Care. 2010;33(7):16651673.

68. Nathan DM, Davidson MB, DeFronzo RA, et al. American Diabetes Association. Impaired fasting glucose and impaired glucose tolerance: implications for care. Diabetes Care. 2007;30(3):753-759.

69. Herman WH. Diabetes epidemiology: guiding clinical and public health practice: the Kelly West award lecture, 2006. Diabetes Care. 2007;30(7):1912-1919.

70. Chiu SY, Lai H, Yen AM, Fann JC, Chen LS, Chen HH. Temporal sequence of the bidirectional relationship between hyperglycemia and periodontal disease: a community-based study of 5,885 Taiwanese aged 35-44 years (KCIS no. 32). Acta Diabetol. 2015;52 (1):123-131.

71. Benguigui C, Bongard V, Ruidavets JB, et al. Metabolic syndrome, insulin resistance, and periodontitis: a cross-sectional study in a middle-aged French population. J Clin Periodontol. 2010;37(7):601608.

72. Emrich LJ, Shlossman M, Genco RJ. Periodontal disease in noninsulin-dependent diabetes mellitus. J Periodontol. 1991;62(2):123131.

73. Hong JW, Noh JH, Kim DJ. The prevalence and associated factors of periodontitis according to fasting plasma glucose in the korean adults: the 2012-2013 Korea National Health and Nutrition Examination Survey. Medicine. 2016;95(14):e3226.

74. Kowall B, Holtfreter B, Völzke H, et al. Pre-diabetes and well-controlled diabetes are not associated with periodontal disease: the SHIP Trend study. J Clin Periodontol. 2015;42(5):422-430.

75. Lamster IB, Cheng B, Burkett S, Lalla E. Periodontal findings in individuals with newly identified pre-diabetes or diabetes mellitus. J Clin Periodontol. 2014;41(11):1055-1060.

76. Lim SG, Han K, Kim HA, et al. Association between insulin resistance and periodontitis in Korean adults. J Clin Periodontol. 2014;41 (2):121-130.

77. Marugame T, Hayasaki H, Lee K, Eguchi H, Matsumoto S. Alveolar bone loss associated with glucose tolerance in Japanese men. Diabet Med. 2003;20(9):746-751. 
78. Pérez CM, Munoz F, Andriankaja OM, et al. Cross-sectional associations of impaired glucose metabolism measures with bleeding on probing and periodontitis. J Clin Periodontol. 2017;44(2):142-149.

79. Saito T, Shimazaki Y, Kiyohara Y, et al. Relationship between obesity, glucose tolerance, and periodontal disease in Japanese women: the Hisayama study. J Periodontal Res. 2005;40(4):346-353.

80. Song IS, Han K, Park YM, et al. Severe periodontitis is associated with insulin resistance in non-abdominal obese adults. J Clin Endocrinol Metab. 2016;101(11):4251-4259.

81. Zuk A, Quinonez C, Lebenbaum M, Rosella LC. The association between undiagnosed glycaemic abnormalities and cardiometabolic risk factors with periodontitis: results from 2007-2009 Canadian Health Measures Survey. J Clin Periodontol. 2017;44(2):132-141.

82. Morita I, Inagaki K, Nakamura F, et al. Relationship between periodontal status and levels of glycated hemoglobin. J Dent Res. 2012;91(2):161-166.

83. Bandyopadhyay D, Marlow NM, Fernandes JK, Leite RS. Periodontal disease progression and glycaemic control among Gullah African Americans with type-2 diabetes. J Clin Periodontol. 2010;37(6):501509.

84. Taylor GW, Burt BA, Becker MP, Genco RJ, Shlossman M. Glycemic control and alveolar bone loss progression in type 2 diabetes. Ann Periodontol. 1998;3(1):30-39.

85. Hensel E, Gesch D, Biffar R, et al. Study of Health in Pomerania (SHIP): a health survey in an east German region; objectives and design of the oral health section. Quintessence Int. 2003;34(5):370378.

86. John U, Greiner B, Hensel E, et al. Study of Health in Pomerania (SHIP): a health examination survey in an east German region: objectives and design. Soz Präventivmed. 2001;46(3):186-194.

87. Völzke H, Alte D, Schmidt CO, et al. Cohort profile: the Study of Health in Pomerania. Int J Epidemiol. 2011;40(2):294-307.

88. Eke PI, Page RC, Wei L, Thornton-Evans G, Genco RJ. Update of the case definitions for population-based surveillance of periodontitis. J Periodontol. 2012;83(12):1449-1454.

89. Page RC, Eke PI. Case definitions for use in population-based surveillance of periodontitis. J Periodontol. 2007;78(Suppl 7):1387-1399.

90. Menke A, Casagrande S, Aviles-Santa ML, Cowie CC. Factors associated with being unaware of having diabetes. Diabetes Care. 2017;40(5):e55-e56.

91. Slade GD, Akinkugbe AA, Sanders AE. Projections of U.S. edentulism prevalence following 5 decades of decline. J Dent Res. 2014;93(10):959-965.

92. Mainous AG III, Tanner RJ, Jo A, Anton SD. Prevalence of prediabetes and abdominal obesity among healthy-weight adults: 18-year trend. Ann Fam Med. 2016;14(4):304-310.

93. Menke A, Casagrande S, Geiss L, Cowie CC. Prevalence of and trends in diabetes among adults in the United States, 1988-2012. JAMA. 2015;314(10):1021-1029.

94. Selvin E, Parrinello CM, Sacks DB, Coresh J. Trends in prevalence and control of diabetes in the United States, 1988-1994 and 19992010. Ann Intern Med. 2014;160(8):517-525

95. Gregg EW, Li Y, Wang J, et al. Changes in diabetes-related complications in the United States, 1990-2010. N Engl J Med. 2014;370 (16):1514-1523.

96. Mayard-Pons ML, Rilliard F, Libersa JC, Musset AM, Farge P. Database analysis of a French type 2 diabetic population shows a specific age pattern of tooth extractions and correlates health care utilization. J Diabetes Complications. 2015;29(8):993-997.

97. Garcia D, Tarima S, Okunseri C. Periodontitis and glycemic control in diabetes: NHANES 2009 to 2012. J Periodontol. 2015;86(4):499506.

98. Simpson TC, Weldon JC, Worthington HV, et al. Treatment of periodontal disease for glycaemic control in people with diabetes mellitus. Cochrane Database Syst Rev. 2015; (11):CD004714.
99. Botero JE, Rodriguez C, Agudelo-Suarez AA. Periodontal treatment and glycaemic control in patients with diabetes and periodontitis: an umbrella review. Aust Dent J. 2016;61(2):134-148.

100. Faggion CM Jr, Cullinan MP, Atieh M. An overview of systematic reviews on the effectiveness of periodontal treatment to improve glycaemic control. J Periodontal Res. 2016;51(6):716-725.

101. Wang TF, Jen IA, Chou C, Lei YP. Effects of periodontal therapy on metabolic control in patients with type 2 diabetes mellitus and periodontal disease: a meta-analysis. Medicine. 2014;93(28):e292

102. Sun QY, Feng $M$, Zhang $M Z$, et al. Effects of periodontal treatment on glycemic control in type 2 diabetic patients:a meta-analysis of randomized controlled trials. Chin J Physiol. 2014;57(6):305-314.

103. Engebretson SP, Hyman LG, Michalowicz BS, et al. The effect of nonsurgical periodontal therapy on hemoglobin a1c levels in persons with type 2 diabetes and chronic periodontitis: a randomized clinical trial. JAMA. 2013;310(23):2523-2532.

104. Borgnakke WS, Chapple IL, Genco RJ, et al. The multi-center randomized controlled trial (RCT) published by the Journal of the American Medical Association (JAMA) on the effect of periodontal therapy on glycated hemoglobin (HbA1c) has fundamental problems. J Evid Based Dent Pract. 2014;14(3):127-132.

105. Chapple IL, Borgnakke WS, Genco RJ. Hemoglobin A1c levels among patients with diabetes receiving nonsurgical periodontal treatment. JAMA. 2014;311(18):1919-1920.

106. Engebretson SP, Hyman LG, Michalowicz BS. Hemoglobin A1c levels among patients with diabetes receiving nonsurgical periodontal treatment-reply. JAMA. 2014;311(18):1921-1922.

107. Merchant AT. Hemoglobin A1c levels among patients with diabetes receiving nonsurgical periodontal treatment. JAMA. 2014;311 (18):1919-1920.

108. Vergnes JN. Hemoglobin A1c levels among patients with diabetes receiving nonsurgical periodontal treatment. JAMA. 2014;311 (18):1920-1921.

109. Gurav AN. Management of diabolical diabetes mellitus and periodontitis nexus: are we doing enough? World J Diabetes. 2016;7 (4):50-66.

110. Javed F, Thafeed Alghamdi AS, Mikami T, et al. Effect of glycemic control on self-perceived oral health, periodontal parameters, and alveolar bone loss among patients with prediabetes. J Periodontol. 2014;85(2):234-241.

111. Katagiri S, Nitta H, Nagasawa T, et al. Effect of glycemic control on periodontitis in type 2 diabetic patients with periodontal disease. $J$ Diabetes Investig. 2013;4(3):320-325.

112. Di Paola R, Mazzon E, Maiere D, et al. Rosiglitazone reduces the evolution of experimental periodontitis in the rat. J Dent Res. 2006;85(2):156-161.

113. Hassumi MY, Silva-Filho VJ, Campos-Junior JC, et al. PPAR-gamma agonist rosiglitazone prevents inflammatory periodontal bone loss by inhibiting osteoclastogenesis. Int Immunopharmacol. 2009;9 (10):1150-1158.

114. Moraes RM, Lima GM, Oliveira FE, et al. Exenatide and sitagliptin decrease interleukin 1beta, matrix metalloproteinase 9, and nitric oxide synthase 2 gene expression but does not reduce alveolar bone loss in rats with periodontitis. J Periodontol. 2015;86 (11):1287-1295.

115. den Ouden H, Berends J, Stellato RK, Beulens JW, Rutten GE. Effect of six years intensified multifactorial treatment on levels of hs-CRP and adiponectin in patients with screen detected type 2 diabetes: the ADDITION-Netherlands randomized trial. Diabetes Metab Res Rev. 2015;31(7):758-766.

116. Andriankaja OM, Jimenez JJ, Munoz-Torres FJ, Perez CM, Vergara $\mathrm{JL}$, Joshipura KJ. Lipid-lowering agents use and systemic and oral inflammation in overweight or obese adult Puerto Ricans: The San Juan Overweight Adults Longitudinal Study (SOALS). J Clin Periodontol. 2015;42(12):1090-1096. 
117. Meisel P, Kroemer HK, Nauck M, Holtfreter B, Kocher T. Tooth loss, periodontitis, and statins in a population-based follow-up study. J Periodontol. 2014;85(6):e160-e168.

118. Stevens JW, Khunti K, Harvey R, et al. Preventing the progression to type 2 diabetes mellitus in adults at high risk: a systematic review and network meta-analysis of lifestyle, pharmacological and surgical interventions. Diabetes Res Clin Pract. 2015;107(3):320331.

119. Diabetes Prevention Program Research Group, Knowler WC, Fowler SE, et al. 10-year follow-up of diabetes incidence and weight loss in the Diabetes Prevention Program Outcomes Study. Lancet. 2009;374(9702):1677-1686.

120. Tuso P. Prediabetes and lifestyle modification: time to prevent a preventable disease. Perma J. 2014;18(3):88-93.

121. Albright A. Prevention of type 2 diabetes requires both intensive lifestyle interventions and population-wide approaches. Am J Manag Care. 2015;21(Suppl 7):S238-S239.

122. Cradock KA, ÓLaighin G, Finucane FM, Gainforth HL, Quinlan LR, Ginis KA. Behaviour change techniques targeting both diet and physical activity in type 2 diabetes: a systematic review and metaanalysis. Int J Behav Nutr Phys Act. 2017;14(1):18.

123. Lalla E, Papapanou PN. Modifying factors. In: Lindhe J, Lang NP, eds. Clinical Periodontology and Implant Dentistry, Vol. 1. Chichester, UK: John Wiley \& Sons, Ltd; 2015:270-289.

124. Saengtipbovorn S, Taneepanichskul S. Effectiveness of lifestyle change plus dental care program in improving glycemic and periodontal status in aging patients with diabetes: a cluster, randomized, controlled trial. J Periodontol. 2015;86(4):507-515.

125. Zoungas S, Woodward M, Li Q, et al. Chalmers J, group AC. Impact of age, age at diagnosis and duration of diabetes on the risk of macrovascular and microvascular complications and death in type 2 diabetes. Diabetologia. 2014;57(12):2465-2474.

126. Kim EK, Lee SG, Choi YH, et al. Association between diabetesrelated factors and clinical periodontal parameters in type-2 diabetes mellitus. BMC Oral Health. 2013;13(64).

127. Guo S, Dipietro LA. Factors affecting wound healing. J Dent Res. 2010;89(3):219-229.

128. Faria-Almeida R, Navarro A, Bascones A. Clinical and metabolic changes after conventional treatment of type 2 diabetic patients with chronic periodontitis. J Periodontol. 2006;77(4):591-598.

129. Christgau M, Palitzsch KD, Schmalz G, Kreiner U, Frenzel S. Healing response to non-surgical periodontal therapy in patients with diabetes mellitus: clinical, microbiological, and immunologic results. J Clin Periodontol. 1998;25(2):112-124.

130. Tervonen T, Karjalainen K. Periodontal disease related to diabetic status; a pilot study of the response to periodontal therapy in type 1 diabetes. J Clin Periodontol. 1997;24(7):505-510.

131. Lang NP, Suvan JE, Tonetti MS. Risk factor assessment tools for the prevention of periodontitis progression a systematic review. $J$ Clin Periodontol. 2015;42(Suppl 16):S59-S70.

132. Stratton IM, Adler Al, Neil HA, et al. Association of glycaemia with macrovascular and microvascular complications of type 2 diabetes (UKPDS 35): prospective observational study. BMJ. 2000;321 (7258):405-412.

133. Inzucchi SE, Bergenstal RM, Buse JB, et al. Management of hyperglycemia in type 2 diabetes, 2015: a patient-centered approach: update to a position statement of the American Diabetes Association and the European Association for the Study of Diabetes. Diabetes Care. 2015;38(1):140-149.

134. Eberhard J, Jepsen S, Jervoe-Storm PM, Needleman I, Worthington HV. Full-mouth treatment modalities (within 24 hours) for chronic periodontitis in adults. Cochrane Database Syst Rev. 2015; (4): CD004622.

135. Van der Weijden GA, Timmerman MF. A systematic review on the clinical efficacy of subgingival debridement in the treatment of chronic periodontitis. J Clin Periodontol. 2002;29(Suppl 3):55-71; 90-91.

136. Wennström J, Tomasi C. Non-surgical therapy. In: Lang NP, Lindhe J, eds. Clinical Periodontology and Implant Dentistry, Vol. 2. Clinical Concepts, 6th edn. Chichester, UK: John Wiley \& Sons, Ltd; 2015:749-766.

137. Lindhe J, Socransky SS, Nyman S, Haffajee A, Westfelt E. "Critical probing depths" in periodontal therapy. J Clin Periodontol. 1982;9 (4):323-336.

138. Westfelt E, Rylander H, Blohme G, Jonasson P, Lindhe J. The effect of periodontal therapy in diabetics; results after 5 years. $J$ Clin Periodontol. 1996;23(2):92-100.

139. Gay IC, Tran DT, Cavender AC, et al. The effect of periodontal therapy on glycaemic control in a Hispanic population with type 2 diabetes: a randomized controlled trial. J Clin Periodontol. 2014;41 (7):673-680.

140. Keestra JA, Grosjean I, Coucke W, Quirynen M, Teughels W. Nonsurgical periodontal therapy with systemic antibiotics in patients with untreated chronic periodontitis: a systematic review and meta-analysis. J Periodontal Res. 2015;50(3):294-314.

141. Matarazzo F, Figueiredo LC, Cruz SE, Faveri M, Feres M. Clinical and microbiological benefits of systemic metronidazole and amoxicillin in the treatment of smokers with chronic periodontitis: a randomized placebo-controlled study. J Clin Periodontol. 2008;35 (10):885-896.

142. Grellmann AP, Sfreddo CS, Maier J, Lenzi TL, Zanatta FB. Systemic antimicrobials adjuvant to periodontal therapy in diabetic subjects: a meta-analysis. J Clin Periodontol. 2016;43(3):250-260.

143. Santos CM, Lira-Junior R, Fischer RG, Santos AP, Oliveira BH. Systemic antibiotics in periodontal treatment of diabetic patients: a systematic review. PLoS ONE. 2015;10(12):e0145262.

144. Rovai ES, Souto ML, Ganhito JA, Holzhausen M, Chambrone L, Pannuti CM. Efficacy of local antimicrobials in the non-surgical treatment of patients with periodontitis and diabetes: a systematic review. J Periodontol. 2016;87(12):1406-1417.

145. Harks I, Koch R, Eickholz P, et al. Is progression of periodontitis relevantly influenced by systemic antibiotics? a clinical randomized trial. J Clin Periodontol. 2015;42(9):832-842.

146. Smiley CJ, Tracy SL, Abt E, et al. Systematic review and meta-analysis on the nonsurgical treatment of chronic periodontitis by means of scaling and root planing with or without adjuncts. JADA. 2015;146(7):508-524, e505.

147. König J, Plagmann HC, Langenfeld N, Kocher T. Retrospective comparison of clinical variables between compliant and non-compliant patients. J Clin Periodontol. 2001;28(3):227-232.

148. Kaldahl WB, Kalkwarf KL, Patil KD, Molvar MP, Dyer JK. Long-term evaluation of periodontal therapy: I. response to 4 therapeutic modalities. J Periodontol. 1996;67(2):93-102.

149. Costa FO, Cota LO, Lages EJ, et al. Periodontal risk assessment model in a sample of regular and irregular compliers under maintenance therapy: a 3-year prospective study. J Periodontol. 2012;83 (3):292-300.

150. Costa FO, Miranda Cota LO, Pereira Lages EJ, et al. Progression of periodontitis and tooth loss associated with glycemic control in individuals undergoing periodontal maintenance therapy: a 5-year follow-up study. J Periodontol. 2013;84(5):595-605.

151. Engstrom S, Berne C, Gahnberg L, Svardsudd K. Effectiveness of screening for diabetes mellitus in dental health care. Diabet Med. 2013;30(2):239-245.

152. Andersen GS, Kamper-Jørgensen Z, Carstensen B, Norredam M, Bygbjerg IC, Jørgensen ME. Diabetes among migrants in Denmark: incidence, mortality, and prevalence based on a longitudinal register study of the entire Danish population. Diabetes Res Clin Prac. 2016;122:9-16.

153. Green A, Sortso C, Jensen PB, Emneus M. Incidence, morbidity, mortality, and prevalence of diabetes in denmark, 2000-2011: 
results from the Diabetes Impact Study 2013. Clin Epidemiol. 2015;7:421-430.

154. Lalla E, Cheng B, Kunzel C, Burkett S, Ferraro A, Lamster IB. Sixmonth outcomes in dental patients identified with hyperglycaemia: a randomized clinical trial. J Clin Periodontol. 2015;42(3):228-235.

155. Dag A, Firat ET, Arikan S, Kadiroglu AK, Kaplan A. The effect of periodontal therapy on serum TNF-alpha and HbA1c levels in type 2 diabetic patients. Aust Dent J. 2009;54(1):17-22.

156. Auyeung L, Wang P-W, Lin R-T, et al. Evaluation of periodontal status and effectiveness of non-surgical treatment in patients with type 2 diabetes mellitus in Taiwan for a 1-year period. J Periodontol. 2012;83(5):621-628.

157. Feres M, Gursky LC, Faveri M, Tsuzuki CO, Figueiredo LC. Clinical and microbiological benefits of strict supragingival plaque control as part of the active phase of periodontal therapy. J Clin Periodontol. 2009;36(10):857-867.

158. Matuliene G, Pjetursson BE, Salvi GE, et al. Influence of residual pockets on progression of periodontitis and tooth loss: results after 11 years of maintenance. J Clin Periodontol. 2008;35(8):685-695.

159. Muzzi L, Nieri M, Cattabriga M, Rotundo R, Cairo F, Pini Prato GP. The potential prognostic value of some periodontal factors for tooth loss: a retrospective multilevel analysis on periodontal patients treated and maintained over 10 years. J Periodontol. 2006;77(12):2084-2089.

160. Smith GT, Greenbaum CJ, Johnson BD, Persson GR. Short-term responses to periodontal therapy in insulin-dependent diabetic patients. J Periodontol. 1996;67(8):794-802.

161. Kiran M, Arpak N, Unsal E, Erdogan MF. The effect of improved periodontal health on metabolic control in type 2 diabetes mellitus. J Clin Periodontol. 2005;32(3):266-272.

162. Talbert J, Elter J, Jared HL, Offenbacher S, Southerland J, Wilder RS. The effect of periodontal therapy on TNF-alpha, II-6 and metabolic control in type 2 diabetics. J Dent Hyg. 2006;80(2):7.

163. Navarro-Sanchez AB, Faria-Almeida R, Bascones-Martinez A. Effect of non-surgical periodontal therapy on clinical and immunological response and glycaemic control in type 2 diabetic patients with moderate periodontitis. J Clin Periodontol. 2007;34(10):835-843.

164. O'Connell PAA, Taba M, Nomizo A, et al. Effects of periodontal therapy on glycemic control and inflammatory markers. J Periodontol. 2008;79(5):774-783.

165. Al-Zahrani MS, Bamshmous SO, Alhassani AA, Al-Sherbini MM. Short-term effects of photodynamic therapy on periodontal status and glycemic control of patients with diabetes. J Periodontol. 2009;80(10):1568-1573.

166. Katagiri S, Nitta H, Nagasawa $\mathrm{T}$, et al. Multi-center intervention study on glycohemoglobin (HbA1c) and serum, high-sensitivity CRP (hs-CRP) after local anti-infectious periodontal treatment in type 2 diabetic patients with periodontal disease. Diabetes Res Clin Pract. 2009;83(3):308-315.

167. Santos VR, Lima JA, De Mendonca AC, Braz Maximo MB, Faveri $M$, Duarte PM. Effectiveness of full-mouth and partial-mouth scaling and root planing in treating chronic periodontitis in subjects with type 2 diabetes. J Periodontol. 2009;80(8):1237-1245.

168. Correa FO, Goncalves D, Figueredo CM, Bastos AS, Gustafsson A, Orrico SR. Effect of periodontal treatment on metabolic control, systemic inflammation and cytokines in patients with type 2 diabetes. J Clin Periodontol. 2010;37(1):53-58.

169. Kardeşler L, Buduneli N, Çetinkalp Ş, Kinane DF. Adipokines and inflammatory mediators after initial periodontal treatment in patients with type 2 diabetes and chronic periodontitis. J Periodontol. 2010;81(1):24-33.

170. Chen L, Luo G, Xuan D, et al. Effects of non-surgical periodontal treatment on clinical response, serum inflammatory parameters, and metabolic control in patients with type 2 diabetes: a randomized study. J Periodontol. 2012;83(4):435-443.
171. Gilowski L, Kondzielnik P, Wiench R, Plocica I, Strojek K, Krzeminski TF. Efficacy of short-term adjunctive subantimicrobial dose doxycycline in diabetic patients-randomized study. Oral Dis. 2012;18(8):763-770.

172. Hungund S, Panseriya BJ. Reduction in HbA1c levels following non-surgical periodontal therapy in type-2 diabetic patients with chronic generalized periodontitis: a periodontist's role. J Indian Soc Periodontol. 2012;16(1):16-21.

173. Moeintaghavi A, Arab HR, Bozorgnia Y, Kianoush K, Alizadeh M. Non-surgical periodontal therapy affects metabolic control in diabetics: a randomized controlled clinical trial. Aust Dent J. 2012;57 (1):31-37.

174. Santos VR, Ribeiro FV, Lima JA, et al. Partial- and full-mouth scaling and root planing in type 2 diabetic subjects: a 12-mo follow-up of clinical parameters and levels of cytokines and osteoclastogenesisrelated factors. J Periodontal Res. 2012;47(1):45-54.

175. Serrano C, Torres N, Bejarano A, Cavie M, Castellanos ME. Clinical and microbiological comparison of three non-surgical protocols for the initial treatment of chronic periodontitis. J Int Acad Periodontol. 2011;13(1):17-26.

176. Santos VR, Lima JA, Miranda TS, et al. Full-mouth disinfection as a therapeutic protocol for type-2 diabetic subjects with chronic periodontitis: twelve-month clinical outcomes: a randomized controlled clinical trial. J Clin Periodontol. 2013;40(2):155-162.

177. Zhang H, Li C, Shang S, Luo Z. Scaling and root planing with enhanced root planing on healthcare for type 2 diabetes mellitus: a randomized controlled clinical trial. J Dent Sci. 2013;8(3):272-280.

178. Kanduluru A, Naganandini S. Effect of nonsurgical periodontal treatment on clinical response and glycemic control in type 2 diabetic patients with periodontitis: controlled clinical trial. J Indian Assoc Public Health Dent. 2014;12(4):261.

179. Raman RP, Taiyeb-Ali TB, Chan SP, Chinna K, Vaithilingam RD. Effect of nonsurgical periodontal therapy verses oral hygiene instructions on type 2 diabetes subjects with chronic periodontitis: a randomised clinical trial. BMC Oral Health. 2014;14:(79).

180. Tsalikis L, Sakellari D, Dagalis $P$, Boura $P$, Konstantinidis A. Effects of doxycycline on clinical, microbiological and immunological parameters in well-controlled diabetes type- 2 patients with periodontal disease: a randomized, controlled clinical trial. J Clin Periodontol. 2014;41(10):972-980.

181. Kaur PK, Narula SC, Rajput R, Sharma RK, Tewari S. Periodontal and glycemic effects of nonsurgical periodontal therapy in patients with type 2 diabetes stratified by baseline $\mathrm{HbA}(1 \mathrm{c})$. J Oral Sci. 2015;57(3):201-211.

182. Wu Y, Chen L, Wei B, Luo K, Yan F. Effect of non-surgical periodontal treatment on visfatin concentrations in serum and gingival crevicular fluid of patients with chronic periodontitis and type 2 diabetes mellitus. J Periodontol. 2015;86(6):795-800.

183. El-Sharkawy HM, Anees MM, Van Dyke TE. Propolis improves periodontal status and glycemic control in patients with type 2 diabetes mellitus and chronic periodontitis: a randomized clinical trial. J Periodontol. 2016;87(12):1418-1426.

184. Taşdemir Z, Özsarı Taşdemir F, Koçyiğit I, Yazıcı C, Gürgan CA. The clinical and systemic effects of periodontal treatment in diabetic and non-diabetic obese patients. J Oral Sci. 2016;58(4):523-531.

185. Haffajee AD, Cugini MA, Dibart S, Smith C, Kent RL Jr, Socransky SS. The effect of SRP on the clinical and microbiological parameters of periodontal diseases. J Clin Periodontol. 1997;24(5):324-334.

186. Feres M, Haffajee AD, Goncalves C, et al. Systemic doxycycline administration in the treatment of periodontal infections (i); effect on the subgingival microbiota. J Clin Periodontol. 1999;26(12):775783.

187. Winkel EG, Van Winkelhoff AJ, Barendregt DS, Van der Weijden GA, Timmerman MF, Van der Velden U. Clinical and microbiological effects of initial periodontal therapy in conjunction with amoxicillin 
and clavulanic acid in patients with adult periodontitis; a randomised double-blind, placebo-controlled study. J Clin Periodontol. 1999;26(7):461-468.

188. Eren KS, Gurgan CA, Bostanci HS. Evaluation of non-surgical periodontal treatment using 2 time intervals. J Periodontol. 2002;73 (9):1015-1019.

189. Van Steijn GJ, Amerongen AV, Veerman EC, Kasanmoentalib S, Overdijk B. Effect of periodontal treatment on the activity of chitinase in whole saliva of periodontitis patients. J Periodontal Res. 2002;37(4):245-249.

190. Apatzidou DA, Kinane DF. Quadrant root planing versus same-day full-mouth root planing. I. Clinical findings. J Clin Periodontol. 2004;31(2):132-140.

191. Carvalho LH, D'Avila GB, Leao A, Haffajee AD, Socransky SS, Feres $M$. Scaling and root planing, systemic metronidazole and professional plaque removal in the treatment of chronic periodontitis in a Brazilian population. I. clinical results. J Clin Periodontol. 2004;31 (12):1070-1076.

192. Emingil G, Atilla G, Sorsa T, Luoto H, Kirilmaz L, Baylas H. The effect of adjunctive low-dose doxycycline therapy on clinical parameters and gingival crevicular fluid matrix metalloproteinase-8 levels in chronic periodontitis. J Periodontol. 2004;75(1):106-115.

193. Colombo AP, Teles RP, Torres MC, et al. Effects of non-surgical mechanical therapy on the subgingival microbiota of Brazilians with untreated chronic periodontitis: 9-month results. J Periodontol. 2005;76(5):778-784.

194. Mascarenhas P, Gapski R, Al-Shammari K, et al. Clinical response of azithromycin as an adjunct to non-surgical periodontal therapy in smokers. J Periodontol. 2005;76(3):426-436.

195. Preshaw PM, Heasman L, Stacey F, Steen N, McCracken GI, Heasman PA. The effect of quitting smoking on chronic periodontitis. $J$ Clin Periodontol. 2005;32(8):869-879.

196. Gorska R, Nedzi-Gora M. The effects of the initial treatment phase and of adjunctive low-dose doxycycline therapy on clinical parameters and MMP-8, MMP-9, and TIMP-1 levels in the saliva and peripheral blood of patients with chronic periodontitis. Arch Immunol Ther Exp. 2006;54(6):419-426.

197. Gomi K, Yashima A, Nagano T, Kanazashi M, Maeda N, Arai T. Effects of full-mouth scaling and root planing in conjunction with systemically administered azithromycin. J Periodontol. 2007;78(3):422-429.

198. Haffajee AD, Torresyap G, Socransky SS. Clinical changes following four different periodontal therapies for the treatment of chronic periodontitis: 1-year results. J Clin Periodontol. 2007;34(3):243-253.

199. Yoshie H, Tai H, Kobayashi T, et al. Salivary enzyme levels after scaling and interleukin-1 genotypes in Japanese patients with chronic periodontitis. J Periodontol. 2007;78(3):498-503.

200. Emingil G, Atilla G, Sorsa T, Tervahartiala T. The effect of adjunctive subantimicrobial dose doxycycline therapy on GCF emmprin levels in chronic periodontitis. J Periodontol. 2008;79(3):469-476.

201. Guentsch A, Jentsch H, Pfister W, Hoffmann T, Eick S. Moxifloxacin as an adjunctive antibiotic in the treatment of severe chronic periodontitis. J Periodontol. 2008;79(10):1894-1903.

202. Cionca N, Giannopoulou C, Ugolotti G, Mombelli A. Amoxicillin and metronidazole as an adjunct to full-mouth scaling and root planing of chronic periodontitis. J Periodontol. 2009;80(3):364-371.

203. Bokhari SAH, Khan AA, Tatakis DN, Azhar M, Hanif M, Izhar M. Non-surgical periodontal therapy lowers serum inflammatory markers: a pilot study. J Periodontol. 2009;80(10):1574-1580.

204. Ioannou I, Dimitriadis N, Papadimitriou K, Sakellari D, Vouros I, Konstantinidis A. Hand instrumentation versus ultrasonic debridement in the treatment of chronic periodontitis: a randomized clinical and microbiological trial. J Clin Periodontol. 2009;36(2):132-141.

205. Swierkot K, Nonnenmacher $\mathrm{Cl}$, Mutters R, Flores-de-Jacoby L, Mengel R. One-stage full-mouth disinfection versus quadrant and full-mouth root planing. J Clin Periodontol. 2009;36(3):240-249.
206. Oteo A, Herrera D, Figuero E, O'Connor A, Gonzalez I, Sanz M. Azithromycin as an adjunct to scaling and root planing in the treatment of Porphyromonas gingivalis-associated periodontitis: a pilot study. J Clin Periodontol. 2010;37(11):1005-1015.

207. Shimada Y, Komatsu Y, Ikezawa-Suzuki I, Tai H, Sugita N, Yoshie $\mathrm{H}$. The effect of periodontal treatment on serum leptin, interleukin6, and C-reactive protein. J Periodontol. 2010;81(8):1118-1123.

208. Emingil G, Gurkan A, Atilla G, Kantarci A. Subantimicrobial-dose doxycycline and cytokine-chemokine levels in gingival crevicular fluid. J Periodontol. 2011;82(3):452-461.

209. Winkel EG, Van Winkelhoff AJ, Timmerman MF, Van der Velden U, Van der Weijden GA. Amoxicillin plus metronidazole in the treatment of adult periodontitis patients; a double-blind placebo-controlled study. J Clin Periodontol. 2001;28(4):296-305.

210. Kruck C, Eick S, Knofler GU, Purschwitz RE, Jentsch HF. Clinical and microbiologic results 12 months after scaling and root planing with different irrigation solutions in patients with moderate chronic periodontitis: a pilot randomized trial. J Periodontol. 2012;83 (3):312-320.

211. Feres M, Soares GM, Mendes JA, et al. Metronidazole alone or with amoxicillin as adjuncts to non-surgical treatment of chronic periodontitis: a 1-year double-blinded, placebo-controlled, randomized clinical trial. J Clin Periodontol. 2012;39(12):1149-1158.

212. Mombelli A, Cionca N, Almaghlouth A, Decaillet F, Courvoisier DS, Giannopoulou C. Are there specific benefits of amoxicillin plus metronidazole in aggregatibacter actinomycetemcomitans-associated periodontitis? double-masked, randomized clinical trial of efficacy and safety. J Periodontol. 2013;84(6):715-724.

213. Preus HR, Gunleiksrud TM, Sandvik L, Gjermo P, Baelum V. A randomized, double-masked clinical trial comparing four periodontitis treatment strategies: 1-year clinical results. J Periodontol. 2013;84 (8):1075-1086.

214. Shirmohammadi A, Babaloo Z, Eskandari A, Purabbas R, Babaloo A The effects of one-stage full-mouth disinfection and quadrant-wise scaling and root planing on serum levels of II-17 and II-1beta and clinical parameters (a randomized controlled trial study). J Dent 2013;10(3):248-255.

215. Teughels W, Durukan A, Ozcelik O, Pauwels M, Quirynen M, Haytac M. Clinical and microbiological effects of Lactobacillus reuteri probiotics in the treatment of chronic periodontitis: a randomized placebo-controlled study. J Clin Periodontol. 2013;40(11):10251035.

216. Ardais R, Mario Tde G, Boligon J, Kantorski KZ, Moreira CH. The effect of smoking bleeding on probing after nonsurgical periodontal therapy: a quasi-experimental study. Braz Oral Res. 2014;28(1):1-7.

217. Perayil J, Suresh N, Fenol A, Vyloppillil R, Bhaskar A, Menon S. Comparison of glycated hemoglobin levels in individuals without diabetes and with and without periodontitis before and after nonsurgical periodontal therapy. J Periodontol. 2014;85(12):1658-1666.

218. Pradeep AR, Singh SP, Martande SS, Naik SB. N P, Kalra N, Suke DK. Clinical and microbiological effects of levofloxacin in the treatment of chronic periodontitis: a randomized, placebo-controlled clinical trial. J Investig Clin Dent. 2015;6(3):170-178.

219. Al Habashneh R, Alsalman W, Khader Y. Ozone as an adjunct to conventional nonsurgical therapy in chronic periodontitis: a randomized controlled clinical trial. J Periodontal Res. 2015;50(1):37-43.

220. Fonseca DC, Cortelli JR, Cortelli SC, et al. Clinical and microbiologic evaluation of scaling and root planing per quadrant and one-stage full-mouth disinfection associated with azithromycin or chlorhexidine: a clinical randomized controlled trial. J Periodontol. 2015;86 (12):1340-1351.

221. Goncalves TE, Feres M, Zimmermann GS, et al. Effects of scaling and root planing on clinical response and serum levels of adipocytokines in patients with obesity and chronic periodontitis. J Periodontol. 2015;86(1):53-61. 
222. Graziani F, Cei S, Orlandi M, et al. Acute-phase response following full-mouth versus quadrant non-surgical periodontal treatment: a randomized clinical trial. J Clin Periodontol. 2015;42 (9):843-852.

223. Laleman I, Yilmaz E, Ozcelik O, et al. The effect of a streptococci containing probiotic in periodontal therapy: a randomized controlled trial. J Clin Periodontol. 2015;42(11):1032-1041.

224. Mombelli A, Almaghlouth A, Cionca N, Courvoisier DS, Giannopoulou C. Differential benefits of amoxicillin-metronidazole in different phases of periodontal therapy in a randomized controlled crossover clinical trial. J Periodontol. 2015;86(3):367-375.

225. Pradeep AR, Singh SP, Martande SS, Naik SB, Kalra N, Priyanka N. Clinical and microbiological effects of levofloxacin in the treatment of Aggregatibacter actinomycetemcomitans-associated periodontitis: a randomized placebo-controlled clinical trial. J Int Acad Periodontol. 2014;16(3):67-77

226. Tekce $M$, Ince G, Gursoy $\mathrm{H}$, et al. Clinical and microbiological effects of probiotic lozenges in the treatment of chronic periodontitis: a 1-year follow-up study. J Clin Periodontol. 2015;42(4):363372.

227. Azad MF, Schwiertz A, Jentsch HF. Adjunctive use of essential oils following scaling and root planing - a randomized clinical trial. BMC Complement Altern Med. 2016;16(171).

228. Bizzarro S, Van der Velden U, Loos BG. Local disinfection with sodium hypochlorite as adjunct to basic periodontal therapy: a randomized controlled trial. J Clin Periodontol. 2016;43(9):778-788.

229. Cosgarea R, Juncar R, Heumann C, et al. Non-surgical periodontal treatment in conjunction with 3 or 7 days systemic administration of amoxicillin and metronidazole in severe chronic periodontitis patients; a placebo-controlled randomized clinical study. J Clin Periodontol. 2016;43(9):767-777.

230. Martande SS, Pradeep AR, Singh SP, et al. Clinical and microbiological effects of systemic azithromycin in adjunct to nonsurgical periodontal therapy in treatment of aggregatibacter actinomycetemcomitans associated periodontitis: a randomized placebocontrolled clinical trial. J Invest Clin Dent. 2016;7(1):72-80.

231. Morales A, Carvajal P, Silva N, et al. Clinical effects of Lactobacillus rhamnosus in non-surgical treatment of chronic periodontitis: a randomized placebo-controlled trial with 1-year follow-up. J Periodontol. 2016;87(8):944-952.

232. Sangwan A, Tewari S, Singh H, Sharma RK, Narula SC. Effect of hyperlipidemia on response to nonsurgical periodontal therapy: statin users versus nonusers. Eur J Dent. 2016;10(1):69-76.

233. Carnevale G, Cairo F, Tonetti MS. Long-term effects of supportive therapy in periodontal patients treated with fibre retention osseous resective surgery. I: recurrence of pockets, bleeding on probing and tooth loss. J Clin Periodontol. 2007;34(4):334-341.
234. Chambrone LA, Chambrone L. Tooth loss in well-maintained patients with chronic periodontitis during long-term supportive therapy in Brazil. J Clin Periodontol. 2006;33(10):759-764.

235. Eickholz P, Kaltschmitt J, Berbig J, Reitmeir P, Pretzl B. Tooth loss after active periodontal therapy. 1: patient-related factors for risk, prognosis, and quality of outcome. J Clin Periodontol. 2008;35 (2):165-174.

236. Faggion CM Jr, Petersilka G, Lange DE, Gerss J, Flemmig TF. Prognostic model for tooth survival in patients treated for periodontitis. J Clin Periodontol. 2007;34(3):226-231.

237. Fardal O, Johannessen AC, Linden GJ. Tooth loss during maintenance following periodontal treatment in a periodontal practice in Norway. J Clin Periodontol. 2004;31(7):550-555.

238. Jansson L, Lagervall M. Periodontitis progession in patients subjected to supportive maintenance care. Swed Dent J. 2008;32 (3):105-114

239. Martinez-Canut P. Predictors of tooth loss due to periodontal disease in patients following long-term periodontal maintenance. J Clin Periodontol. 2015;42(12):1115-1125.

240. Matthews DC, Smith CG, Hanscom SL. Tooth loss in periodontal patients. J Can Dent Assoc. 2001;67(4):207-210.

241. McGuire MK, Nunn ME. Prognosis versus actual outcome. II. the effectiveness of clinical parameters in developing an accurate prognosis. J Periodontol. 1996;67(7):658-665.

242. McLeod DE, Lainson PA, Spivey JD. The predictability of periodontal treatment as measured by tooth loss: a retrospective study. Quintessence Internat. 1998;29(10):631-635.

243. Miyamoto T, Kumagai T, Jones JA, Van Dyke TE, Nunn ME. Compliance as a prognostic indicator: retrospective study of 505 patients treated and maintained for 15 years. J Periodontol. 2006;77(2):9.

244. Ng MC, Ong MM, Lim LP, Koh CG, Chan YH. Tooth loss in compliant and non-compliant periodontally treated patients: 7 years after active periodontal therapy. J Clin Periodontol. 2011;38(5):499-508.

245. Tsami A, Pepelassi E, Kodovazenitis G, Komboli M. Parameters affecting tooth loss during periodontal maintenance in a Greek population. JADA. 2009;140(9):1100-1107.

How to cite this article: Kocher T, König J, Borgnakke WS, Pink C, Meisel P. Periodontal complications of hyperglycemia/ diabetes mellitus: Epidemiologic complexity and clinical challenge. Periodontol 2000. 2018;78:59-97. https://doi.org/ 10.1111/prd.12235 